US Army Corps

of Engineers ${ }_{\circledast}$

Engineer Research and

Development Center

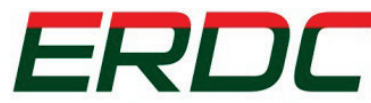

INNOVATIVE SOLUTIONS for a safer, better world

\title{
Concrete Growth and Fatigue Analysis of Chickamauga Lock Miter Gate Anchorages
}

Matthew D. Smith, Allen Hammack, Robert D. Moser,

September 2017

Quincy Alexander, Ben Burnham, and Sarah L. Williams

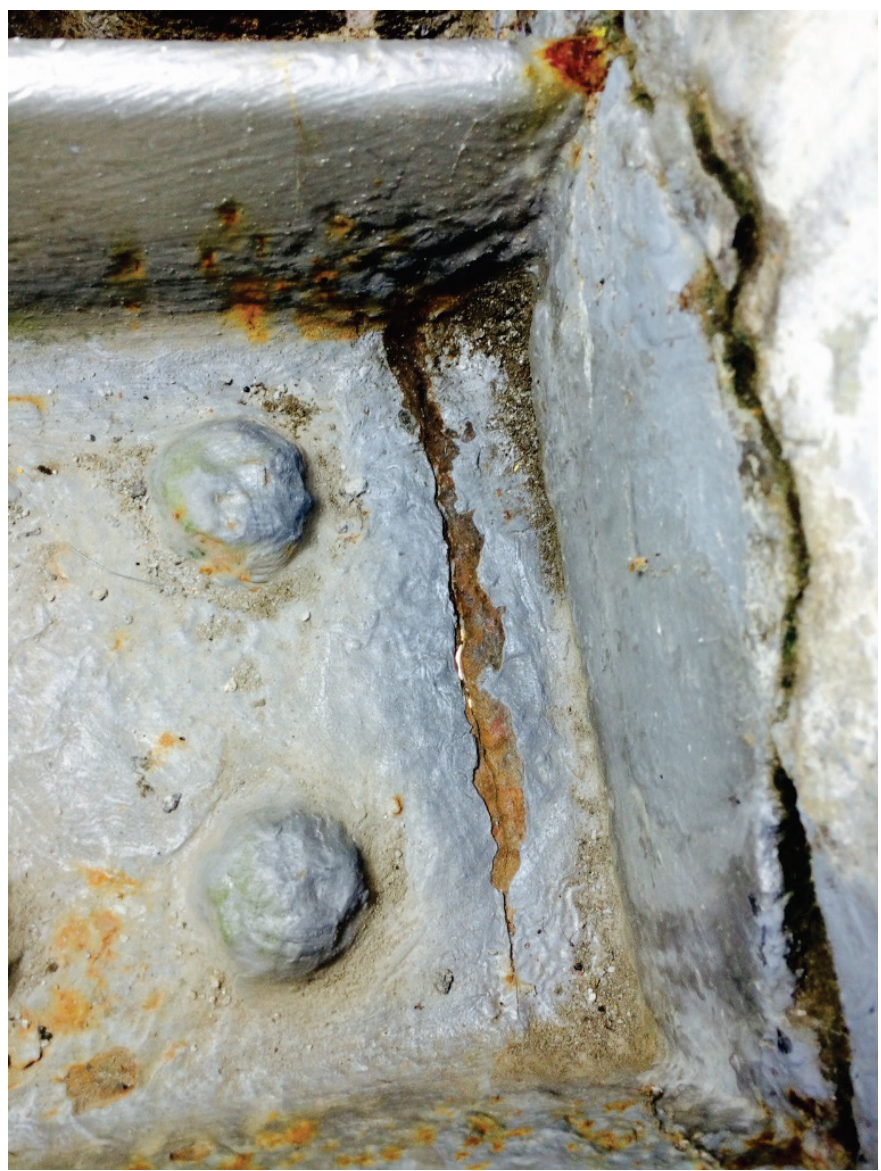


The U.S. Army Engineer Research and Development Center (ERDC) solves the nation's toughest engineering and environmental challenges. ERDC develops innovative solutions in civil and military engineering, geospatial sciences, water resources, and environmental sciences for the Army, the Department of Defense, civilian agencies, and our nation's public good. Find out more at www.erdc.usace.army.mil.

To search for other technical reports published by ERDC, visit the ERDC online library at http://acwc.sdp.sirsi.net/client/default. 


\section{Concrete Growth and Fatigue Analysis of Chickamauga Lock Miter Gate Anchorages}

Matthew D. Smith, Allen Hammack, and Ben Burnham

Coastal and Hydraulics Laboratory

U.S. Army Engineer Research and Development Center

3909 Halls Ferry Road

Vicksburg, MS 39180-6199

Robert D. Moser and Sarah L. Williams

Geotechnical and Structures Laboratory

U.S. Army Engineer Research and Development Center 3909 Halls Ferry Road

Vicksburg, MS 39180-6199

Quincy Alexander

Information Technology Laboratory

U.S. Army Engineer Research and Development Center

3909 Halls Ferry Road

Vicksburg, MS 39180-6199

Final report

Approved for public release; distribution is unlimited.

Prepared for U.S. Army Corps of Engineers, Nashville District

110 9th Avenue South

Nashville, TN 37203-3863

Under Project 111274, "Structural Analysis of Chickamauga Lock Gate Anchor Rods" 


\section{Abstract}

Severe cracking has been observed on the miter gate anchorages at Chickamauga Lock, Nashville District, U.S. Army Corps of Engineers. A structural analysis of these anchorages was conducted to determine how much longer they could remain in service before failure is expected. This analysis included a review of existing structural analysis reports, estimates and prediction of observed concrete growth in the area near the anchorages, and fatigue life estimates. The fatigue life estimates included the concrete growth estimates and also included the stresses and strains taken from measurements recorded during miter gate movements during lockages. The results of this analysis are discussed as well as possible ways to extend the life of the existing anchorages and considerations for if and when the anchorages are replaced.

DISCLAIMER: The contents of this report are not to be used for advertising, publication, or promotional purposes. Citation of trade names does not constitute an official endorsement or approval of the use of such commercial products. All product names and trademarks cited are the property of their respective owners. The findings of this report are not to be construed as an official Department of the Army position unless so designated by other authorized documents. 


\section{Contents}

Abstract.................................................................................................................................. if

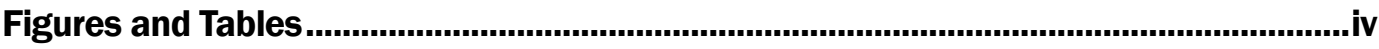

Preface ........................................................................................................................vi

Unit Conversion Factors...................................................................................................viii

1 Introduction ........................................................................................................ 1

1.1 Background: History of Chickamauga Lock and Dam ...................................1

1.2 Statement of problem .......................................................................10

1.3 Objectives and scope ....................................................................

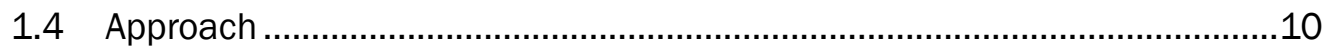

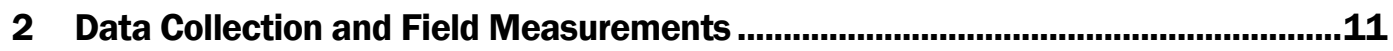

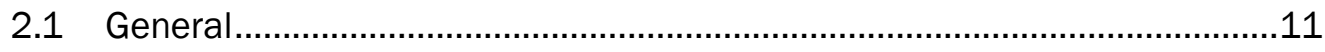

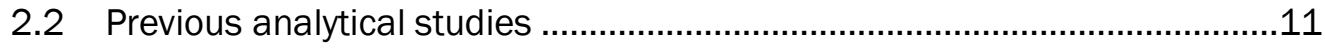

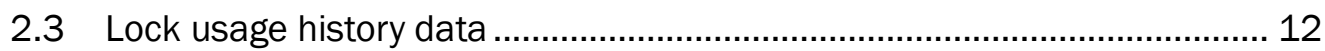

2.4 Concrete monolith expansion data.......................................................... 13

2.5 Gudgeon anchorage strain measurements ..............................................17

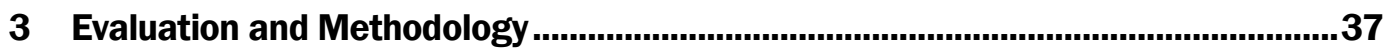

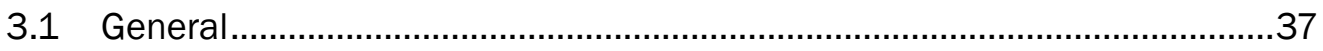

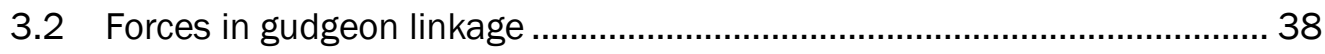

3.3 Finite element models of anchorage channels ......................................... 44

3.4 Linear fatigue damage model.............................................................. 52

3.5 Evaluation of gudgeon anchorage channels ...........................................57

3.6 Evaluation of embedded A-frame ......................................................... 58

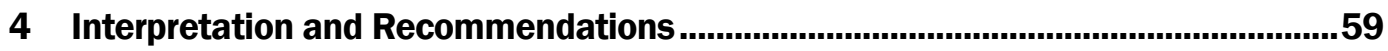

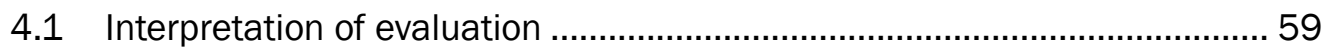

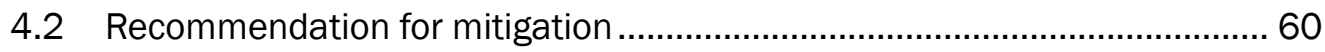

5 Summary and Conclusions …...................................................................................61

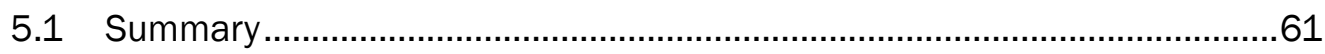

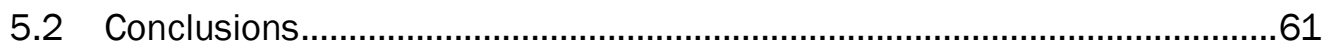

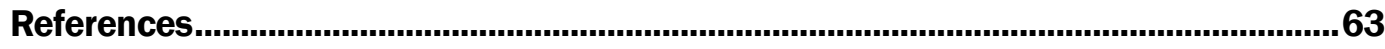

Report Documentation Page 


\section{Figures and Tables}

\section{Figures}

Figure 1. Chickamauga Lock and Dam - aerial view. ...................................................... 2

Figure 2. Chickamauga lock schematic.......................................................................... 3

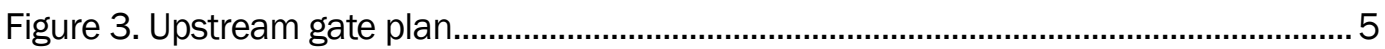

Figure 4. Gudgeon anchorage assembly detail................................................................. 6

Figure 5. Gudgeon anchorage A-frame detail..................................................................... 7

Figure 6. Top view of embedded miter gate anchorage crack observed in October

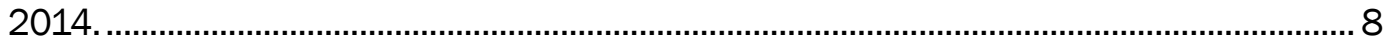

Figure 7. Close-up view of embedded west miter anchorage

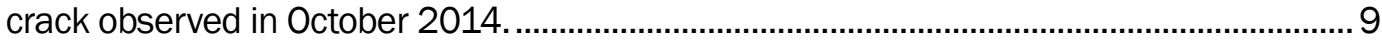

Figure 8. Repaired riverside miter anchorage channel. ....................................................... 9

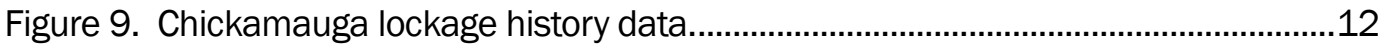

Figure 10. Plan view of lock.........................................................................................

Figure 11. Vertical growth - Block 22 (from HATCH [2015a], Figure 4-7) ..........................16

Figure 12. Vertical growth - Block 37 (from HATCH [2015a], Figure 4-11).........................16

Figure 13. Landside anchorage instrumentation plan view. ..............................................18

Figure 14. Riverside anchorage instrumentation plan view. ..............................................19

Figure 15. Landside anchor channel instrumentation detail. ..............................................20

Figure 16. Riverside anchor channel instrumentation detail. .........................................21

Figure 17. Circular segment anchorage instrumentation details.......................................22

Figure 18. Rectangular segment anchorage instrumentation details. ................................23

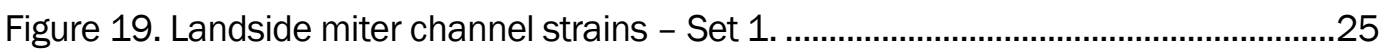

Figure 20. Landside miter round segment strains - Set 1.................................................26

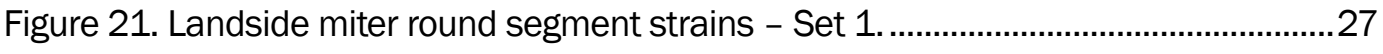

Figure 22. Landside recess channel strains - Set 1......................................................28

Figure 23. Landside recess round segment strains - Set 1..........................................29

Figure 24. Riverside miter channel strains - Set 2 ........................................................30

Figure 25. Riverside miter round segment strains - Set 2 ...............................................31

Figure 26. Riverside miter flat segment strains - Set 2 ….............................................32

Figure 27. Riverside recess channel strains - Set 3..........................................................3

Figure 28. Riverside recess round segment strains - Set 3. ............................................34

Figure 29. Riverside miter round segment strains - Set 3..................................................35

Figure 30. Riverside miter flat segment strains - Set 3. ..................................................36

Figure 31. Computed forces in landside miter rectangular segment - Set 1....................40

Figure 32. Computed forces in riverside miter rectangular segment - Set 2....................41

Figure 33. Computed forces in riverside miter rectangular segment - Set 3.....................42

Figure 34. Computed forces in landside miter channel pin - Set 1...................................45 
Figure 35. Computed forces in riverside miter channel pin - Set 2.................................46

Figure 36. Computed forces in riverside miter channel pin - Set 3..................................4 47

Figure 37. Computed forces in landside recess channel pin - Set 1...............................48

Figure 38. Computed forces in riverside recess channel pin - Set 3. ................................49

Figure 39. Finite element model of gudgeon linkage and channels................................50

Figure 40. Finite element model - channel stresses (Von Mises).....................................50

Figure $41 . \mathrm{S} / \mathrm{N}$ curve used for fatigue life evaluation. .......................................................55

\section{Tables}

Table 1. Summary of growthmeter and extensometer measurements

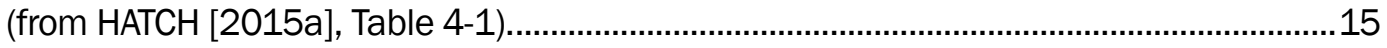

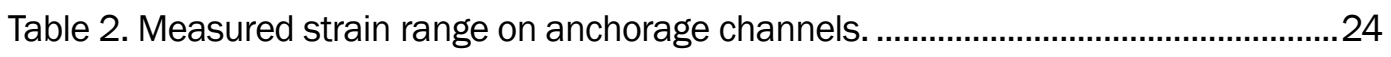

Table 3. Computed force range at anchorage channel pins................................................51

Table 4. Finite element microstrain from measured forces (tension positive)....................51

Table 5. Finite element microstrain from vertical expansion (tension positive)..................51

Table 6. Percent error of strain - finite element strains vs. measured...............................52

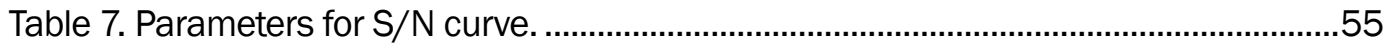

Table 8. Corrected damage indices................................................................................. 


\section{Preface}

This study was conducted for the U.S. Army Corps of Engineers (USACE), Nashville District, under Project "Structural Analysis of Chickamauga Lock Gate Anchor Rods.”

The work was performed by members of three different laboratories of the U.S. Army Engineer Research and Development Center (ERDC): the Coastal and Hydraulics Laboratory (CHL), the Geotechnical and Structures Laboratory (GSL), and the Information Technology Laboratory (ITL).

The CHL portion of the work was completed by the Navigation Branch, Locks Group (CEERD-HNN-L) of the Navigation Division (CEERD-HN). At the time of publication, Mr. Tim Shelton was Chief, CEERD-HNN; Dr. Jackie S. Pettway was Chief, CEERD-HN. The Deputy Director of ERDC-CHL was Mr. Jeffrey R. Eckstein, and the Director was Mr. José E. Sánchez.

The GSL portion of the work was completed by the Concrete and Materials Branch (CEERD-GMC) of the Engineering Systems and Materials Division (CEERD-GM); Mr. Chris Moore was Chief, CEERD-GMC. The Deputy Director of ERDC-GSL was Dr. William P. Grogan, and the Director was Mr. Bartley P. Durst.

The ITL portion of the work was completed by the Sensor Integration Branch (CEERD-IEI) of the Computational Science and Engineering Division (CEERD-IE); Dr. Dan Eng was Chief, CEERD-IEI. The Deputy Director of ERDC-ITL was Ms. Patti Duett, and the Director was Dr. Reed L. Mosher.

Jeff Lillycrop, CEERD-HZT, was the Technical Director for Navigation Systems.

COL Bryan S. Green was the Commander of ERDC, and the Director was Dr. David W. Pittman.

The authors extend special thanks to the operations and maintenance staff at Chickamauga Lock and Dam who went above and beyond the call of duty to allow ERDC to collect data efficiently and easily. Mr. Thomas Hood, Headquarters, USACE, and Mr. John Cheek with the Great Lakes and Ohio 
River Division were very helpful in collecting and deciphering information about lock usage history. Appreciation is also expressed to Mr. Bruce Barker of ERDC-ITL for his assistance in collecting the load measurements at Chickamauga Lock. 


\section{Unit Conversion Factors}

\begin{tabular}{|l|c|l|}
\hline Multiply & By & To Obtain \\
\hline cubic feet & 0.02831685 & cubic meters \\
\hline cubic yards & 0.7645549 & cubic meters \\
\hline degrees (angle) & 0.01745329 & radians \\
\hline feet & 0.3048 & meters \\
\hline inches & 0.0254 & meters \\
\hline miles (nautical) & 1,852 & meters \\
\hline miles (U.S. statute) & $1,609.347$ & meters \\
\hline
\end{tabular}




\section{Introduction}

\subsection{Background: History of Chickamauga Lock and Dam}

Chickamauga Lock and Dam (Figure 1) is one of nine multipurpose main river projects on the Tennessee River. Together, these projects provide a 652-mile navigable waterway from the mouth of the Tennessee River at Paducah, KY, to the source of the river above Knoxville, TN. Chickamauga is located at River Mile 471, which is 58.9 miles downstream from Watts Bar Dam and 46.3 miles upstream from Nickajack Dam. Chickamauga Lock and Dam consists of a power plant with 4 hydroelectric generating units, a dam composed of 18 spillway gates, and a single navigation lock with a 60 feet $(\mathrm{ft}) \times 360 \mathrm{ft}$ chamber. The Tennessee Valley Authority (TVA) owns the lock and dam, and the U.S. Army Corps of Engineers (USACE), Nashville District (LRN), operates and maintains the navigation lock.

Extensive concrete surface cracking was observed at Chickamauga Lock and Dam soon after construction was completed in 1940. Subsequently, minor structural problems developed in the early 1950s, primarily in the form of misalignment of rotating parts of the power generation equipment at the dam. Major structural problems began in the navigation lock in the mid-1960s. Petrographic examinations of concrete cores confirmed that the Chickamauga project was experiencing "concrete growth" caused by alkali-aggregate reaction (AAR). AAR is a chemical reaction that occurs between the cement and the aggregate used in the concrete. A gel forms during the chemical reaction, and the gel expands as it absorbs moisture, causing the concrete to slowly and irreversibly expand.

The AAR expansion of the concrete has caused the following problems:

- cracking of the lock-approach wall piers and discharge ports

- significant deflections of the main lock walls and the approach walls

- misalignment of the lock miter gates and mooring bitt channels

- damage to miter gate pintles and anchorages

- separation and instability of lock blocks. 
Figure 1. Chickamauga Lock and Dam - aerial view.

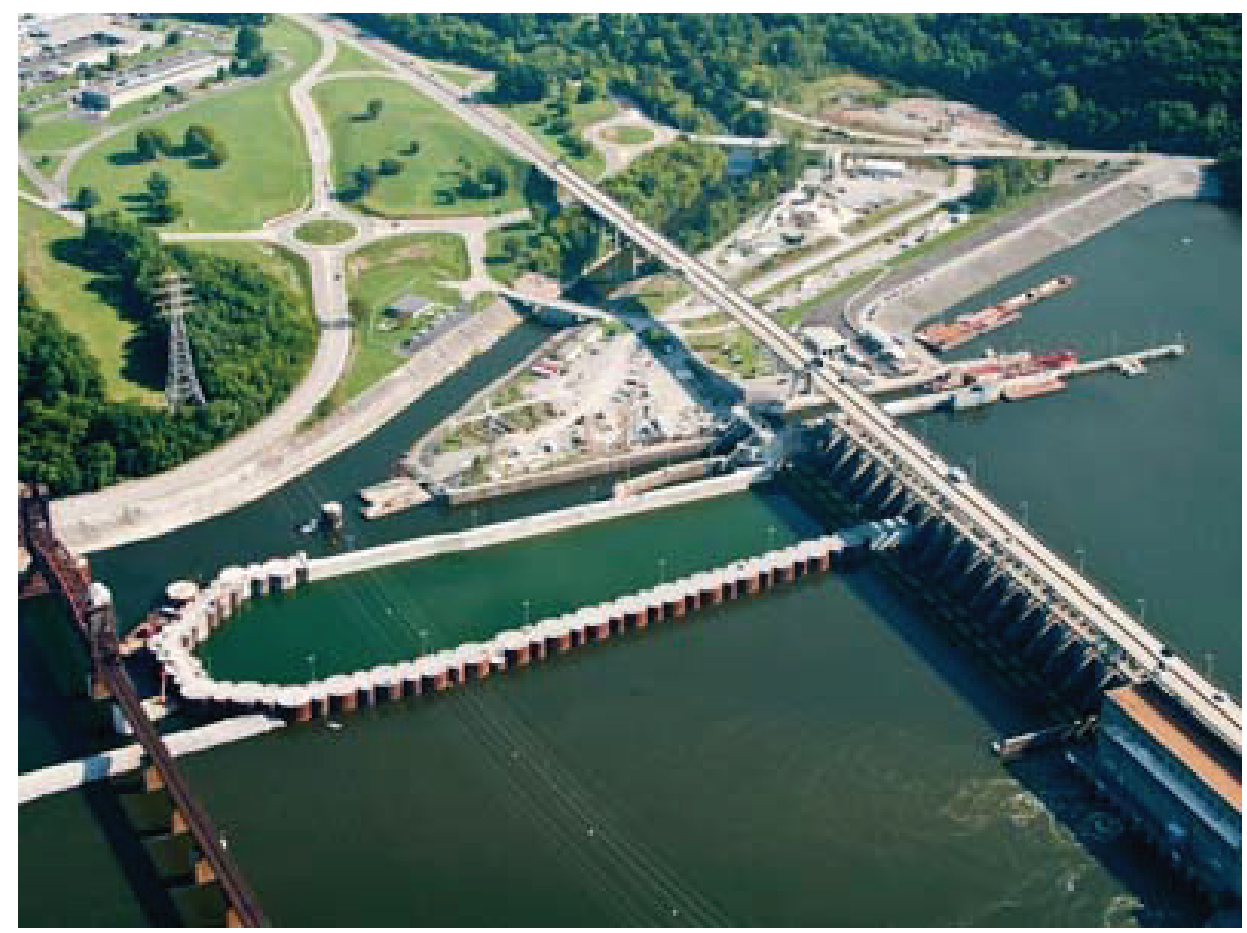

At the time of writing this report, Chickamauga has over 300 retrofit posttensioned anchors installed in the concrete structures to help maintain operability and to restore structural integrity of the lock.

The structural problems experienced at Chickamauga Lock and Dam could lead to low structural reliability or an imminent failure, which would cause an unscheduled lock closure to make emergency repairs. A lock closure would close navigation to 318 miles of the Tennessee River above Chattanooga, TN, including the river entry to Knoxville and Oak Ridge, TN. Closing this section of the Tennessee River would impact the ability to ship large bulk materials such as asphalt for local highway construction, coal, oil, scrap steel, grain, chemicals for the Olin Chemical Plant, oversized components such as nuclear steam generators for Watts Bar Nuclear Power Plant, and components for the $\$ 1.7$ billion Spallation Neutron Source program at Oak Ridge National Laboratory. Also, Chickamauga Lock is one of the mostly highly used locks for recreational traffic in the USACE Great Lakes and Ohio River Division.

In years prior to the current study described in this report, an instrumentation system was installed at Chickamauga to monitor various aspects of the lock. This system contains instruments and survey markers that record information and enter it into a database for review. This 
instrumentation system includes survey points for monitoring horizontal and vertical monolith movement, inverted pendulums for measuring horizontal monolith movement, growthmeters, crackmeters, jointmeters, slot movement measurements, in situ stress measurements, embankment piezometers, uplift cells, temperature measurements, tendon strainmeters, and ShapeAccelArray measurements. A total-station Leica survey system has also been installed to monitor the upper approach wall and the highway bridge at the lock. Instrument readings are analyzed for detection of long-term trends and for prediction of potentially serious problems.

LRN has contracted multiple companies to review the structural reliability of Chickamauga Lock. In the most recent Alkali Aggregate Reaction Investigation Report for Chickamauga Lock, Monolith 37 (Figure 2) is noted for having the highest vertical displacement of any monolith on the entire lock-1.9 inches (in.) from 1981 to 2014. HATCH (2015b) also performed a stability analysis of the lock walls neglecting AAR forces, which would be similar to the case of slip occurring at an assumed failure plane. The HATCH (2015b) report mentions that Monolith 37 does not meet minimum overturning requirements when neglecting AAR. However, this monolith will not overturn and is considered acceptable because it is more than $80 \%$ in compression.

Figure 2. Chickamauga lock schematic.*

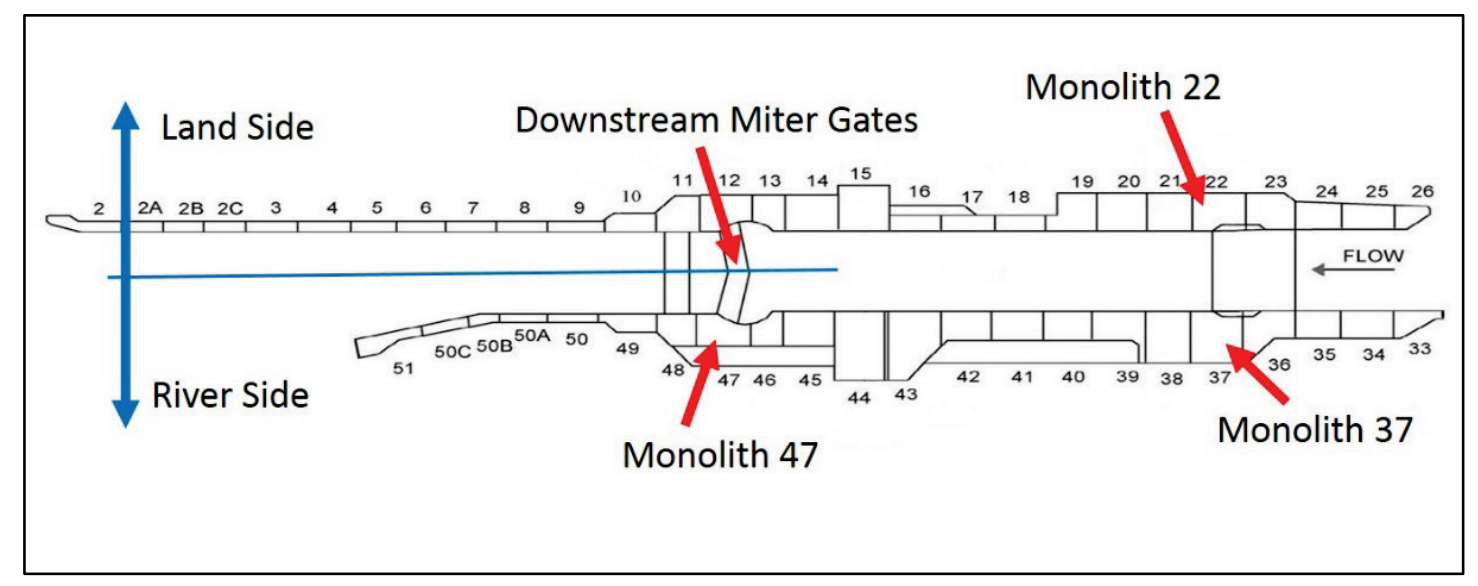

*This figure was created by modifying Figure 1-1 in the HATCH (2015b) report. 
In 2006, ANATECH Corp (James 2006) evaluated the current and future predicted structural conditions of the steel A-frames embedded in Monolith 47 (Figure 2), specifically (Figure 3 through Figure 5). Their findings (James 2006) indicate that the expansion of the concrete monoliths have likely caused severe yielding and possible rupture of the embedded A-frame steel members, but this damage does not pose a significant threat to the performance of those downstream lock gates due to the concrete confinement. However, since the steel A-frame structures are functioning under circumstances well beyond their original design and intent and because the surrounding concrete continues to deteriorate and crack, ANATECH recommended developing plans to eventually repair or rehabilitate the A-frames.

Based on ANATECH's (James 2006) recommendation and readings from instruments in the lower miter gate area, LRN has replaced the A-frame anchorage assemblies on the lower miter gates of the lock at both the river and land monoliths to better accommodate the anticipated concrete growth and to ensure the lock continues to operate safely. ANATECH also noted that advancement of cracking around the miter gate anchor channel arm connections extending from the A-frame in the concrete or new or increased cracking in the top of the monolith would indicate early warning signs for immediate repair or replacement of the miter gate anchorages.

During routine lock maintenance on 27 October 2014, extensive concrete cracks in the area of the miter gate anchorage for Monolith 22 were noticed. The maintenance engineer who noticed the concrete cracks contacted LRN engineers to further inspect the cracks. During an examination of the cracks in the concrete, LRN and Chickamauga Lock personnel decided to also examine the opposing miter gate monolith, Monolith 37, to compare with the cracks found in the concrete on Monolith 22. During this inspection, a large crack (shown in Figure 6 and Figure 7) in the web of the top steel channel of the miter anchorage at Monolith 37 (river side of lock) was found. Immediate operation of the lock was postponed, and a repair plan by the LRN and TVA was soon drafted. For the next 8 days, USACE and TVA personnel repaired the channel. 
Figure 3. Upstream gate plan.

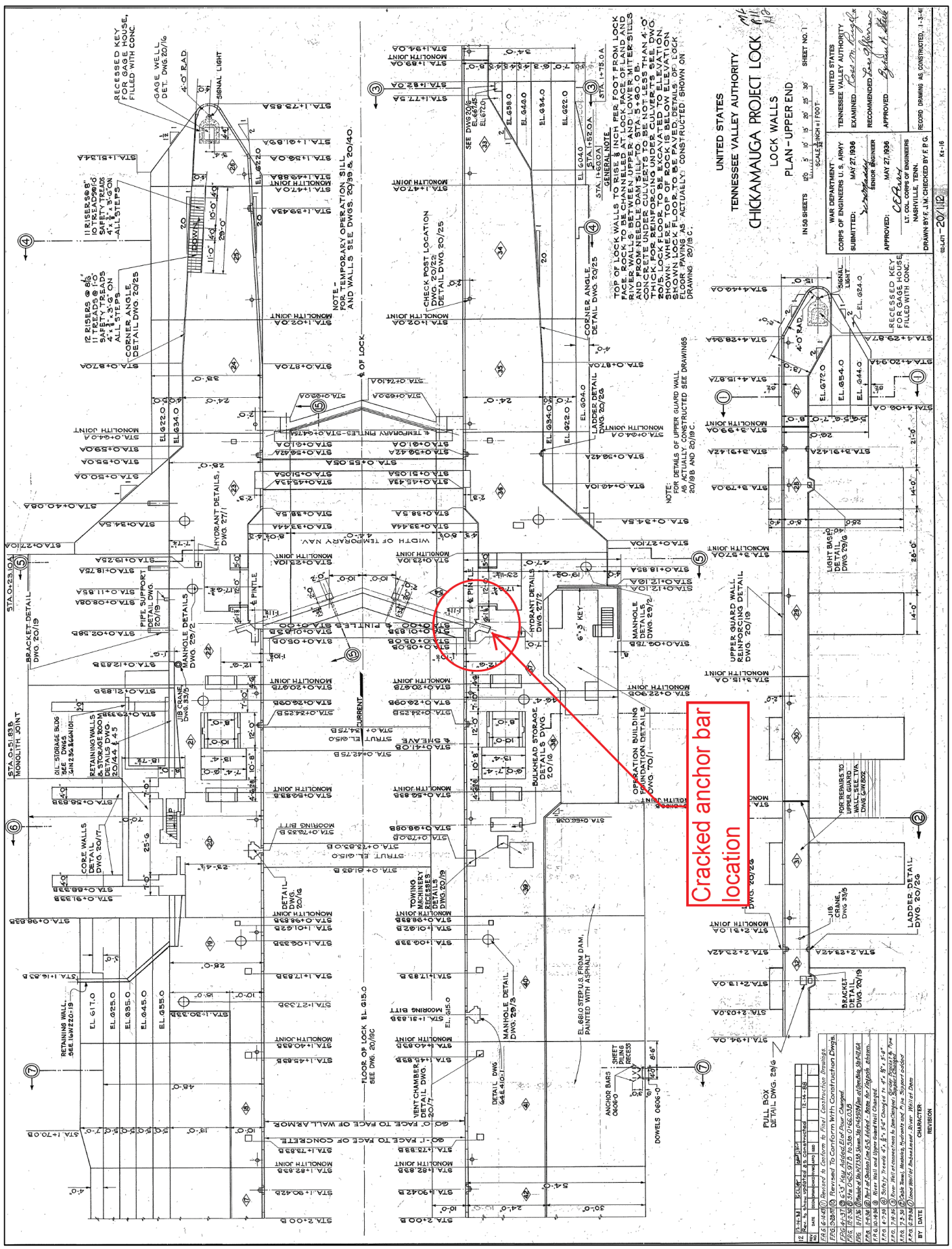


Figure 4. Gudgeon anchorage assembly detail.

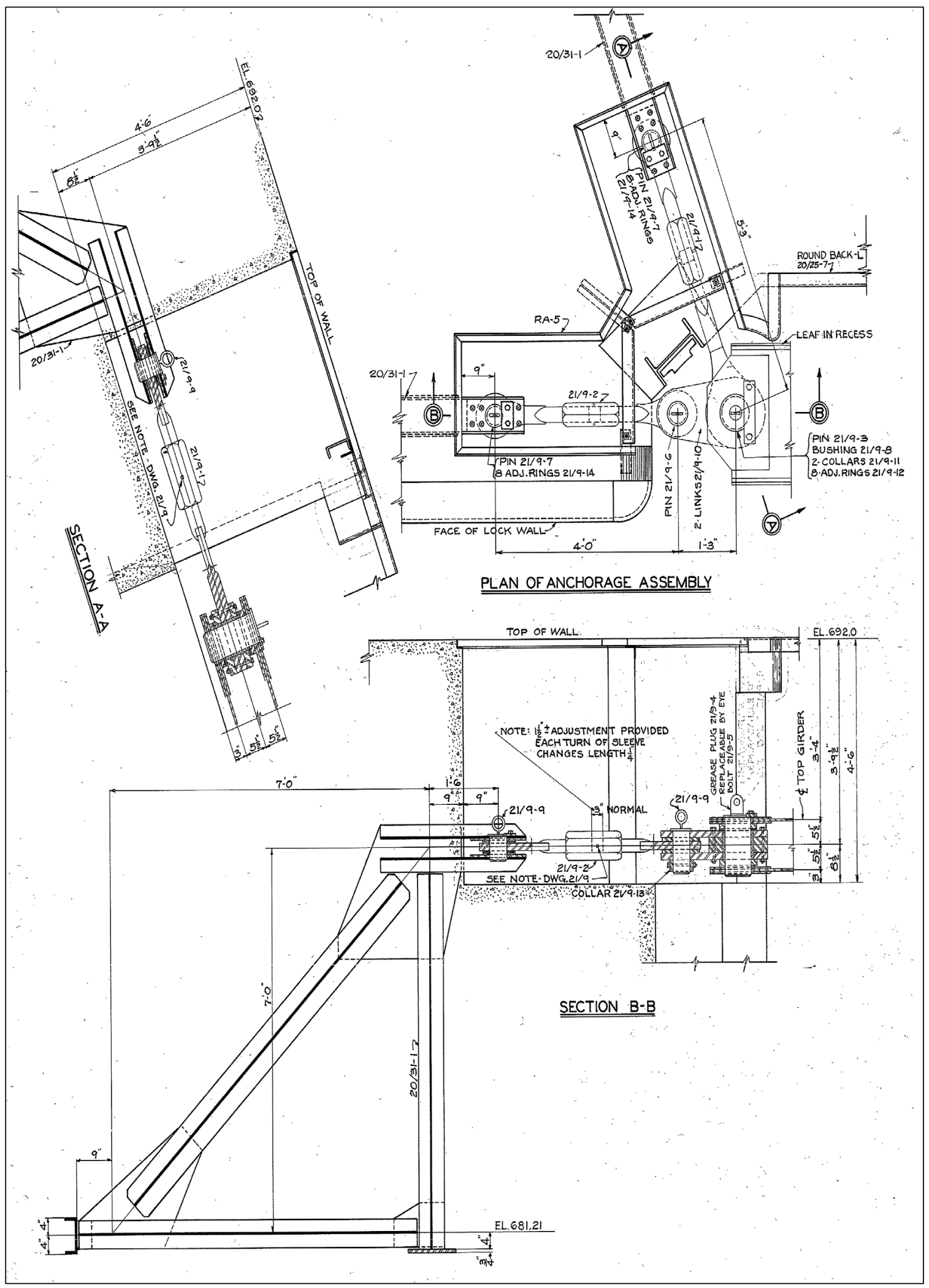


Figure 5. Gudgeon anchorage A-frame detail.

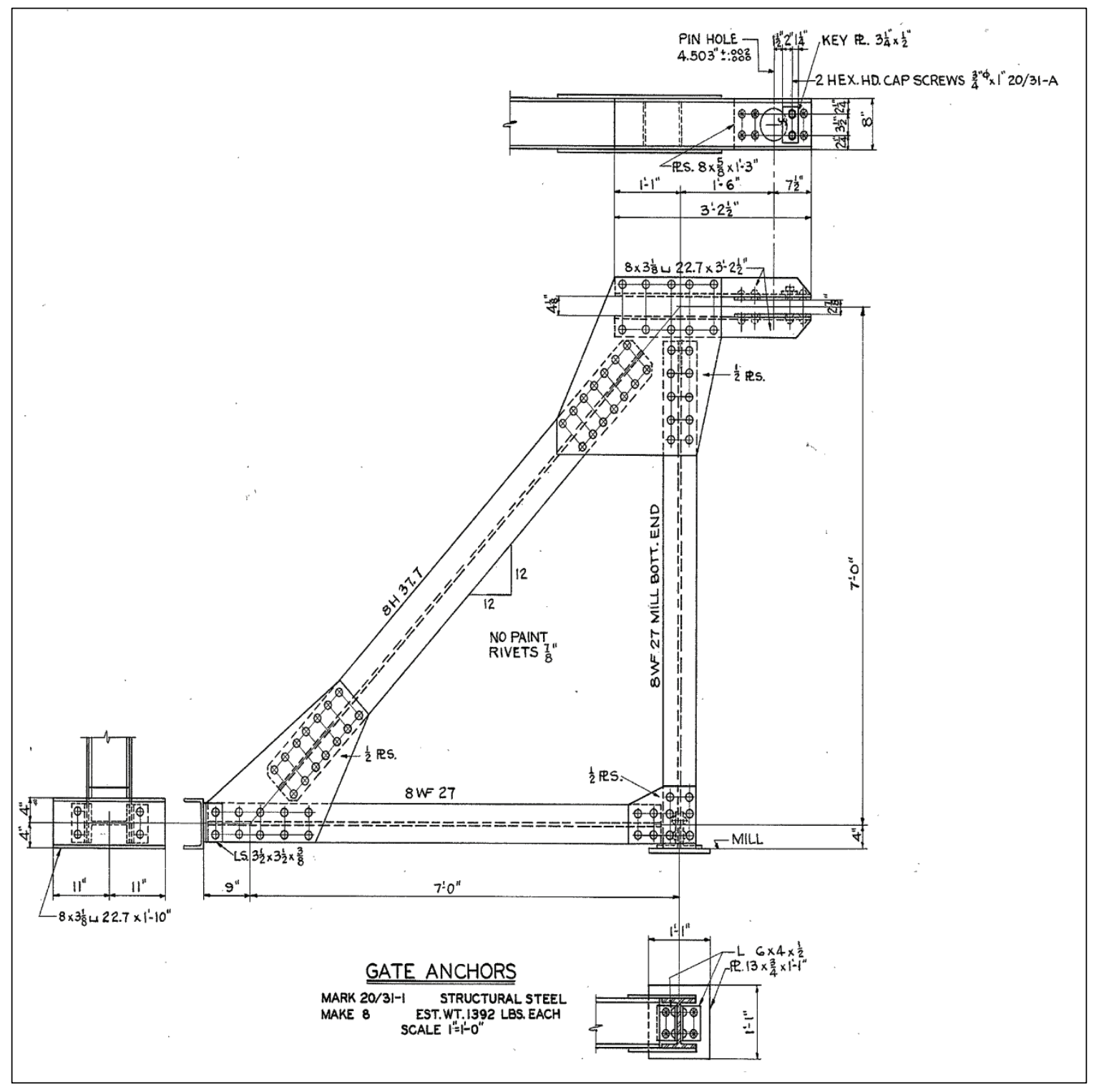


Figure 6. Top view of embedded miter gate anchorage crack observed in October 2014.

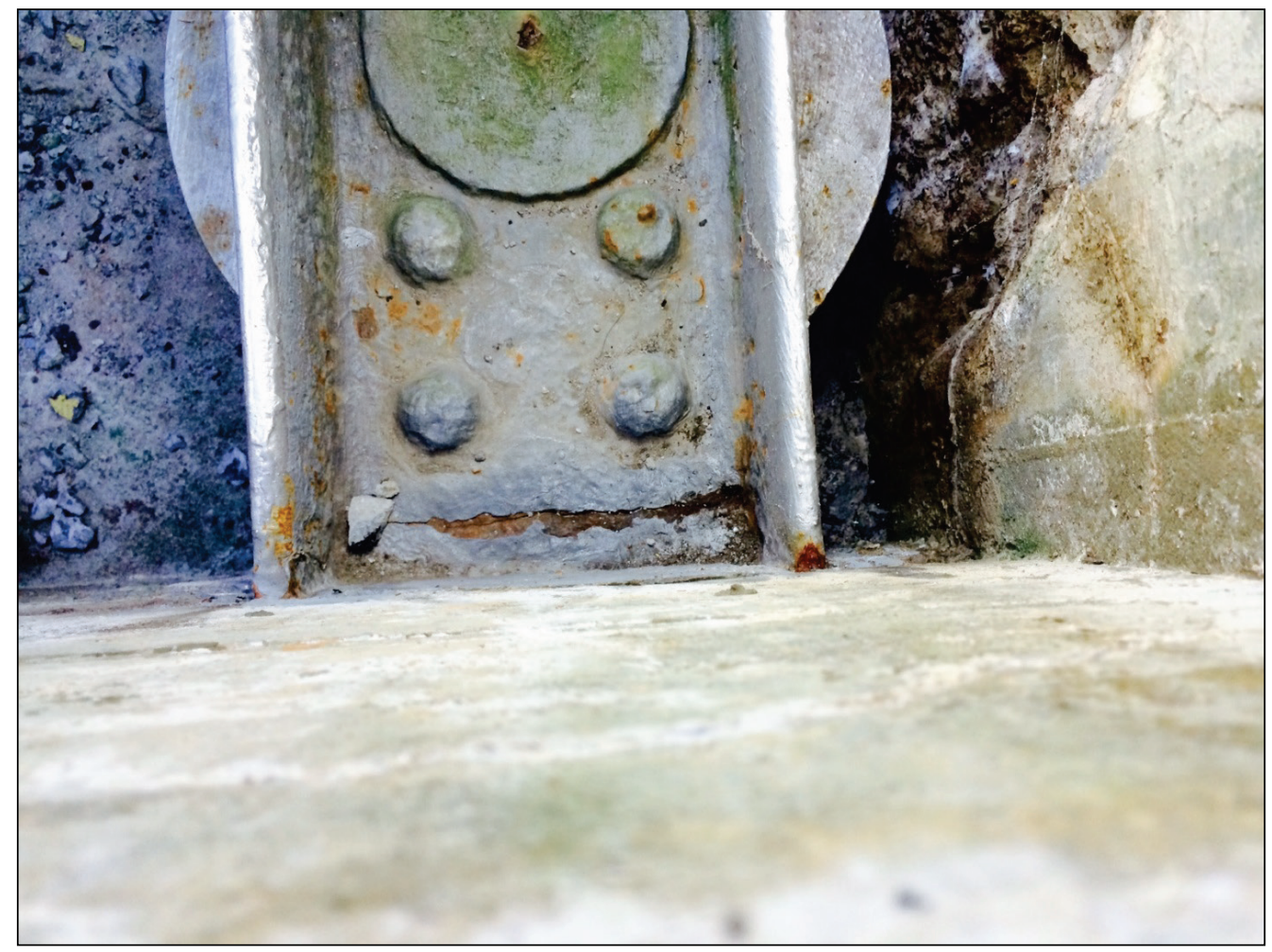

The repair strategy started with the removal of all anchor pins and gudgeon linkages for the miter and recess anchors. Next, the doubler plate on the upper embedded miter anchor channel was removed to repair the crack, cutting a $1.25 \mathrm{in}$. wide slot in the damaged channel web around the crack with a torch. A replacement doubler plate was then installed by welding the new doubler plate to the anchor channel in the old rivet locations and sides of the plate to the side of the channel (Figure 8). Next, the slot where the crack was removed was welded and nondestructively tested to ensure a good weldment was present. New pins were fabricated and placed in new line-bored holes on both miter and recess gudgeon linkages. Several adjustments of the miter linkage were made to have a final resting quoin clearance of 0.027 in. at the top. During the adjustment phase after the repair, the gate remained at the same elevation with each gate cycle. 
Figure 7. Close-up view of embedded west miter anchorage crack observed in October 2014.

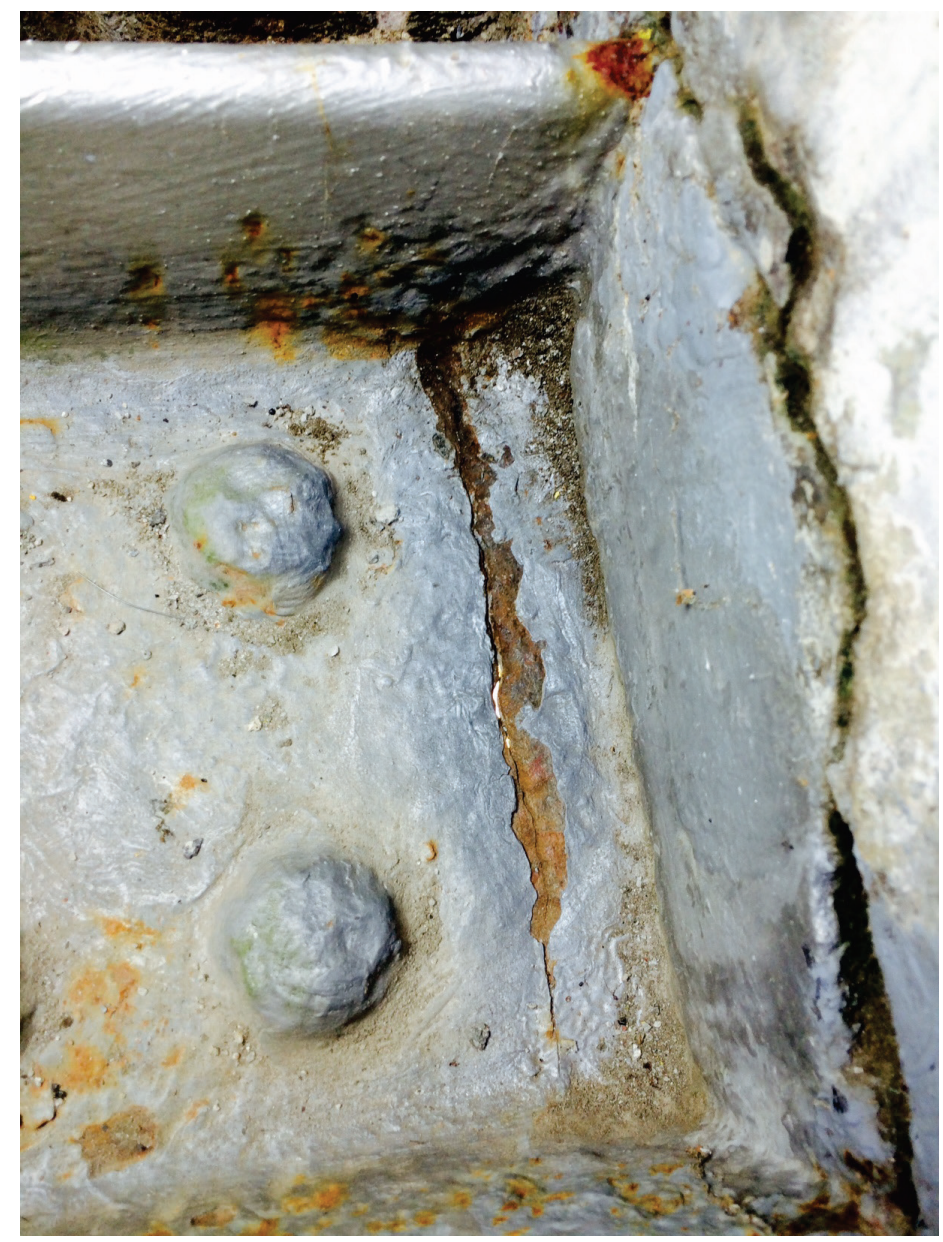

Figure 8. Repaired riverside miter anchorage channel.

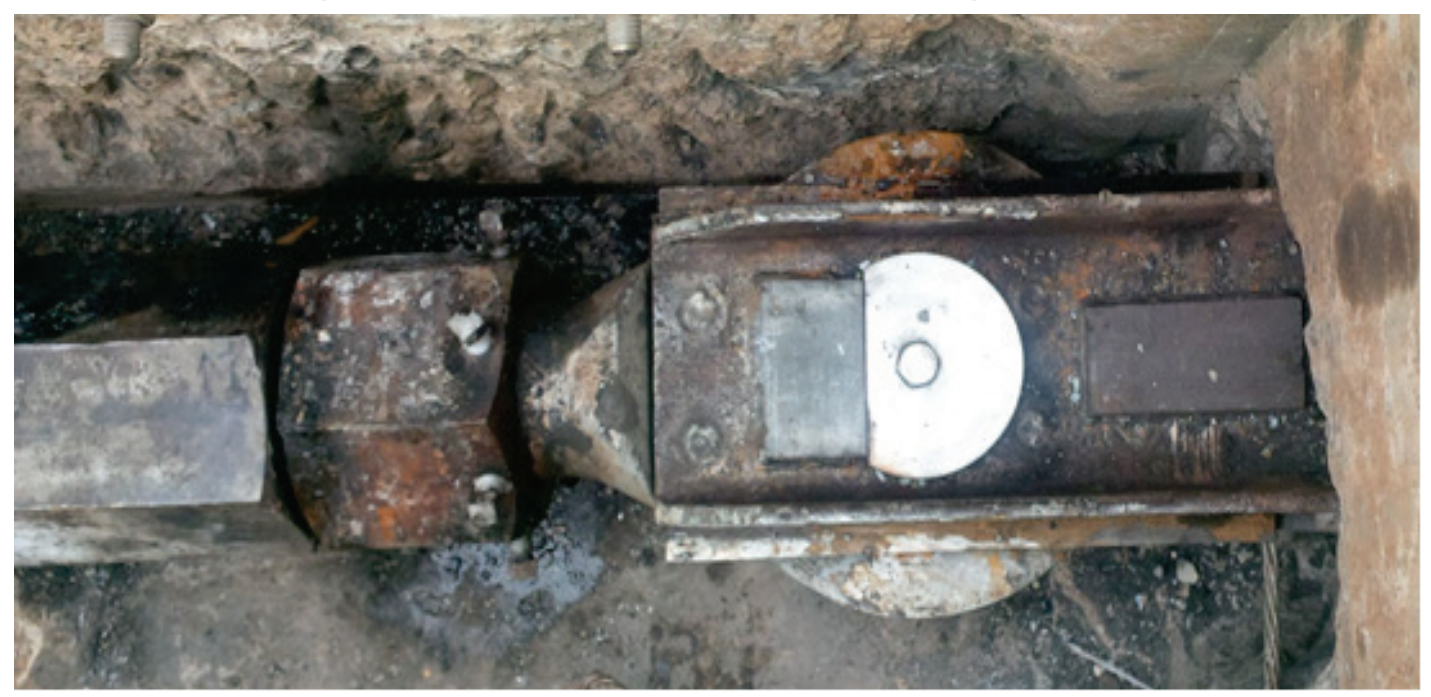




\subsection{Statement of problem}

Following the gudgeon anchorage repair by LRN and TVA, and reviewing the ANATECH (James 2006) and HATCH (2015a, b) reports, LRN requested that the U.S. Army Engineer Research and Development Center (ERDC) analyze the structural loading and response of the upper miter gate anchors, Monoliths 22 and 37, to determine the cause of the anchorage channel crack. Additionally, ERDC was requested to comment on the remaining life of the current anchorage assemblies (both riverside and landside) and possible replacement.

\subsection{Objectives and scope}

The objectives of this study were to determine if the gudgeon anchorage on the upstream miter lock gates at Chickamauga Lock and Dam are at significant risk of experiencing fatigue cracks that may lead to unscheduled outages or catastrophic failure and to provide potential mitigation strategies as necessary. To that end, the ERDC has collected and evaluated lock usage history, concrete expansion data, and structural response data. This report describes the data and findings as well as some potential mitigation strategies to preserve lock gate integrity and reliability.

\subsection{Approach}

The approach is addressed in Chapter 3, "Evaluation and Methodology." 


\section{Data Collection and Field Measurements}

\subsection{General}

To evaluate the reliability of the existing gudgeon anchorage, several types of data were needed. The previous evaluation of the embedded A-frames by ANATECH (James 2006) was reviewed. As the observed cracking in the channels was assumed to be due to fatigue, the history of lock usage was needed to determine the number of load cycles imposed on the anchorage. In addition, the magnitude of vertical expansion of the concrete due to AAR was needed as well as the mechanical strain response of the anchorage channels to cyclic loading. This chapter describes the data and collection processes.

\subsection{Previous analytical studies}

The 2006 ANATECH report (James 2006), which assessed the reliability of the downstream embedded A-frame structures, was reviewed for accuracy and applicability to the upstream embedded A-frames. ANATECH concluded that the downstream A-frames had likely been significantly distorted by the AAR expansion of the surrounding concrete. Consideration was given to the degree of the concrete-to-steel bond as well as the uncertainties in steel material properties. The degree of distortion was shown to likely far exceed the yield point of the steel material, meaning that the A-frame components would be in a state of plastic elongation (net section yielding). However, ANATECH concluded that the likelihood of major tearing or rupture of the A-frame components was small. Further, ANATECH evaluated the effects of ruptured A-frame components and found that rupture likely would neither cause excessive concrete cracking in the monolith nor significantly reduce the anchorage performance of the A-frame, which would have potentially jeopardized the miter gate integrity. Therefore, ANATECH did not recommend any immediate repair or replacement of the downstream embedded A-frame anchorages but did recommend USACE create repair or rehabilitation plans for the anchorage in case concrete cracking occurred, causing loss of confinement. 


\subsection{Lock usage history data}

Annual lockage history from 1989-current was obtained from the Lock Performance Monitoring System (LPMS) database. Also, a random sampling method was employed using the paper lockage log books at the Chickamauga Lock for the years of 1954-1988. No data were available for 1940-1953. The collected lockage history is shown in Figure 9. The variance was calculated for each yearly sample collected from log books, and the standard deviations are shown on the plot for 1954-1988. The LPMS data contained the total lockages for the year and were not sampled; thus, no variance was computed for those values.

Figure 9. Chickamauga lockage history data.

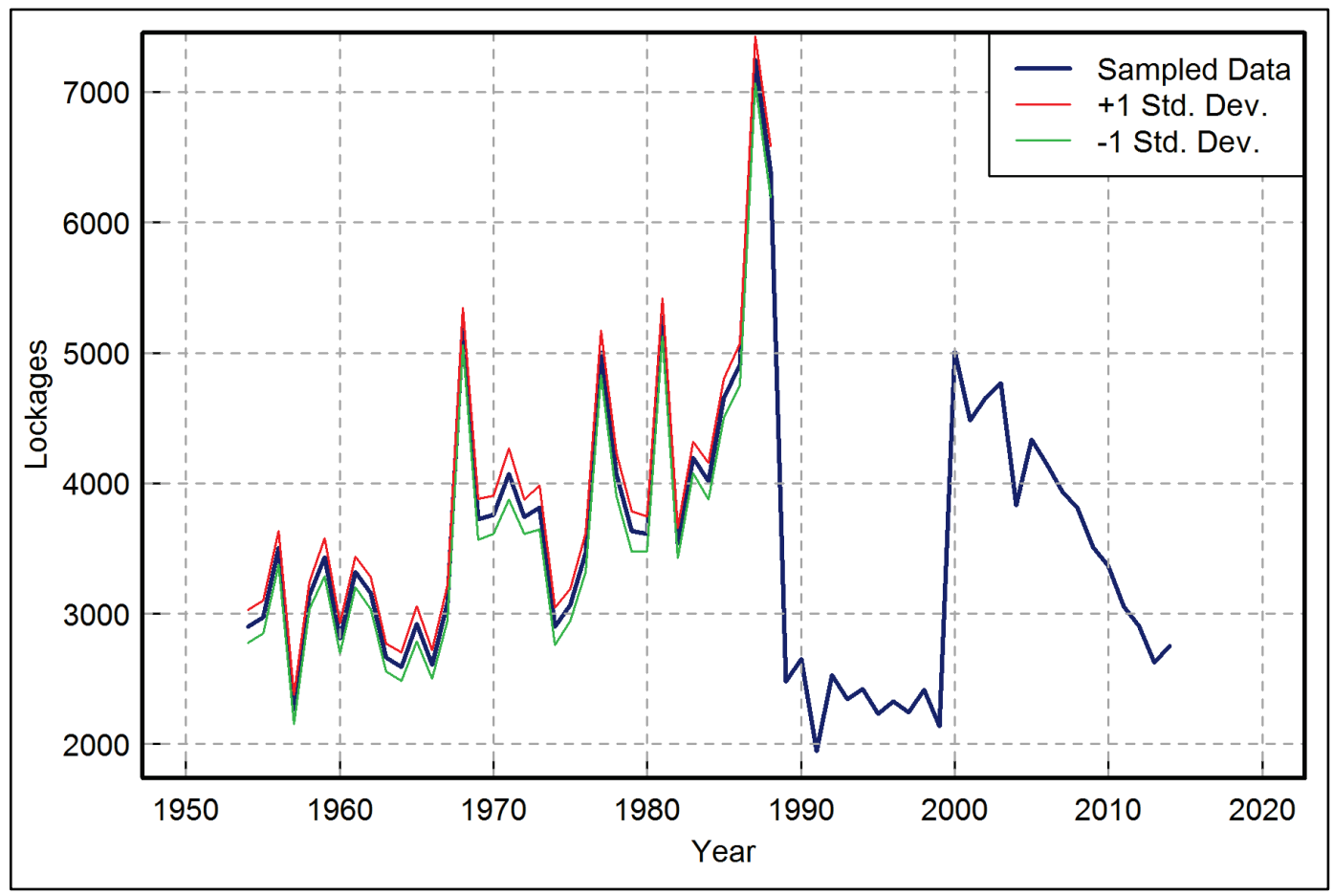

There was uncertainty about whether the paper logs recorded counts of lockage cycles or number of vessels. Some operator shifts recorded more than 10 lockages in a single 8-hour shift. This was deemed an unrealistically high number based on discussions with LRN operations personnel.

The data from LPMS has a sharp change in yearly lockage numbers between 1989 and 1999 and 2000 to the present. Discussions with the USACE Institute for Water Resources revealed that a significant database structure change in 2000 makes knowing if vessels or lockages were 
recorded during the 1990 os impossible. Personnel at the Great Lakes and Ohio River Division and the LRN were consulted to help understand the discontinuity in data. However, no clear reliable estimate of lockage history was available. Visual inspection of the data suggests that the data collected during the 1990 s used a different metric than the other data. The average number of lockages in a year, not considering the data from 1989 to 1999 , is 3,777 .

\subsection{Concrete monolith expansion data}

AAR is pervasive throughout the lock structure, and "concrete growth" resulting from this AAR has caused numerous maintenance and safety concerns. The two known forms of AAR are alkali-silica reaction (ASR) and alkali-carbonate reaction (ACR). Both forms are present in Chickamauga Lock and Dam.

Damage to concrete structures by the ASR is a widespread problem, known to affect airfields, pavements, bridges, and other infrastructure. While ongoing research to better understand the underlying mechanisms and nature of the reaction products formed by ASR continues, there is general agreement within the materials science community that reactions between alkali anions $(\mathrm{K}+, \mathrm{Na}+)$ and hydroxyl groups $(\mathrm{OH}-)$ present in the pore solution and poorly crystallized siliceous minerals (e.g., cristobalite, cryptocrystalline quartz, chalcedony) and historically reactive rock types such as greywackes found in some aggregates cause the formation of an ASR gel product. In the presence of sufficient moisture, swelling of this hygroscopic gel causes expansion and cracking of the affected concrete element. Often, internal tensile stresses caused by the expansion lead to significant damage to the concrete. With significant expansion, reduction in concrete compressive and tensile strengths can also lead to reductions in structural load carrying capacity. ACR is caused by similar reactions but with particular carbonate rock types. For ACR to occur, a specific combination of an approximately 50:50 proportion of calcite-to-dolomite is required in the aggregate source and with insoluble residue/clay at $5 \%-$ $25 \%$ by mass. The results of ACR are very similar to ASR, with expansion of concrete and resulting displacements, cracking, and reductions in strength and stiffness.

Numerous instruments and survey points have been installed to study the concrete growth movement trends, dating back to 1982. (No historical data are available to characterize movement trends prior to 1982.) The 
instrumentation system includes survey points for monitoring horizontal and vertical monolith movement, inverted pendulums for measuring horizontal monolith movement, growthmeters and extensometers, tendon strandmeters, crackmeters, jointmeters, slot closure measurements, in situ stress cells, embankment piezometers, uplift cells, and temperature measurements. Detailed results from these instruments are provided in Sections 2-12 of "Review and Evaluation of Instrumentation Data" (HATCH 2015a), respectively. The following measurements were found to be consistent and accurate, so they will be particularly useful for model calibration: growthmeter and extensometer measurements, slot closure measurements, and stress cell measurements. A plan view of the lock is shown in Figure 10.

Figure 10. Plan view of lock.

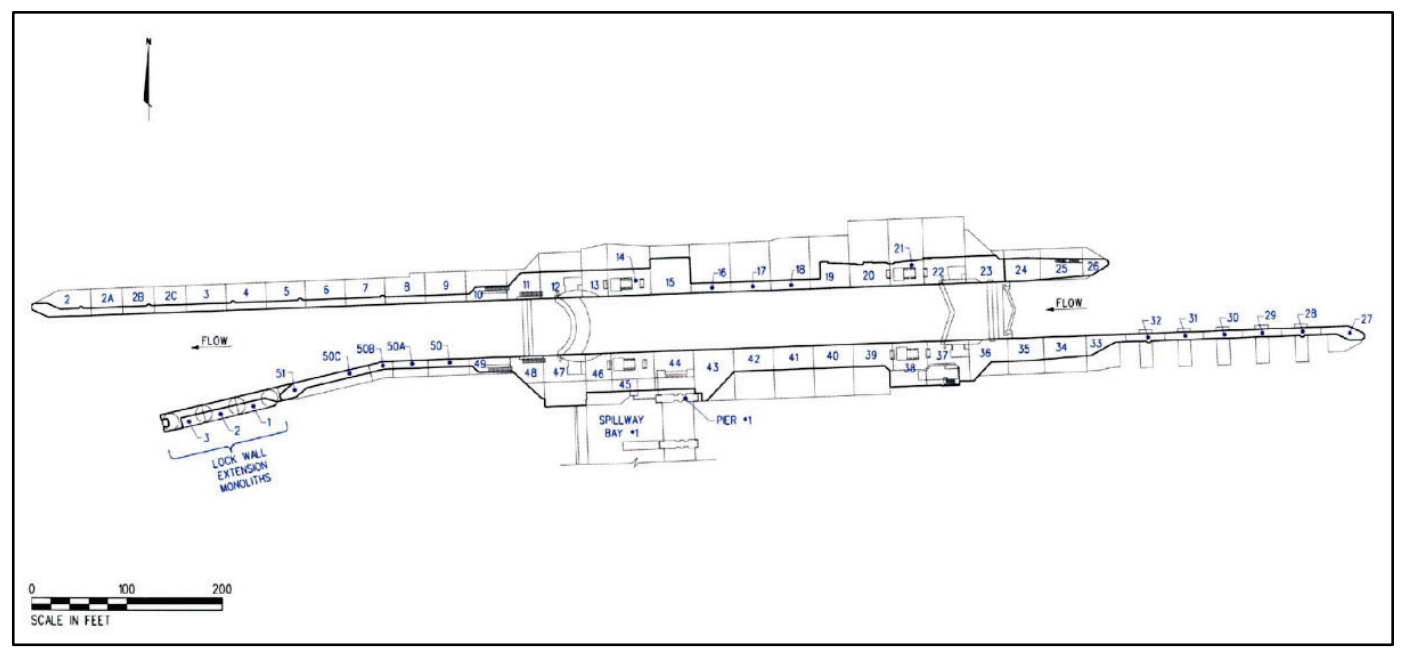

Table 1 provides a summary of the growthmeter and extensometer measurements. Vertical displacement measurements made at Monoliths 22 and 37 (located on the north and south sides of the upstream miter gate, respectively) are shown in Figure 11 and Figure 12, respectively. Linear growth is observed at both locations with an accumulation of approximately 600 microstrain $(\mu \varepsilon)$ over the course of 18 years of monitoring. Expansion data were available for review between 1982 and 2008 in addition to earlier survey measurements and historical information. The expansion was nearly linear and was fit to a concrete growth model to extrapolate expansion back to construction.

The predicted expansion levels correlate well with the qualitative descriptions of damage in periodic inspections reports from that time. This concrete is unique because the expansion is apparently occurring nearly 
linearly since construction with only some slowing in the last decade. Vertical growth at the monoliths of interest at the upstream miter gates is approximately $40 \mu \varepsilon$ per year. When this strain level is extrapolated over the wall height between the pintle and top anchorage of $30 \mathrm{ft}$, the result is a vertical expansion of $1.08 \mathrm{in}$. This calculation is based on results derived from observations and data presented in the HATCH (2015a) report. Similar expansion levels of approximately $50 \mu \varepsilon$ are reported in the Anatech report. Based on the results of these analyses, a linear concrete growth rate of $40 \mu \varepsilon$ per year was selected for use in finite element simulations projected over the $30 \mathrm{ft}$ height of the wall. This displacement value was input into the finite element model to represent support displacements at the gate anchorage.

Table 1. Summary of growthmeter and extensometer measurements (from HATCH [2015a], Table 4-1).

\begin{tabular}{|c|c|c|c|c|}
\hline Block & Instrument & Elevation & Orientation & $\begin{array}{c}\text { Expansion Rate } \\
(\mu \varepsilon / y r)\end{array}$ \\
\hline 37 & GM37_656LC & 656 & Longitudinal & 0.2 \\
\hline 38 & GM38_656LC & 656 & Longitudinal & 0.2 \\
\hline 39 & GM39_656LC & 656 & Longitudinal & 0.2 \\
\hline 40 & GM40_656LC & 656 & Longitudinal & 8.3 \\
\hline M1 & GMM1_656TC & 656 & Transverse & 0.1 \\
\hline M2 (Riverward) & GMM2L_656TC & 656 & Transverse & 0.3 \\
\hline M2 (Landward) & GMM2R_656TC & 656 & Transverse & 0.2 \\
\hline 22 & GM22_656TC & 656 & Transverse & 0.4 \\
\hline 37 & GM37_656TC & 656 & Transverse & 0.3 \\
\hline \multicolumn{5}{|l|}{ Landwall } \\
\hline 11 & EX11_675_630-Growth & $630-675$ & Vertical & 31 \\
\hline 14 & EX14 690630 -Growth & $630-690$ & Vertical & 23 \\
\hline 20 & EX20_690_630_Growth & $630-690$ & Vertical & 39 \\
\hline 22 & EX22_690_630_Growth & $630-690$ & Vertical & 40 \\
\hline 26 & EX26_690_630_Growth & $630-690$ & Vertical & 24 \\
\hline \multicolumn{5}{|l|}{ Riverwall } \\
\hline \multirow[t]{6}{*}{33} & EX33_690_613_Growth & $613-690$ & Vertical & 37 \\
\hline & EX33_690_621_Growth & $621-690$ & Vertical & 38 \\
\hline & EX33_690_630_Growth & $630-690$ & Vertical & 40 \\
\hline & EX33_690_640_Growth & $640-690$ & Vertical & 42 \\
\hline & EX33_690_650_Growth & $650-690$ & Vertical & 45 \\
\hline & EX33_690_660_Growth & $660-690$ & Vertical & 46 \\
\hline 37 & EX37-5_690_630_Growth & $630-690$ & Vertical & 34 \\
\hline \multirow[t]{4}{*}{44} & EX44_690_660_Growth & $660-690$ & Vertical & 44 \\
\hline & EX44_690_650_Growth & $650-690$ & Vertical & 41 \\
\hline & EX44_690_640_Growth & $640-690$ & Vertical & 41 \\
\hline & EX44_690_630_Growth & $630-690$ & Vertical & 39 \\
\hline 47 & EX47_690_640_Growth & $640-690$ & Vertical & 29 \\
\hline 48 & EX48_675_630_Growth & $630-675$ & Vertical & 22 \\
\hline
\end{tabular}


Figure 11. Vertical growth - Block 22 (from HATCH [2015a], Figure 4-7).

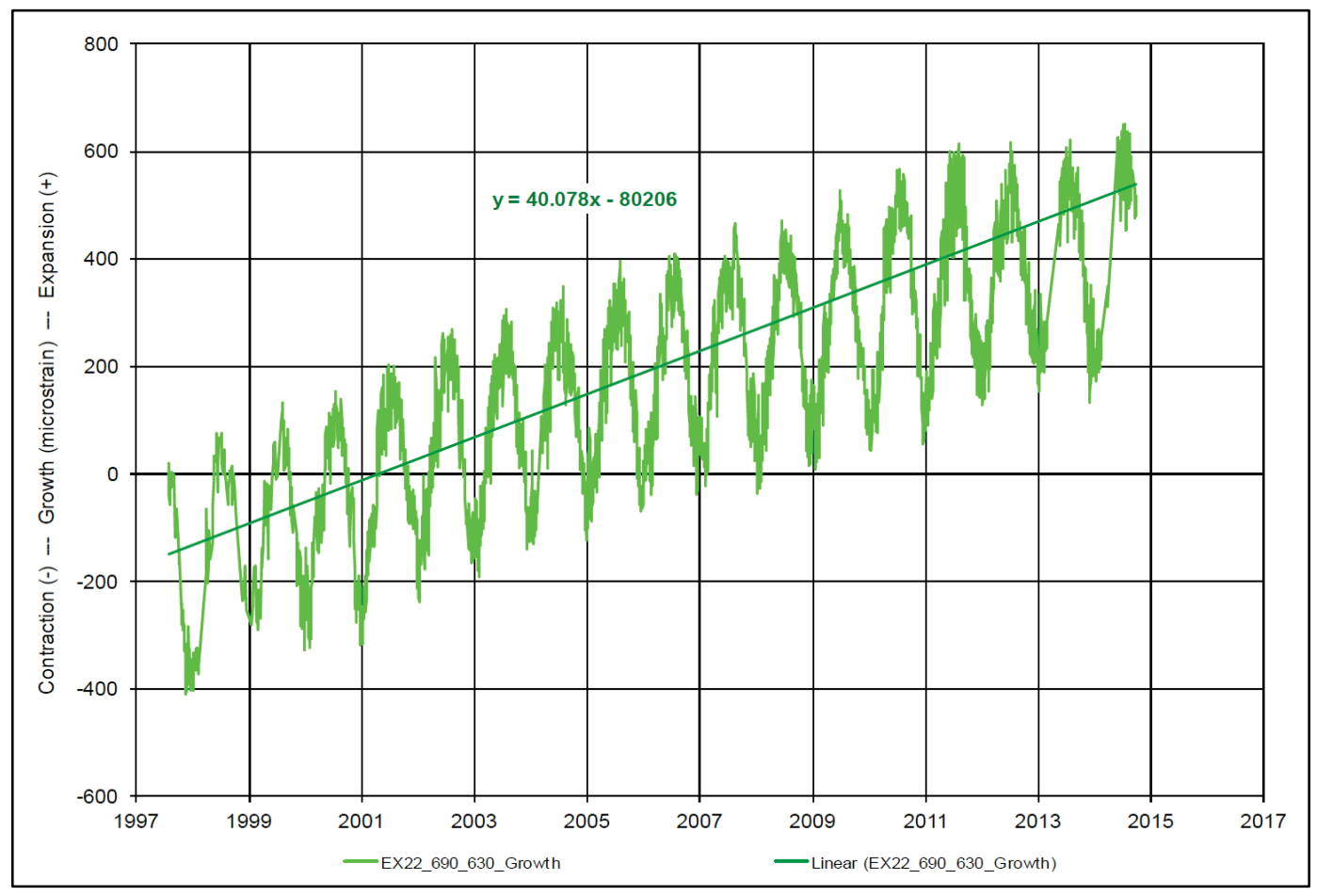

Figure 12. Vertical growth - Block 37 (from HATCH [2015a], Figure 4-11).

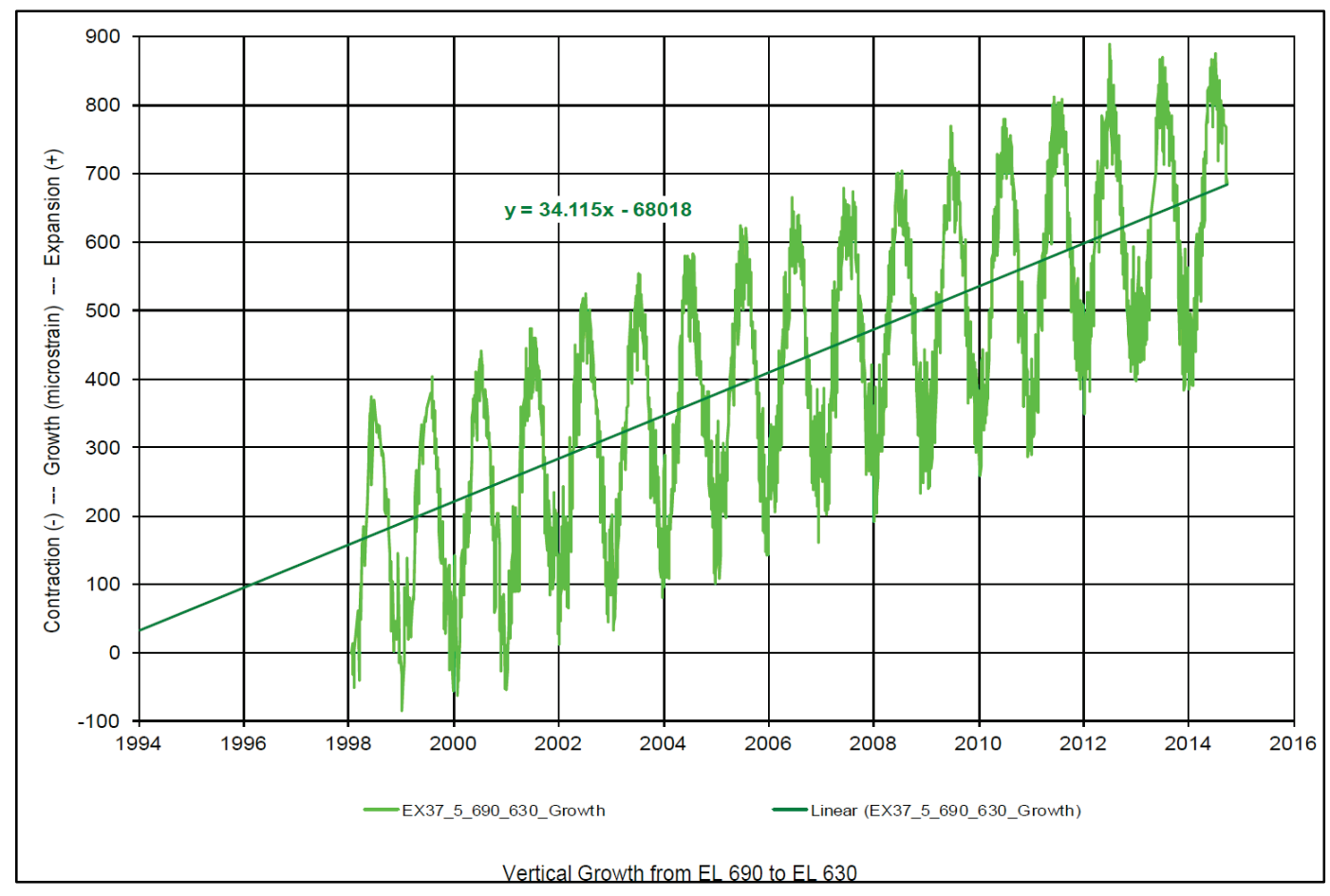




\subsection{Gudgeon anchorage strain measurements}

Measuring the strain in the anchorage channels in response to the loading induced by a lockage cycle was necessary. A total of 30 electric resistance strain gages were placed on the anchorage channels at each side (land and riversides) for a total of 60 gages. The steel mounting surface was ground smooth and cleaned prior to an epoxy-based gage application. The gages were covered with an acrylic protectant.

Data were collected using a Hi-Techniques, Inc. Synergy 8 model, 32channel, high-performance data acquisition system. The Synergy uses a 16-bit/2 million samples-per-second (S/s) analog-to-digital converter, with a 10-pole analog pre-filter to provide o-200 kilohertz base bandwidth. Sample rates and digital filters were then selected to optimize the system for $200 \mathrm{~S} / \mathrm{s}$. A low-pass Gaussian digital filter provided an effective $0-5$ hertz bandwidth for the strain gages.

The gages were designated with a naming convention. The first letter of the gage name was either $\mathrm{R}$ or $\mathrm{L}$, indicating the riverside or landside of the lock. The second letter of the gage name was either $\mathrm{M}$ or $\mathrm{R}$, indicating the miter or recess anchorage. The third letter of the gage was $\mathrm{C}, \mathrm{R}$, or F, indicating the gage was on the channels, round cylindrical segment of the gudgeon linkage, or on the flat rectangular segment of the gudgeon linkage. The last portion of the gage name was a numeric identifier. The gages were placed according to the gage plans shown in Figure 13 through Figure 18.

The gage locations on the channels were chosen to provide an indication of the strain distribution across the top channel. The bottom channel was generally inaccessible, so only a single gage could be placed on a channel flange. The gages on the rectangular portion of the miter anchor linkage were placed to provide a robust measurement of the axial force and bending moment in the linkage. There was no similar segment on the recess linkage, so gages were placed on the cylindrical segments of the linkage for both miter and recess to provide a way to measure axial force and bending moment in the recess linkage by calibrating those gages to the forces indicated by the rectangular gages. This process is described in detail in Chapter 3. 
Figure 13. Landside anchorage instrumentation plan view.
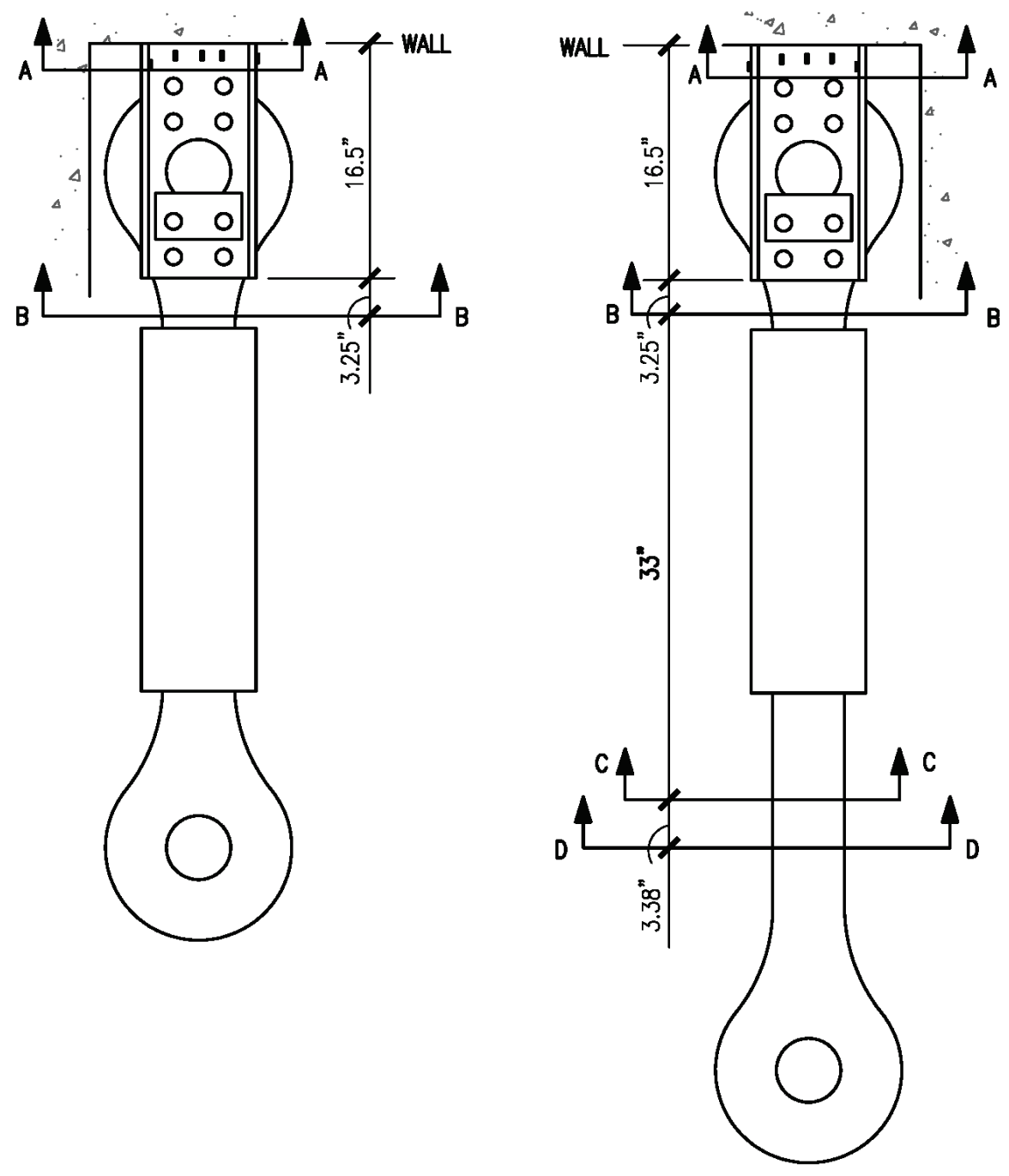

(a) RECESS ANCHORAGE

(b) MITER ANCHORAGE 
Figure 14. Riverside anchorage instrumentation plan view.

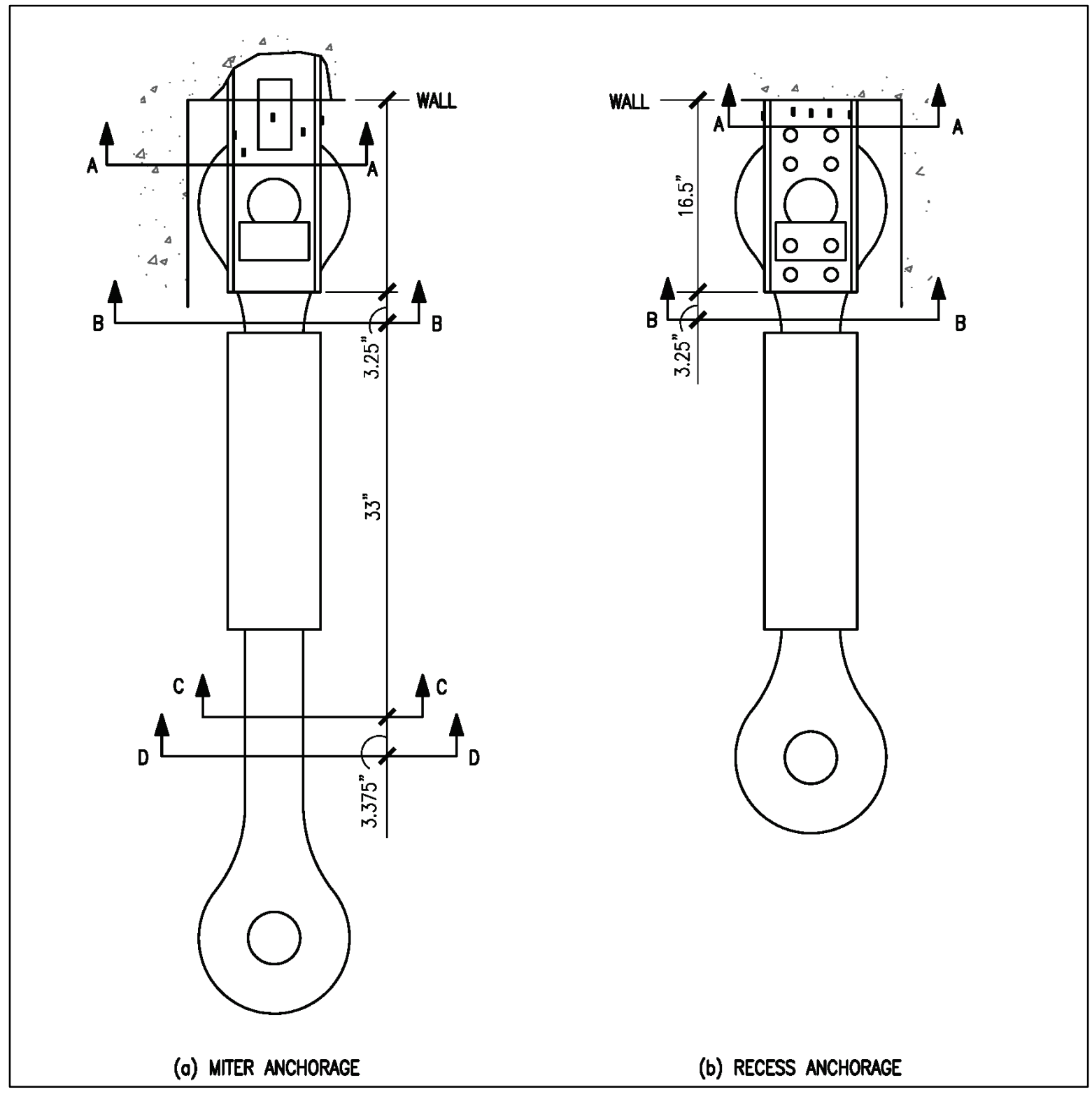


Figure 15. Landside anchor channel instrumentation detail.

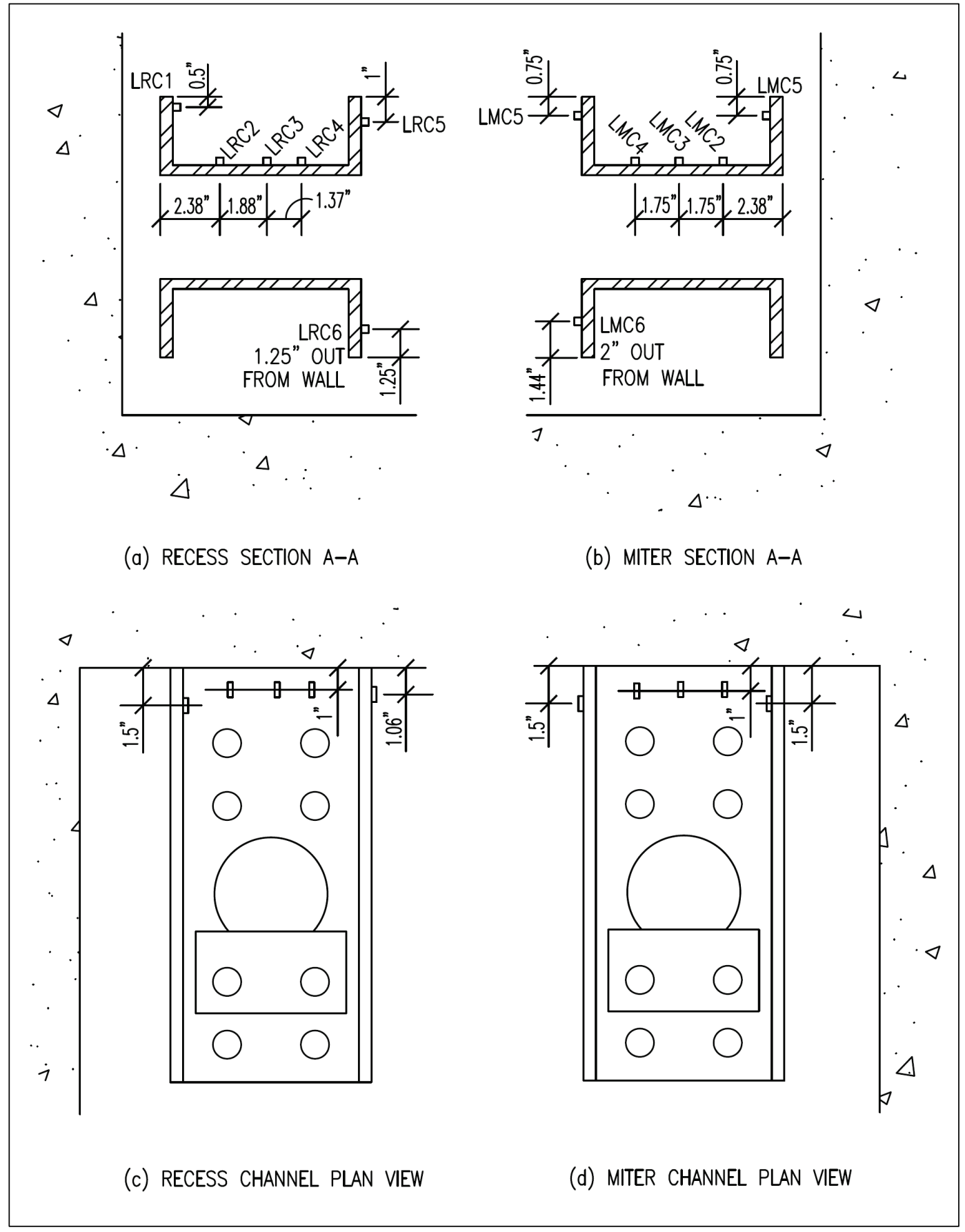


Figure 16. Riverside anchor channel instrumentation detail.

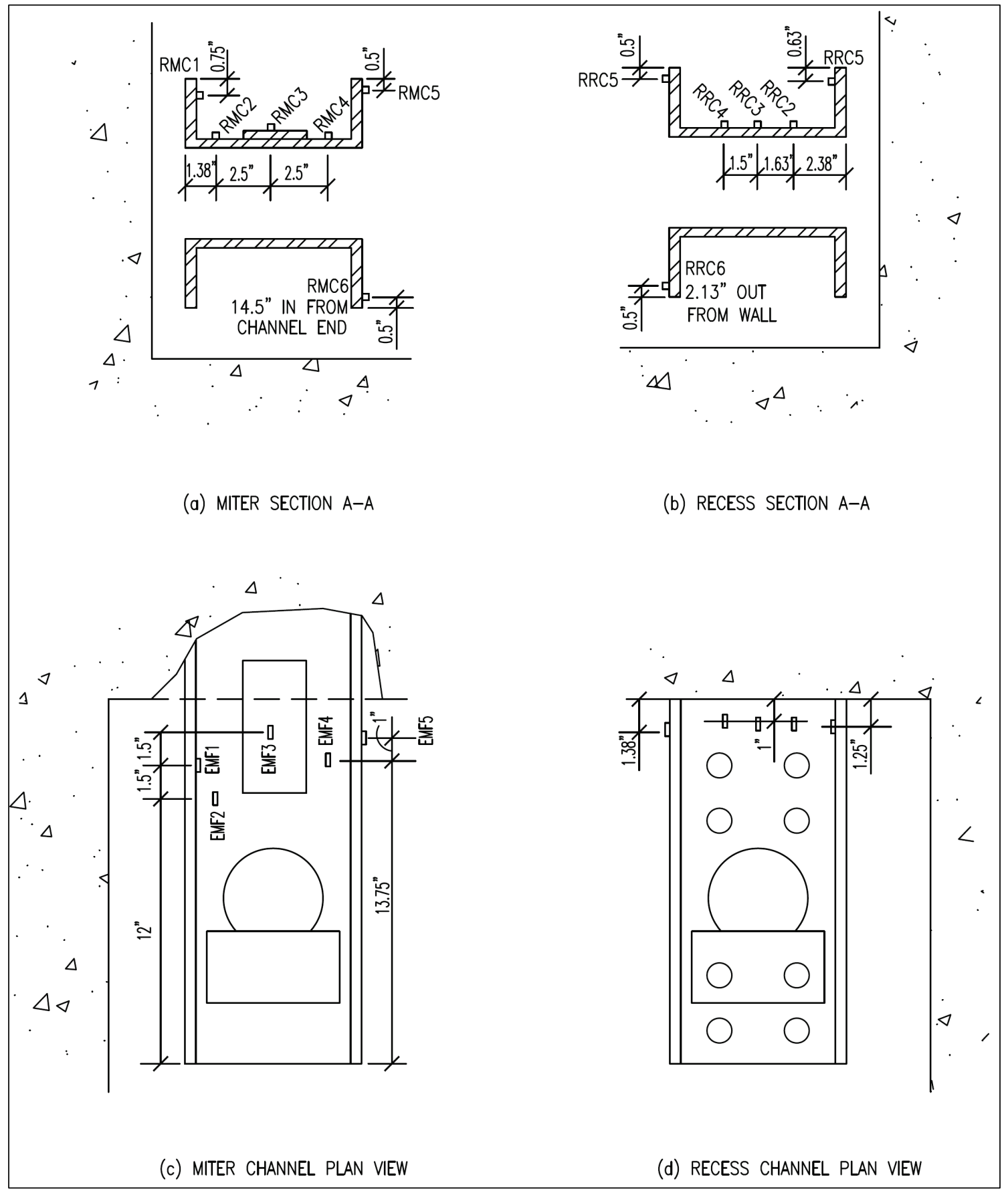


Figure 17. Circular segment anchorage instrumentation details.

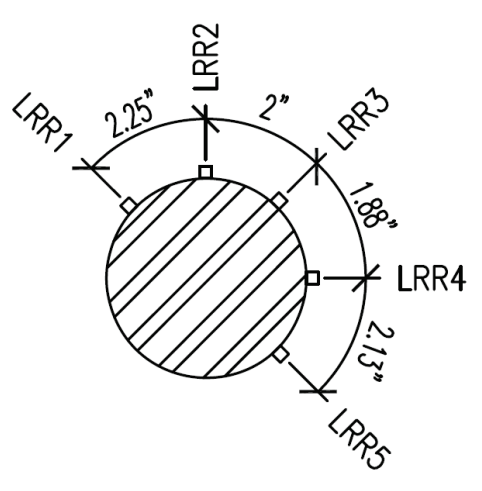

(a) LAND RECESS SECTION B-B

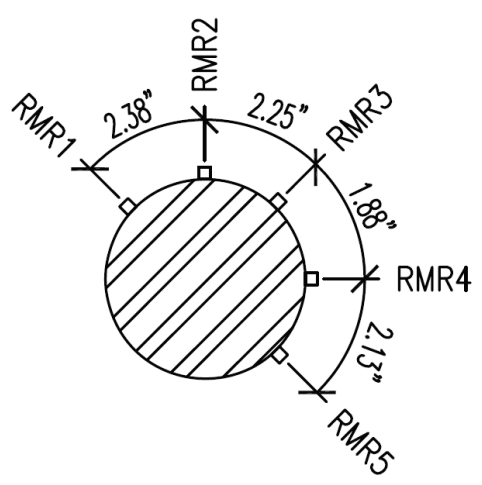

(c) RIVER MITER SECTION B-B

\section{LRR2 AND LMR2 \\ ALIGNED WITH \\ CHANNEL CENTERLINES}

\section{RMR2 AND RRR2 \\ ALIGNED WITH \\ CHANNEL \\ CENTERLINES}

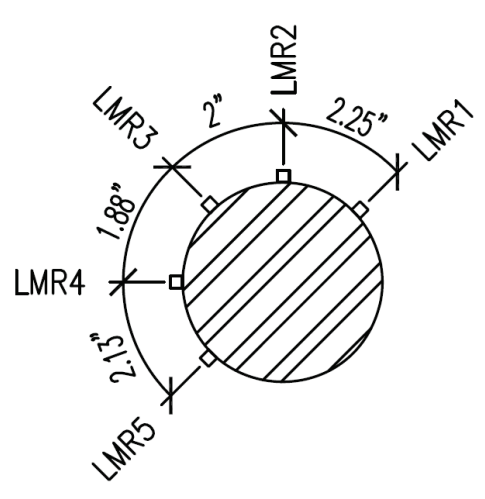

(b) LAND MITER SECTION B-B

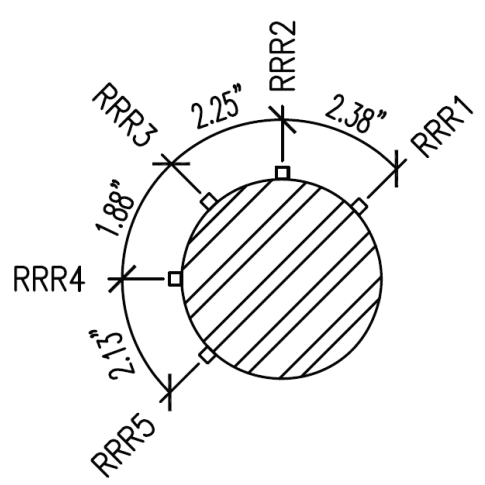

(d) RIVER RECESS SECTION B-B 
Figure 18. Rectangular segment anchorage instrumentation details.

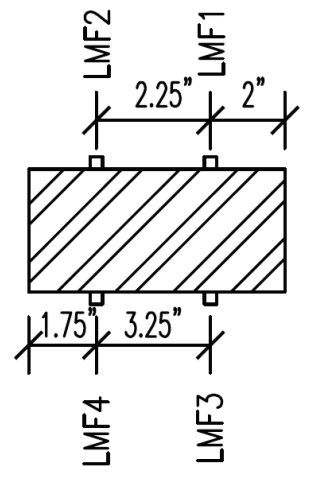

(a) LAND SECTION C-C (FLAT SECTION 1)

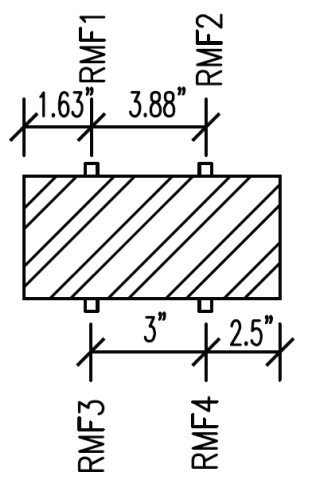

(c) RIVER SECTION C-C (FLAT SECTION 1)

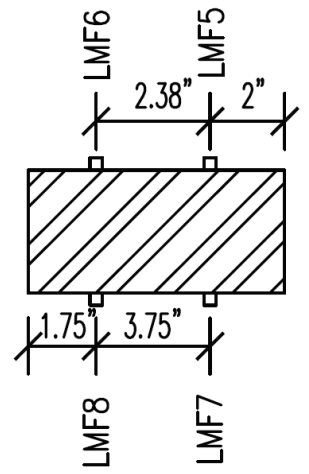

(b) LAND SECTION D-D (FLAT SECTION 2)

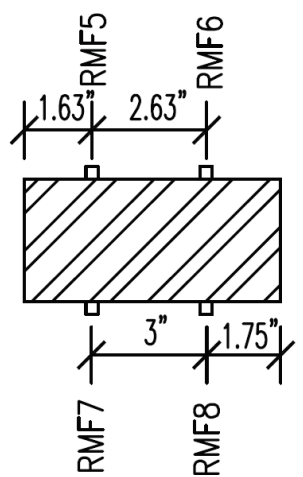

(d) RIVER SECTION D-D (FLAT SECTION 2)

Table 2 lists the maximum and minimum strains used in fatigue calculations as determined from the recorded sensor signals.

The gage records were analyzed to determine when the gates were in recess but not being compressed into the wall. This gate position was used to determine the no-stress condition of the gages on the miter anchorage (xMx gages). The gage records were also analyzed to determine when the gates had just come into contact at the miter blocks but the gates had not yet been compressed together. This gate position was used to determine the no-stress condition of the gages on the recess anchorages (xRx gages). These points were used to set the "zero" value for the gage records, and the gage plots shown already include this offset. The strain measurements are shown in Figure 19 through Figure 30. 
Table 2. Measured strain range on anchorage channels.

\begin{tabular}{|c|c|c|}
\hline Gage Name & Min. Strain $(\mu \varepsilon)$ & Max. Strain $(\mu \varepsilon)$ \\
\hline \multicolumn{3}{|c|}{ Land Miter } \\
\hline LMC1 & -4 & 200 \\
\hline LMC2 & -11 & 290 \\
\hline LMC3 & -13 & 337 \\
\hline LMC4 & -23 & 534 \\
\hline LMC5 & -7 & 245 \\
\hline LMC6 & -25 & 437 \\
\hline \multicolumn{3}{|c|}{ Land Recess } \\
\hline LRC1 & -13 & 61 \\
\hline LRC2 & -17 & 76 \\
\hline LRC3 & -5 & 49 \\
\hline LRC4 & -2 & 52 \\
\hline \multicolumn{3}{|c|}{ River Miter } \\
\hline RMC1 & -33 & 89 \\
\hline RMC2 & -31 & 136 \\
\hline RMC3 & -14 & 66 \\
\hline RMC4 & -12 & 103 \\
\hline RMC5 & -7 & 112 \\
\hline RMC6 & 0 & 185 \\
\hline \multicolumn{3}{|c|}{ River Recess } \\
\hline RRC1 & -30 & 141 \\
\hline $\mathrm{RRC2}$ & -38 & 131 \\
\hline RRC3 & -36 & 155 \\
\hline RRC4 & -26 & 172 \\
\hline RRC5 & -4 & 82 \\
\hline RRC6 & -10 & 111 \\
\hline
\end{tabular}




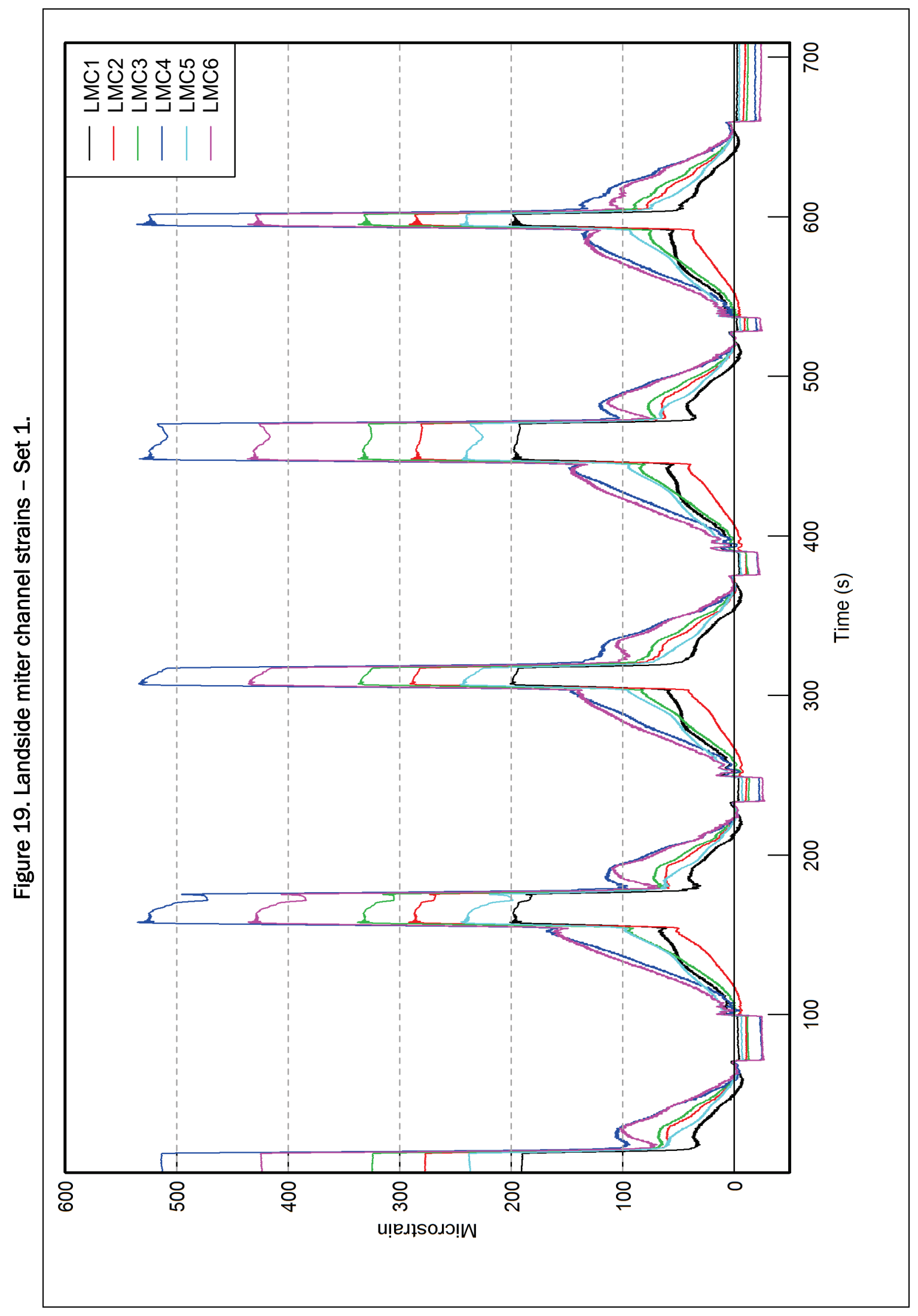




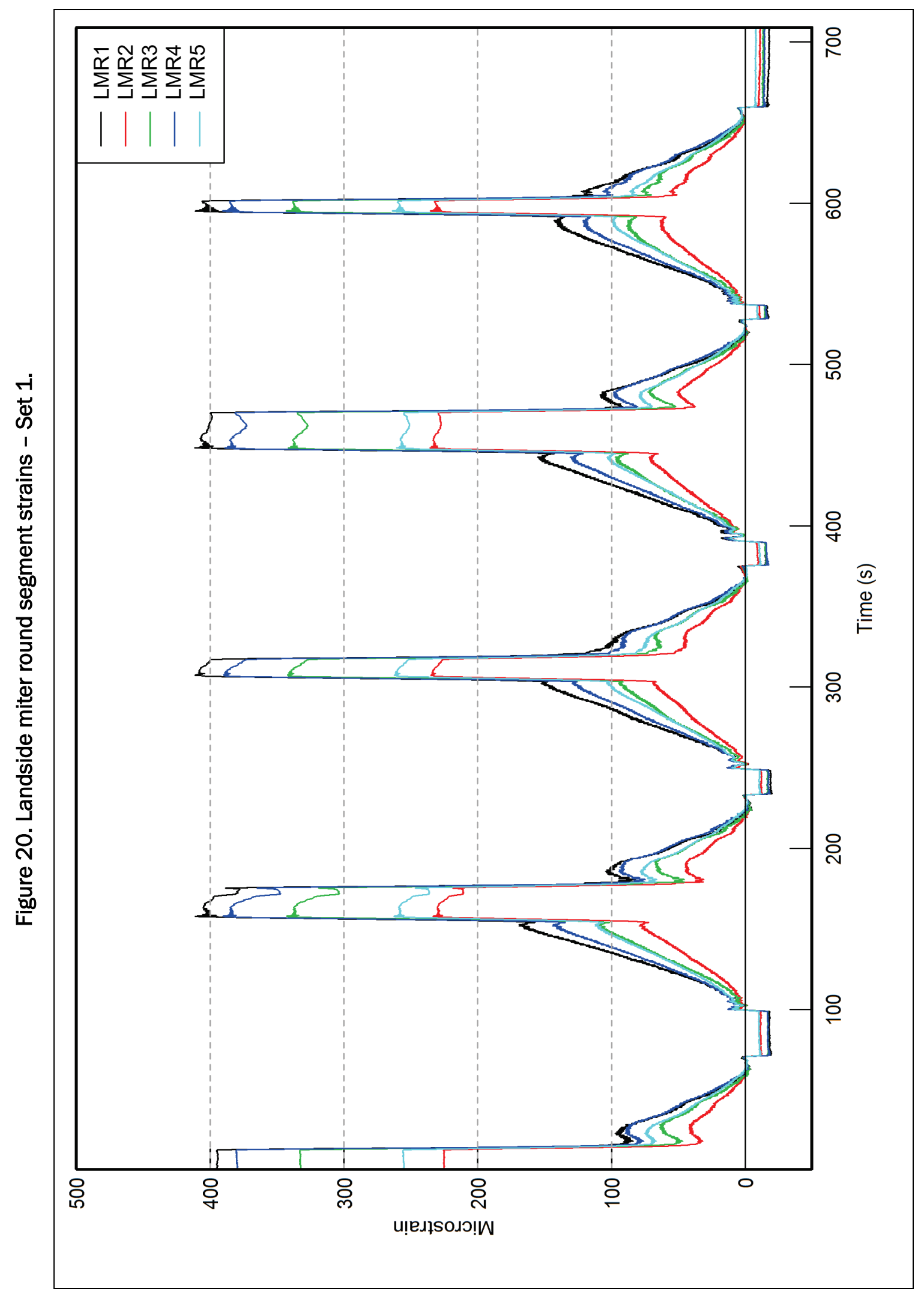




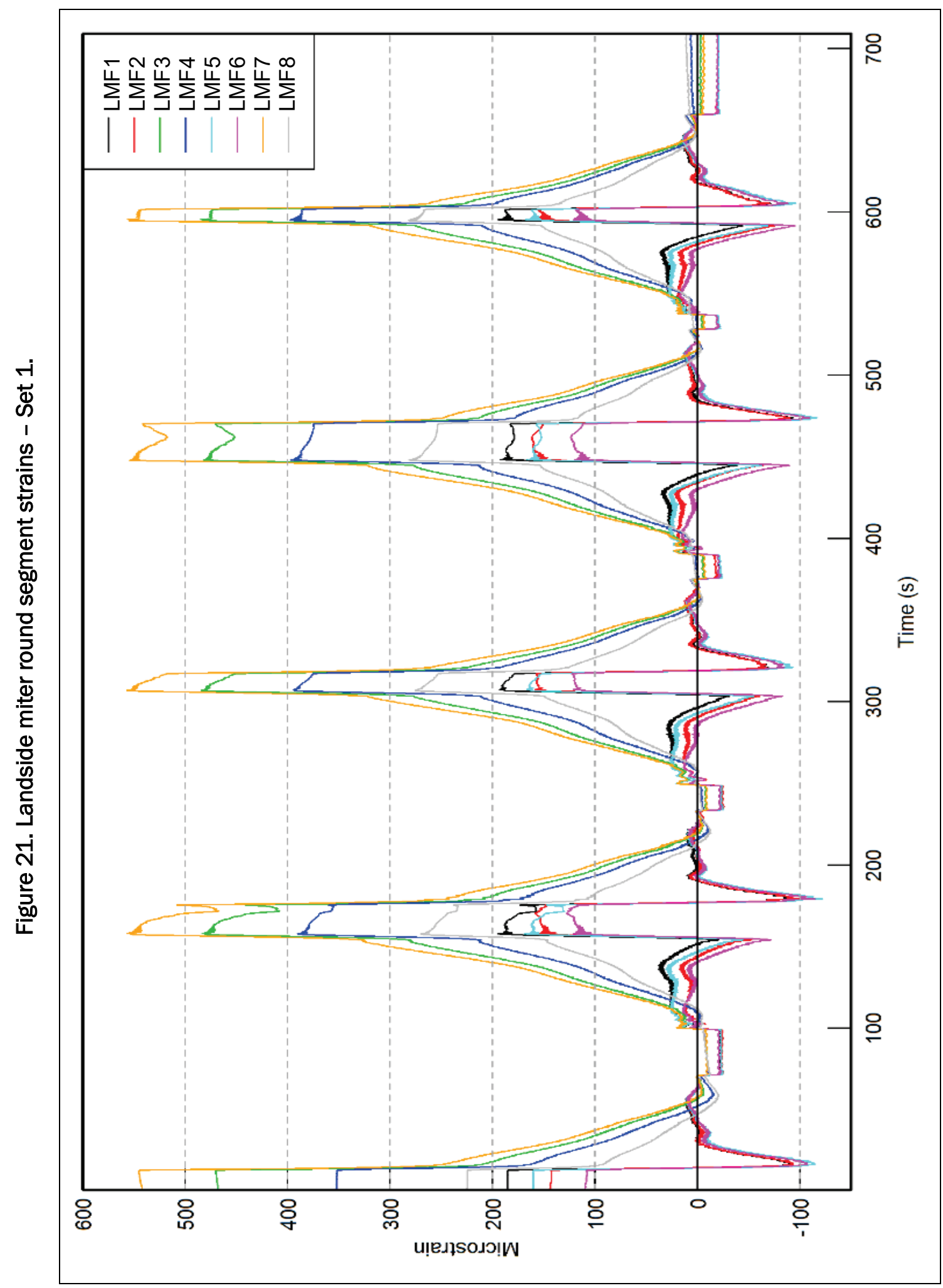




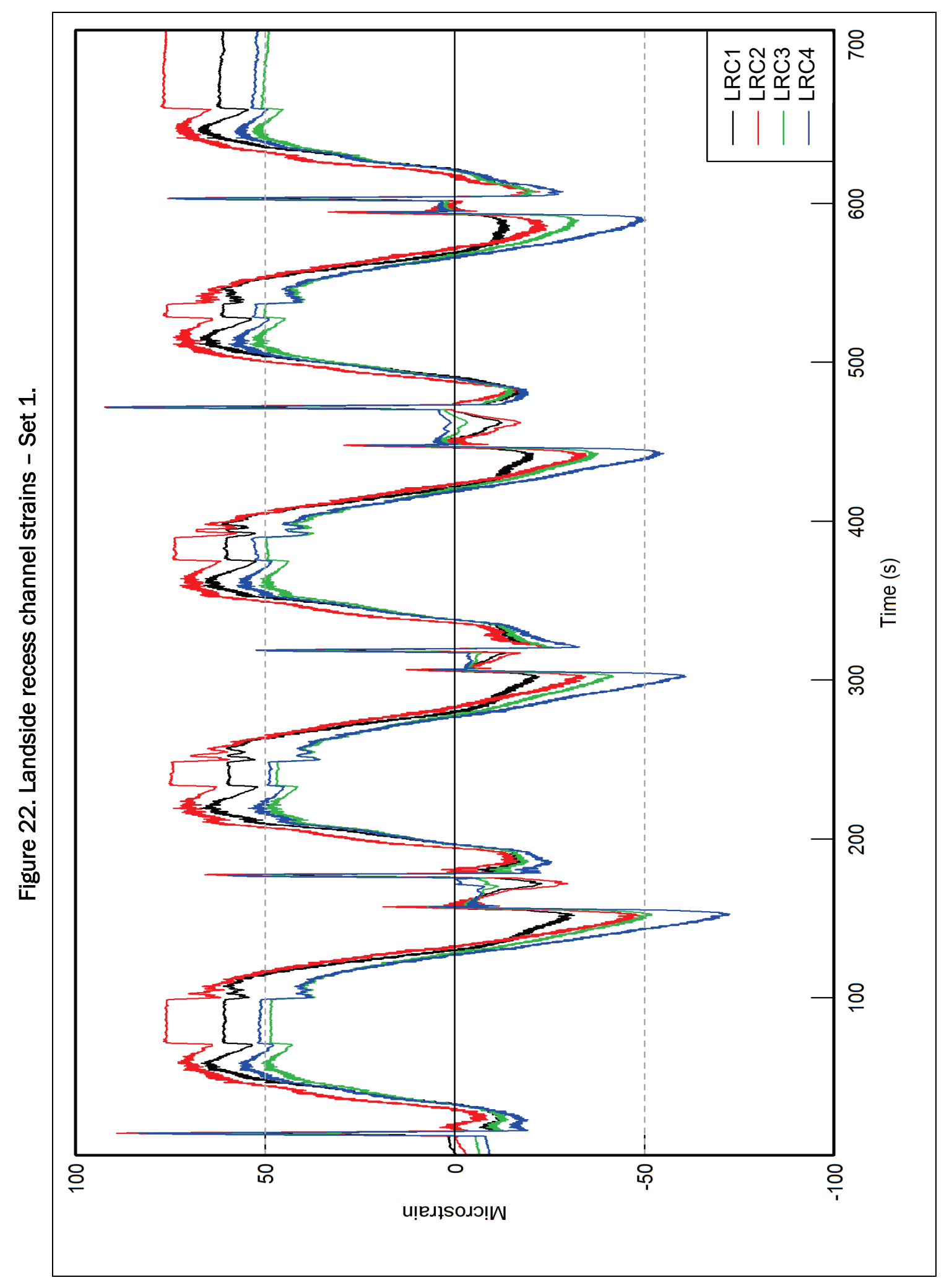




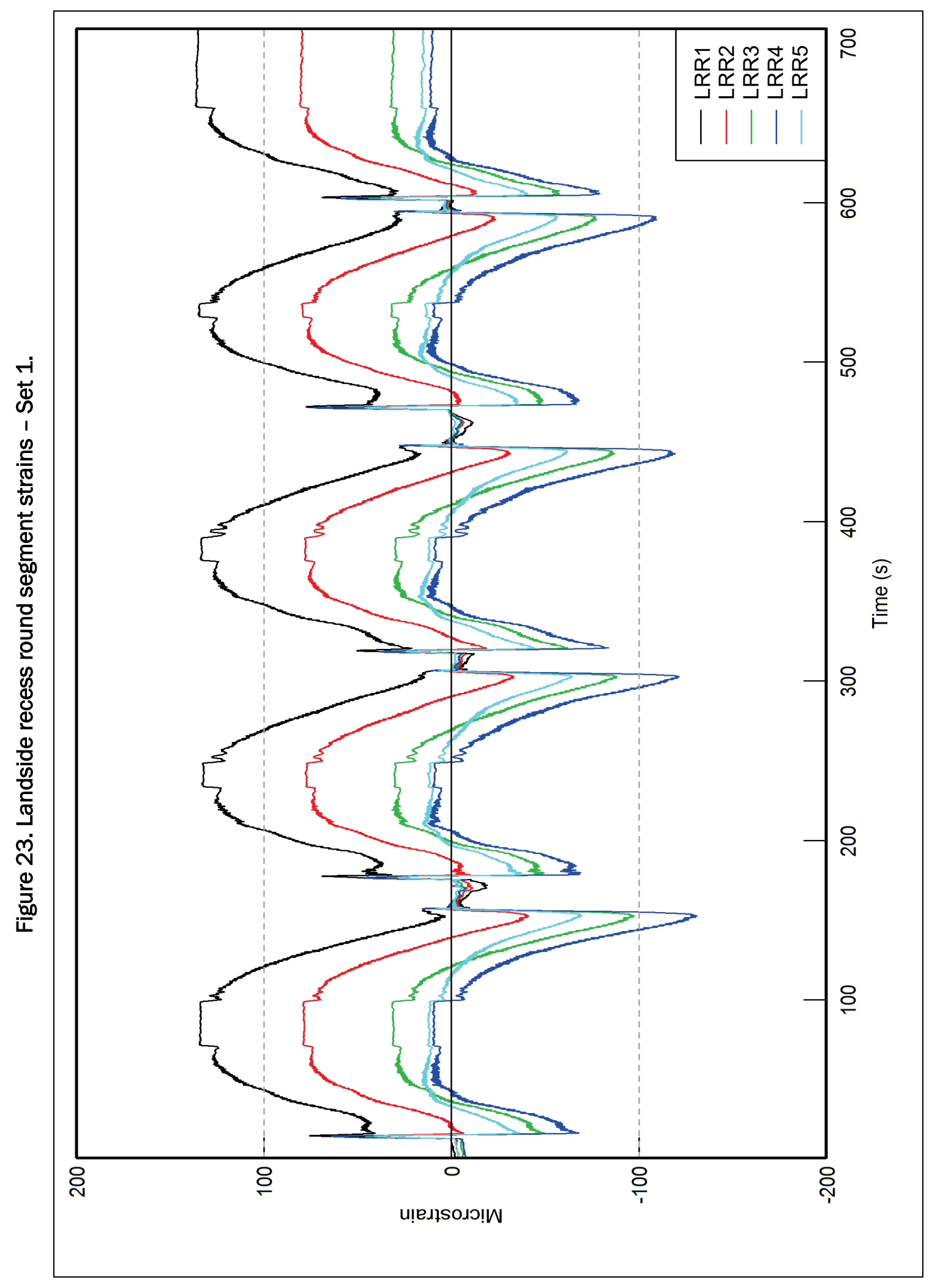




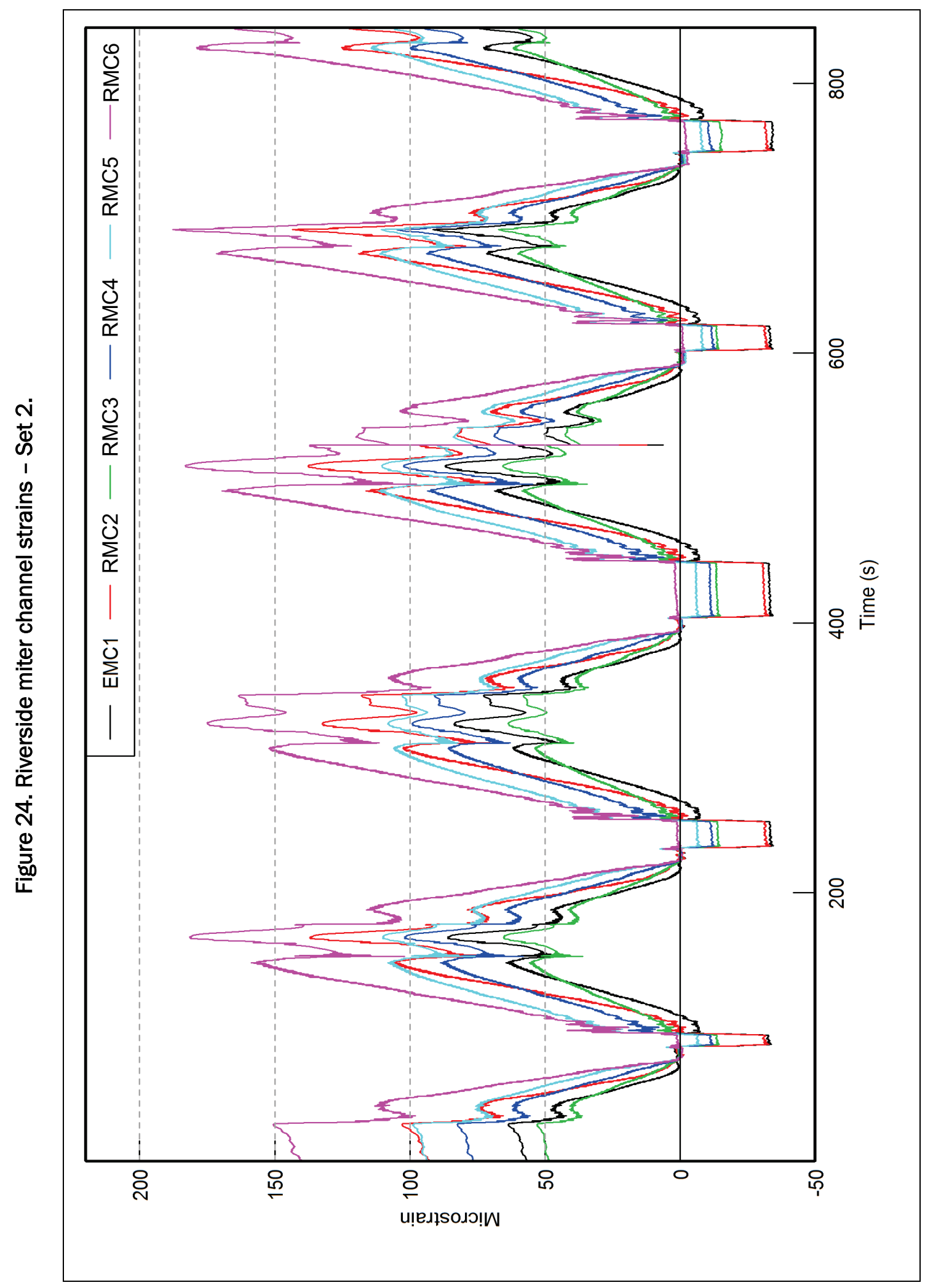




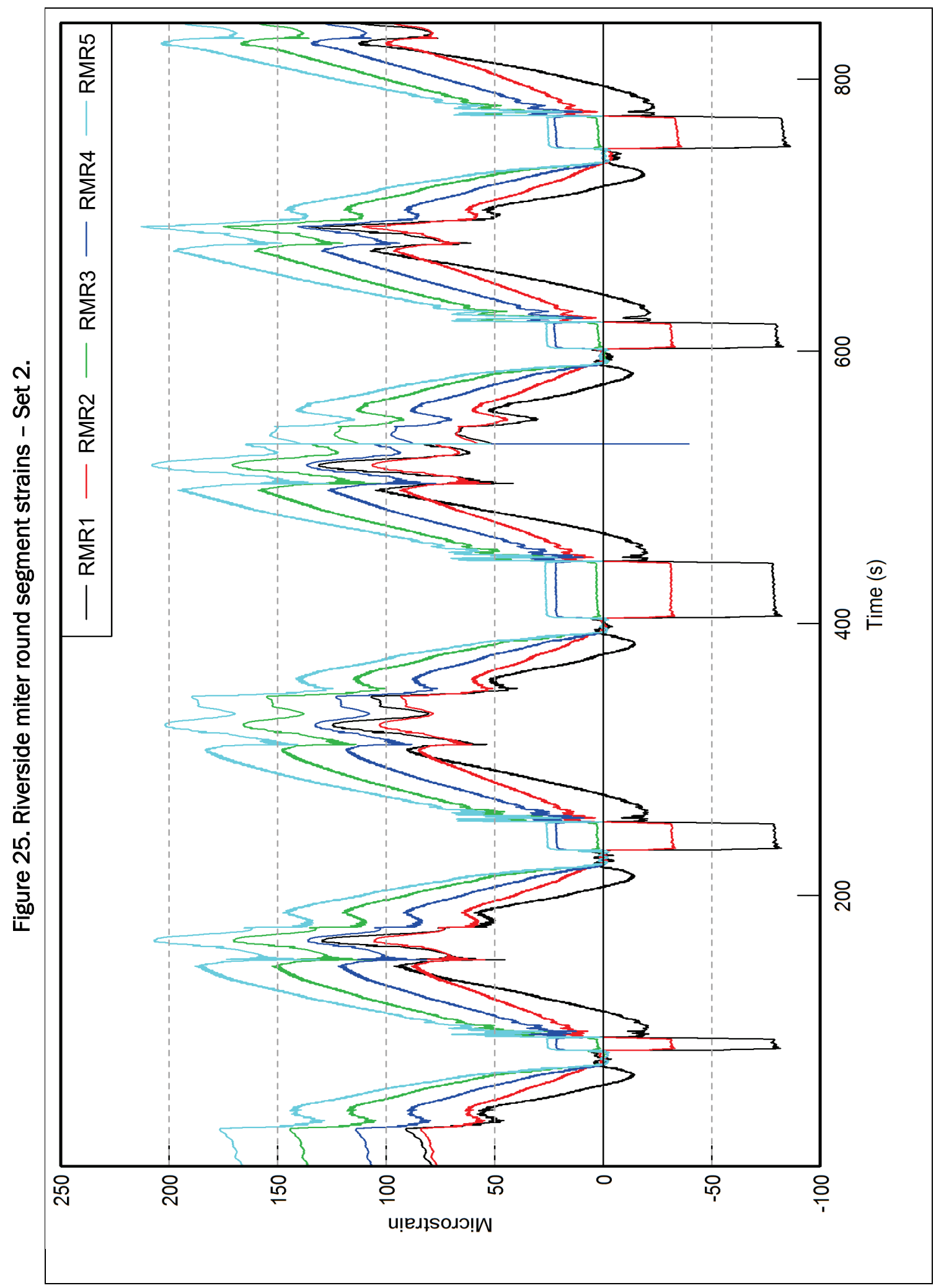




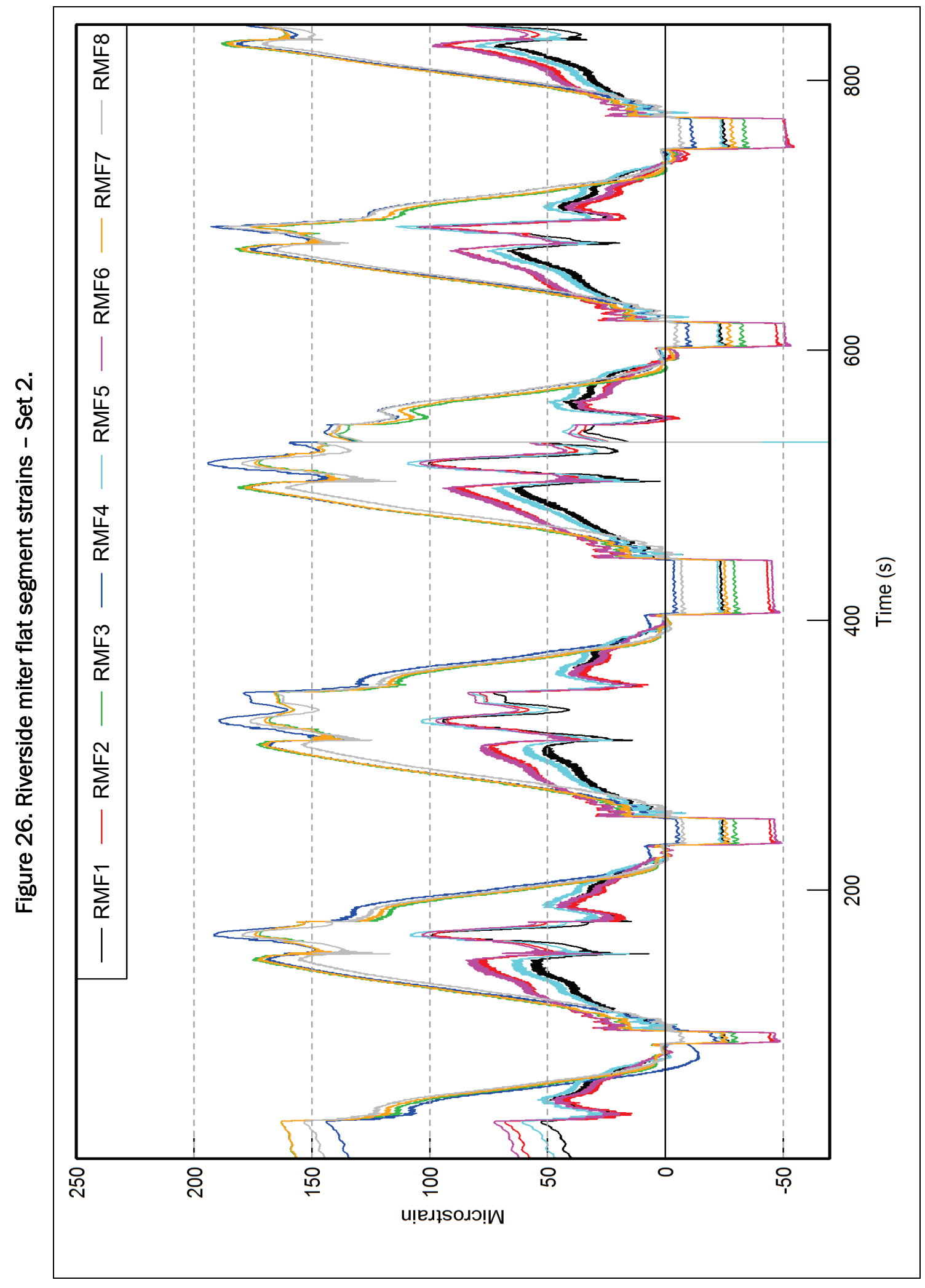




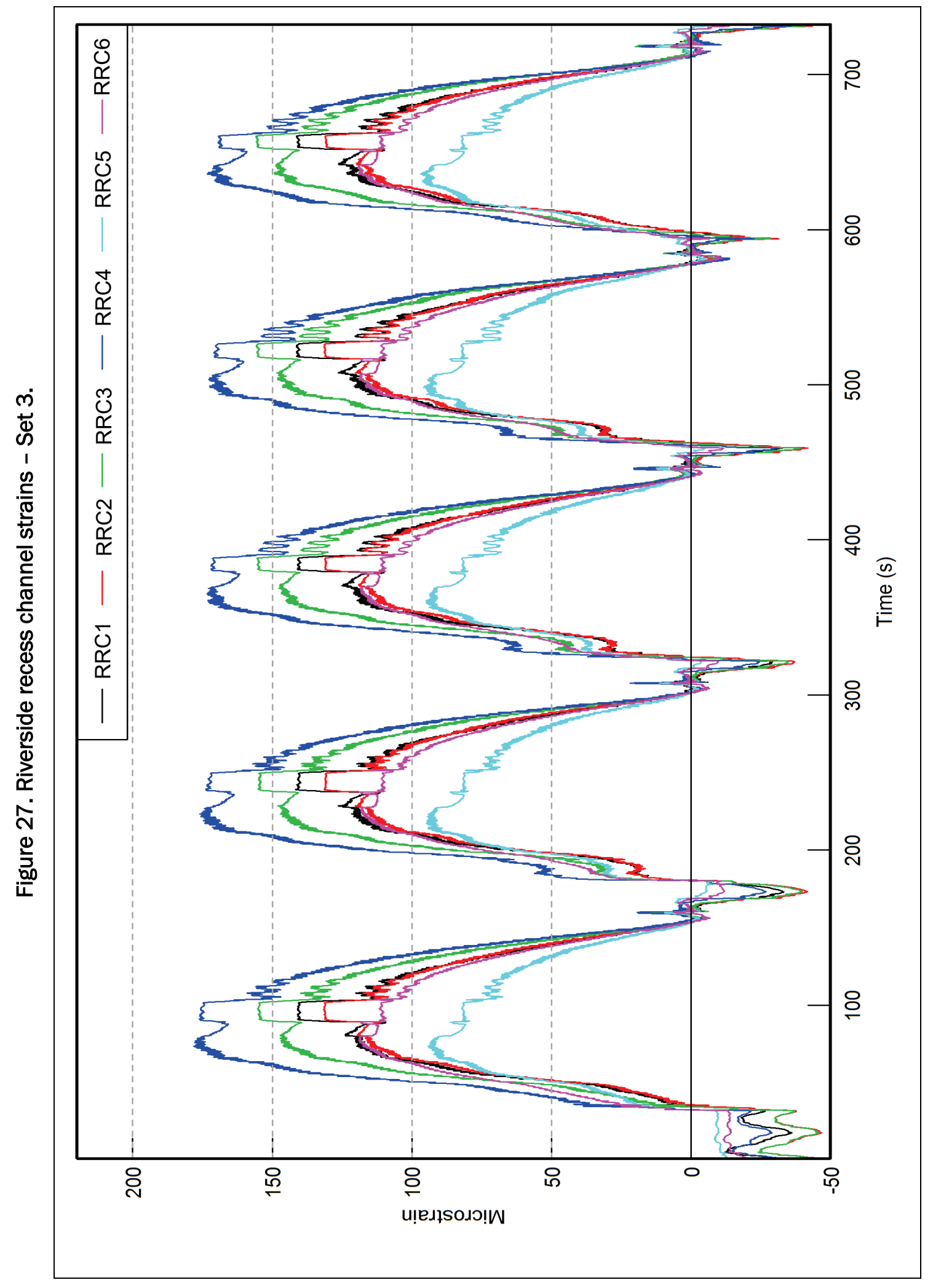




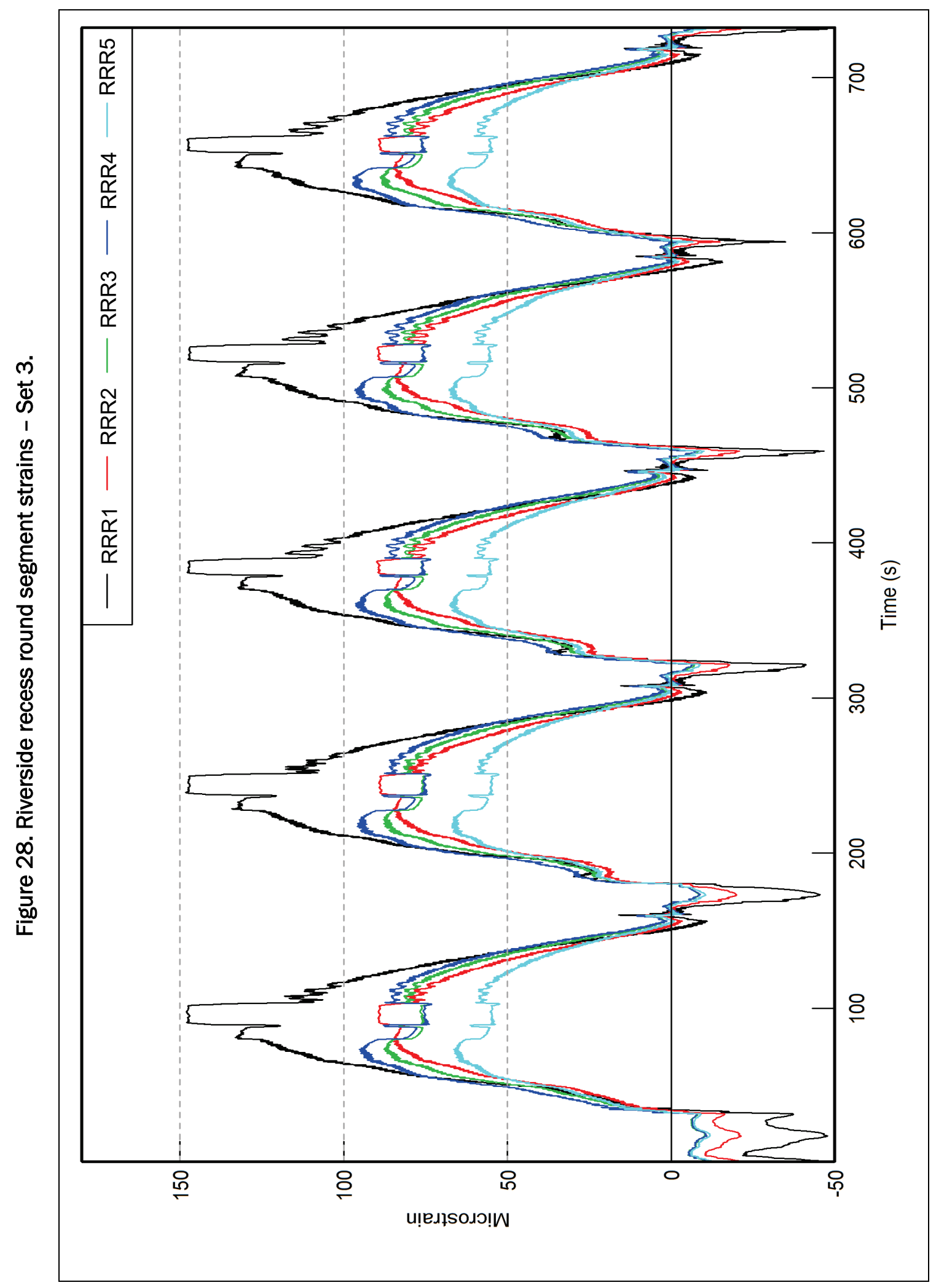




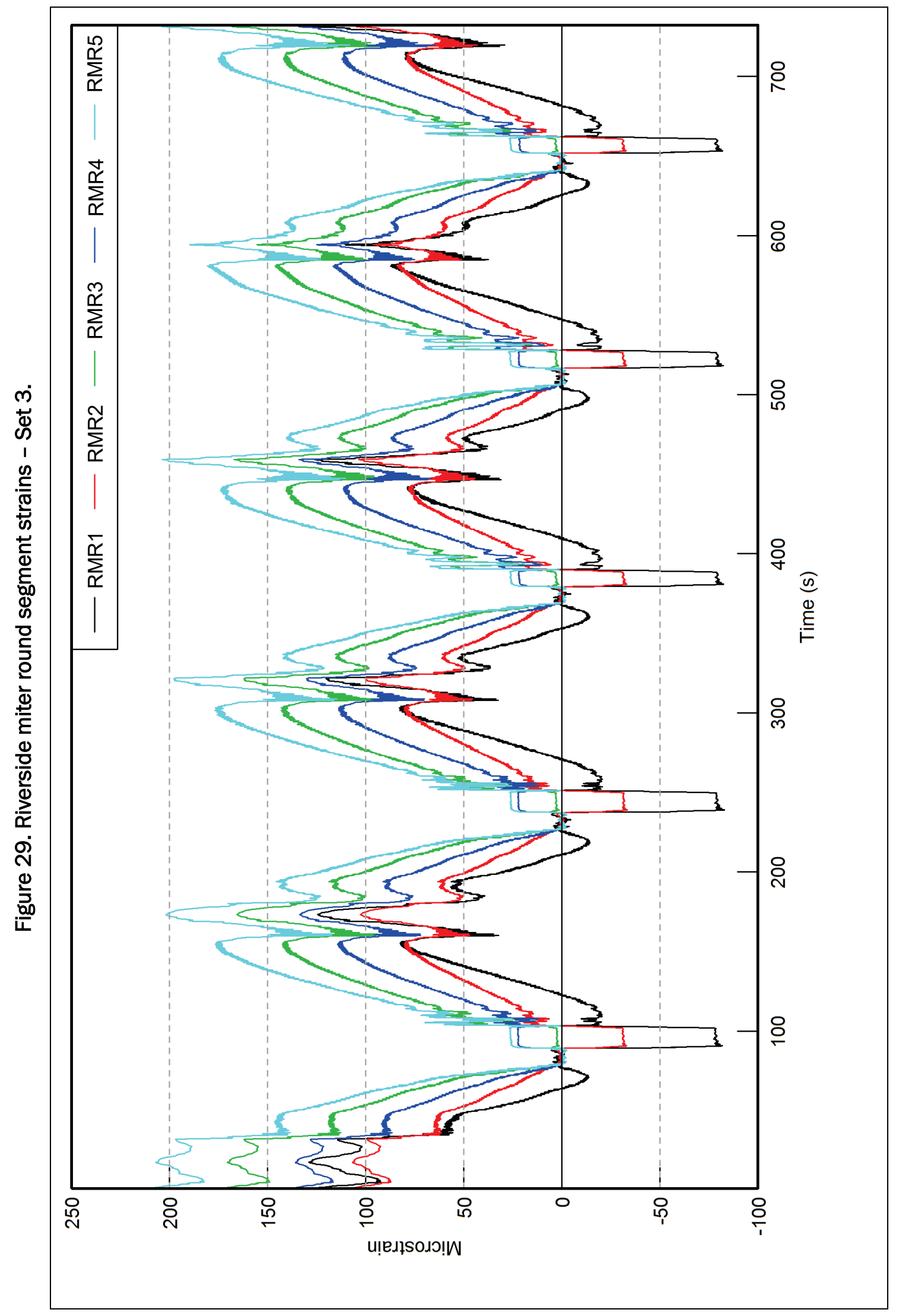




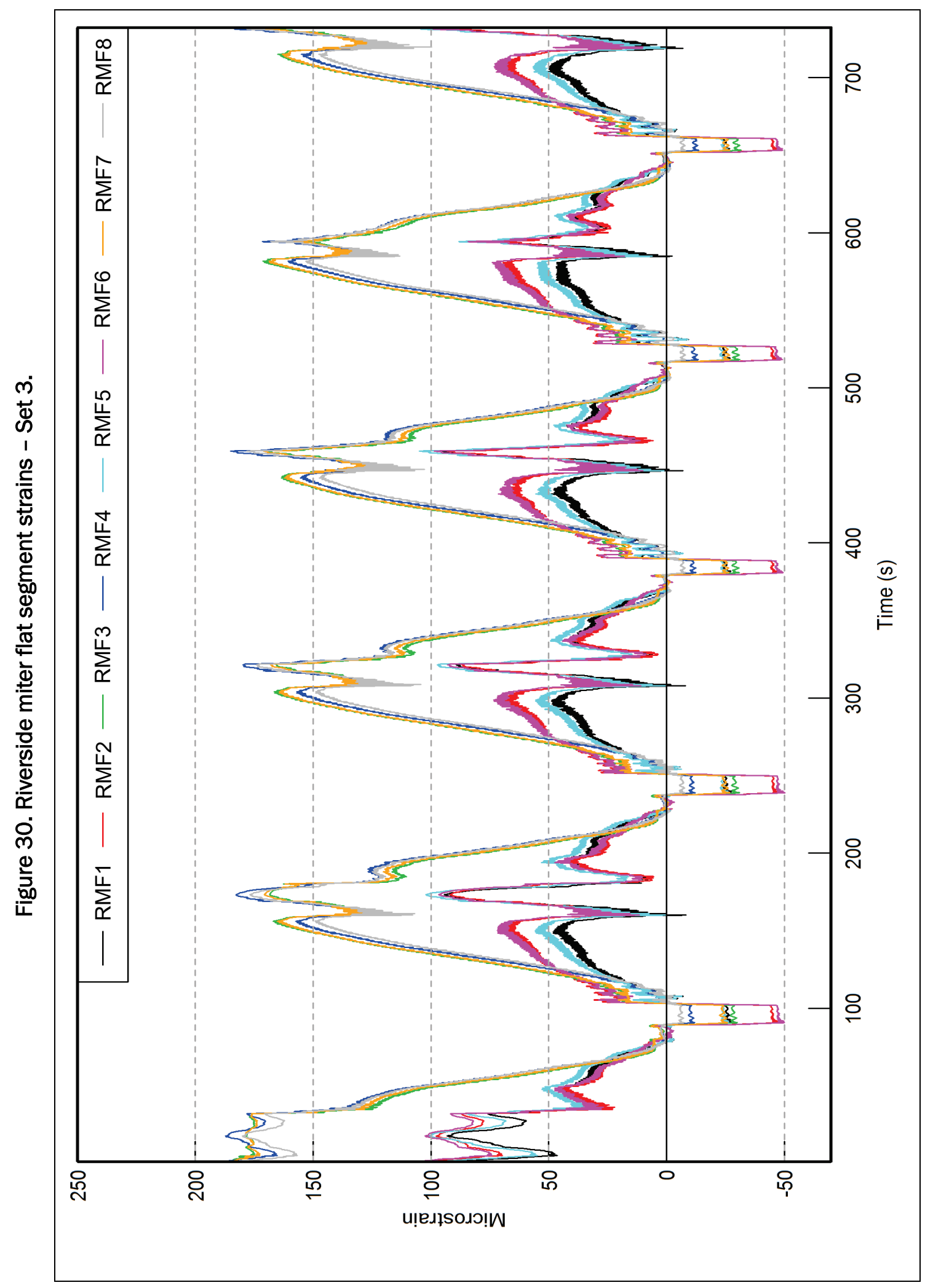




\section{Evaluation and Methodology}

\subsection{General}

The ERDC team has investigated the integrity of the embedded steel anchorage channels supporting the upstream miter gates on each side of the Chickamauga Lock chamber. Physical considerations included both fatigue induced by operational cyclic stresses and pseudo-static deformations caused by the vertical expansion of the concrete walls relative to the lock gate.

A typical fatigue evaluation for crack initiation includes a cyclic load history, stress/strain range, and an $\mathrm{S} / \mathrm{N}$ (Wöhler) curve for the material investigated. However, there were difficulties encountered in constructing the necessary data for a typical fatigue investigation.

The particular type of material of which the anchorage channels were composed could not be found on the drawings or through consultations with the LRN. Therefore, assumptions were necessary to complete the evaluation. In addition to the uncertainty of material properties, there were difficulties in reconstructing the cyclic load history from lockage history (Chapter 2).

These difficulties led the ERDC team to use an alternative, ad hoc evaluation procedure. The premise was to use the riverside miter channels to calibrate a damage index model for the undamaged channels. The process followed these general steps:

1. Use observed gate swing forces and a finite element model to estimate strains in the pre-damaged riverside miter anchorage channels due to gate swing and vertical wall expansion.

2. Assume there were 3,700 strain cycles per year and that the wall vertical expansion of 1.08 in. occurred linearly over 75 years.

3. Use the aforementioned $\mathrm{S} / \mathrm{N}$ curve, corrected for corrosion and mean stress in conjunction with Miner's linear damage rule, to determine a damage index, $D_{e m}$, due to the strain history constructed in step 2.

4. Define a correction factor $C=1 / D_{e m}$, to account for model errors.

5. Use the measured strains from gate swing and modeled strains from the finite element model to construct a strain history for the other three anchorages in agreement with step 2. 
6. Use the same linear damage model to calculate the damage index for each of the undamaged anchorage channels, and scale by the correction factor $C$ to account for model errors.

7. Compare undamaged anchorage channel corrected damage indices to unity for investigating the potential for damage ( $>1$ indicates possible damage).

\subsection{Forces in gudgeon linkage}

The forces in the gudgeon linkage were needed to validate a finite element model. Also, the riverside miter channel was repaired after previous cracking. This repair realigned the geometry, possibly released some builtup elastic strains, and changed the local stiffness distribution of the channel with the added reinforcement plate. A mechanics-based approach was used to determine the axial force, bending moment, and shear applied to the anchorage channels by the pins by fitting a model to the miter gudgeon linkage gage data and using that to inform for the recess. The process is described in detail below.

The gudgeon linkage geometry differs for the miter and recess anchors (Figure 13). Both miter and recess linkage have a segment with a round cross section (Figure 13, section B-B). However, this round segment was not long enough to allow the stresses to attenuate to a state represented by linear beam theory (i.e., planar strain distributions). Therefore, while strain gages could be placed on those round segments, basic linear mechanics are insufficient to describe the total stress and strain distributions and their accumulation into internal forces.

The miter gudgeon linkage has a segment with a rectangular cross section (Figure 13, sections C-C and D-D), closer to the gudgeon pin, with a width of $6.25 \mathrm{in}$. and a depth of 3 in. This rectangular cross section was long enough that strain gages could be placed one member depth (plate thickness) away from the nearest geometry changes, the distance indicated by St. Venant's principle (Love 1927) necessary for the stresses and strains to attenuate to a planar distribution. Two cross sections were instrumented within this segment using two strain gages on the top face and two on the bottom face.

Since the stresses and strains can be assumed to be planar at the gaged rectangular cross sections, linear elastic mechanics was used to compute 
the axial force and bending moment (about the horizontal axis) at those cross sections. Linear elastic mechanics results in the following equations:

$$
\begin{gathered}
\sigma_{\text {top }}=\varepsilon_{\text {top }} E=\frac{P}{A}-\frac{M}{S} \\
\sigma_{\text {bottom }}=\varepsilon_{\text {bottom }} E=\frac{P}{A}+\frac{M}{S}
\end{gathered}
$$

where $\sigma_{\text {top }}$ and $\sigma_{\text {bottom }}$ are the normal stresses on the cross section on the top and bottom faces, respectively; $\varepsilon_{\text {top }}$ and $\varepsilon$ bottom are the normal strains on the cross section on the top and bottom faces, respectively; $E$ is the modulus of elasticity; $P$ is the axial force; $M$ is the bending moment; $A$ is the cross-sectional area; and $S$ is the flexural section modulus. Solving equations 3.1 and 3.2 for the $P$ and $M$ yields the following:

$$
\begin{gathered}
P=\frac{E A}{2}\left(\varepsilon_{\text {top }}+\varepsilon_{\text {botom }}\right) \\
M=\frac{E S}{2}\left(\varepsilon_{\text {bottom }}-\varepsilon_{\text {top }}\right)
\end{gathered}
$$

There were two strain gages on the top and two on the bottom at each gaged rectangular cross section, so $\varepsilon_{\text {top }}$ and $\varepsilon_{\text {bottom }}$ were calculated by averaging the top and bottom gages, respectively. Then, Equations 3.3 and 3.4 were used with the measured strain gage data to determine $P$ and $M$ for the rectangular gaged cross sections. Figure 31 through Figure 33 show the axial force and bending moment calculated (as described above) in the rectangular gudgeon linkage segments. Because the bending moments were computed at two separate cross sections, the shear force $V$ between them was calculated by assuming a sign convention such that positive bending caused compression on the top face and a positive shear would push upward on the channel pins, using the following equation:

$$
V=\frac{M_{1}-M_{2}}{l}
$$

where $l$ is the distance between cross section C-C (location of $M_{1}$ ) and cross section D-D (location of $M_{2}$ ), indicated in Figure 13 and Figure 14. 
Figure 31. Computed forces in landside miter rectangular segment - Set 1.

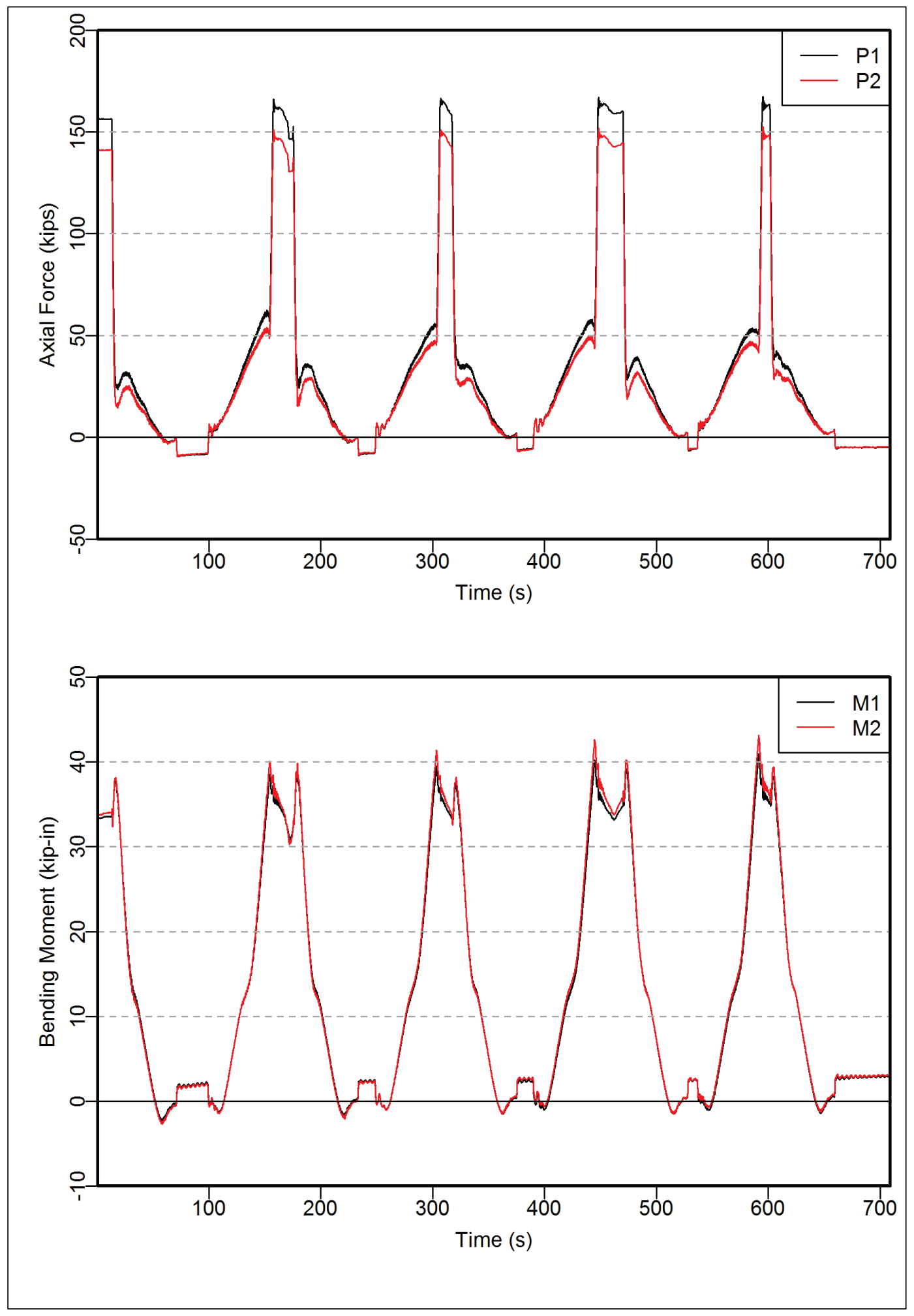


Figure 32. Computed forces in riverside miter rectangular segment - Set 2.

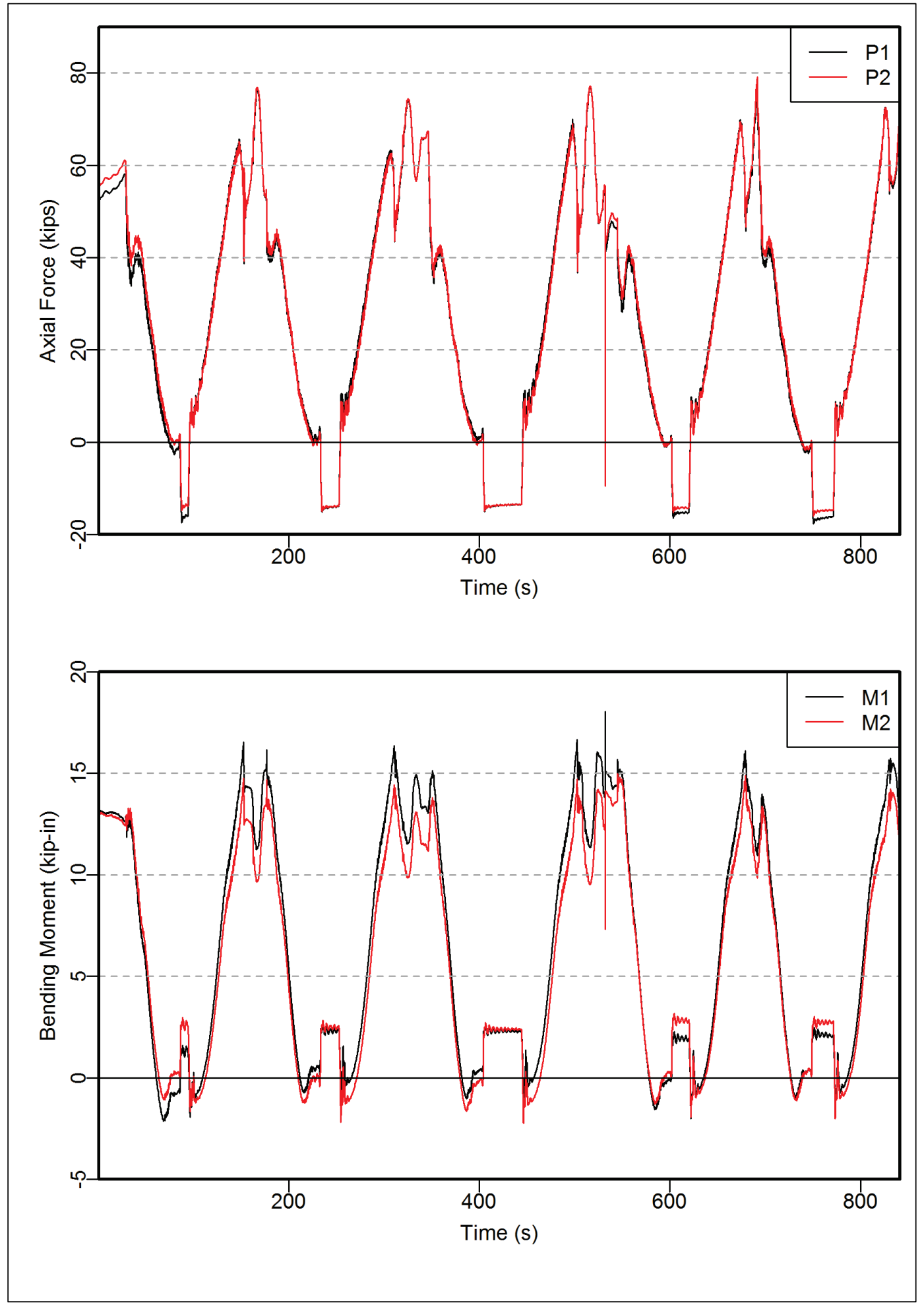


Figure 33. Computed forces in riverside miter rectangular segment - Set 3.

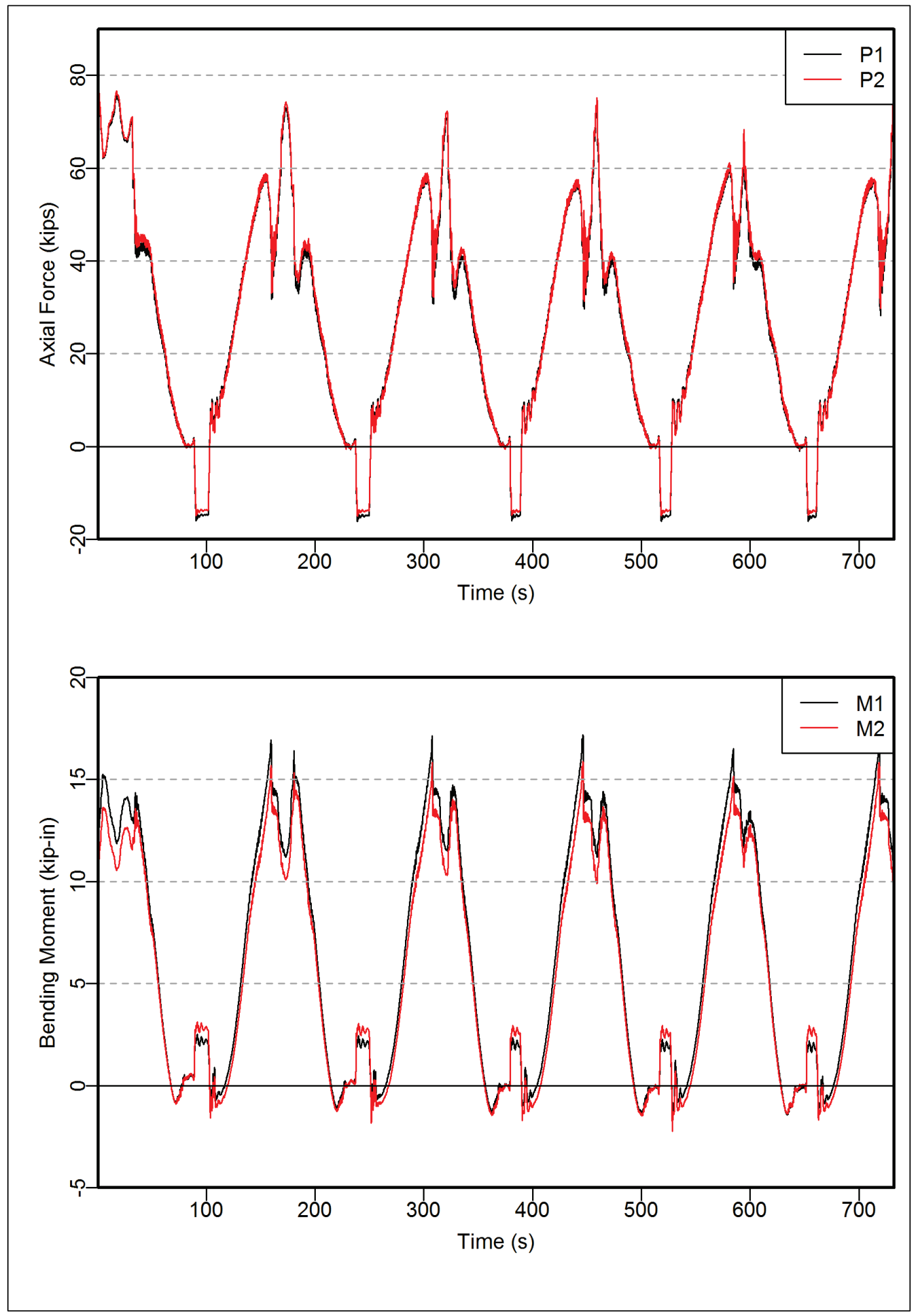


Once the axial force, bending moment, and shear were computed for the rectangular segments, a free body diagram was used to determine the axial force and bending moments $\left(M_{1}+33 V\right)$ at the round gaged cross sections on the miter gudgeon linkage. Even though the strain distribution in the round segments was not planar, the relationship between load magnitude and strain should still be linear, given that the strains were far below the elastic limit. Therefore, a model that computes the axial force and bending moments as a linear combination of the measured strains at the round cross sections was used. The linear model was represented by the following equations:

$$
\begin{aligned}
& P_{R}=a_{1} \varepsilon_{1}+a_{2} \varepsilon_{2}+a_{3} \varepsilon_{3}+a_{4} \varepsilon_{4}+a_{5} \varepsilon_{5} \\
& M_{R}=b_{1} \varepsilon_{1}+b_{2} \varepsilon_{2}+b_{3} \varepsilon_{3}+b_{4} \varepsilon_{4}+b_{5} \varepsilon_{5}
\end{aligned}
$$

where $a_{i}$ and $b_{i}$ were model coefficients, $\varepsilon_{i}$ were the measured strains at the round cross sections, and $P_{R}$ and $M_{R}$ are the computed axial force and bending moment at the round cross section, respectively. A linear least squares fit was made to determine the model coefficients given the measured strains and the computed forces, producing the models for the landside anchorage:

$$
\begin{gathered}
P_{R}=-0.0377 \varepsilon_{1}+0.9226 \varepsilon_{2}+0.7793 \varepsilon_{3}-1.7559 \varepsilon_{4}+1.4563 \varepsilon_{5} \\
M_{R}=-0.0856 \varepsilon_{1}-0.9092 \varepsilon_{2}-0.5408 \varepsilon_{3}+1.4092 \varepsilon_{4}-0.3361 \varepsilon_{5}
\end{gathered}
$$

The resulting models for the riverside anchorage are the following:

$$
\begin{gathered}
P_{R}=0.0290 \varepsilon_{1}+0.7256 \varepsilon_{2}-0.5343 \varepsilon_{3}+0.1840 \varepsilon_{4}+0.2939 \varepsilon_{5} \\
M_{R}=0.7602 \varepsilon_{1}-0.7809 \varepsilon_{2}-2.2072 \varepsilon_{3}-2.3057 \varepsilon_{4}+3.4151 \varepsilon_{5}
\end{gathered}
$$

The model coefficients for each side of the lock differ significantly. These differences are believed to be caused by differences in how the anchorage geometry has been warped due to concrete expansion and the resulting out-of-plane flexural and torsional effects in the strain measurements. Figures 34 through Figure 36 show how these computed forces fit with those computed from the free-body diagram. $P_{1}$ and $P_{2}$ should agree with 
$P_{R} . M_{R}$ should agree with $M_{1}+33 V$. The models of Equations 3.6 and 3.7 captured the force and moment ranges accurately.

The strain gages on the round segments of the recess were carefully placed to match the locations on the miter round segments. The same models (Equations 3.8-3.11) were used with the corresponding gages on the round segments of the recess to compute the axial force and bending moments at the pin in the recess anchorage channels. Figure 37 and Figure 38 show these computed forces for the recess channels. Table 3 lists the minimum and maximum axial forces and the corresponding bending moments at the channel pins as computed from these models from the strain data.

\subsection{Finite element models of anchorage channels}

The strain gages were only able to measure the cyclic operational strains associated with opening and closing of the lock gates. Any strain accumulated from the vertical expansion of the walls would have already existed in the steel when the gages were placed. As theses strains are associated with the relative vertical movement of the channels with respect to the top of the gate, these strains are not expected to vary with gate position but are expected to change the baseline strain state of the channels for all gate positions. This situation precluded any field measurement of this strain, necessitating a finite element simulation of the wall growth effect on the anchorage.

The general-purpose finite element software ABAQUS was used to build numerical models of the channels and gudgeon linkage (Figure 39 and Figure 40). The material was modeled as elastic perfectly plastic with a yield stress of 36 kips per square inch (ksi) and a modulus of elasticity of $29,000 \mathrm{ksi}$. The portions of the channels embedded in the concrete were treated as fully fixed and rigid. The gudgeon linkage, including the pin through the channels, was also treated as rigid.

Strains associated with the pin forces in Table 3 were extracted from the model. In addition, the gudgeon linkage was pulled down 1.08 in. at the center of the pin farthest from the channels, causing a bending moment and shear at the channel pin to simulate the long-term deformation associated with wall vertical expansion. These strains are reported in Table 4 and Table 5 . 
Figure 34. Computed forces in landside miter channel pin - Set 1.

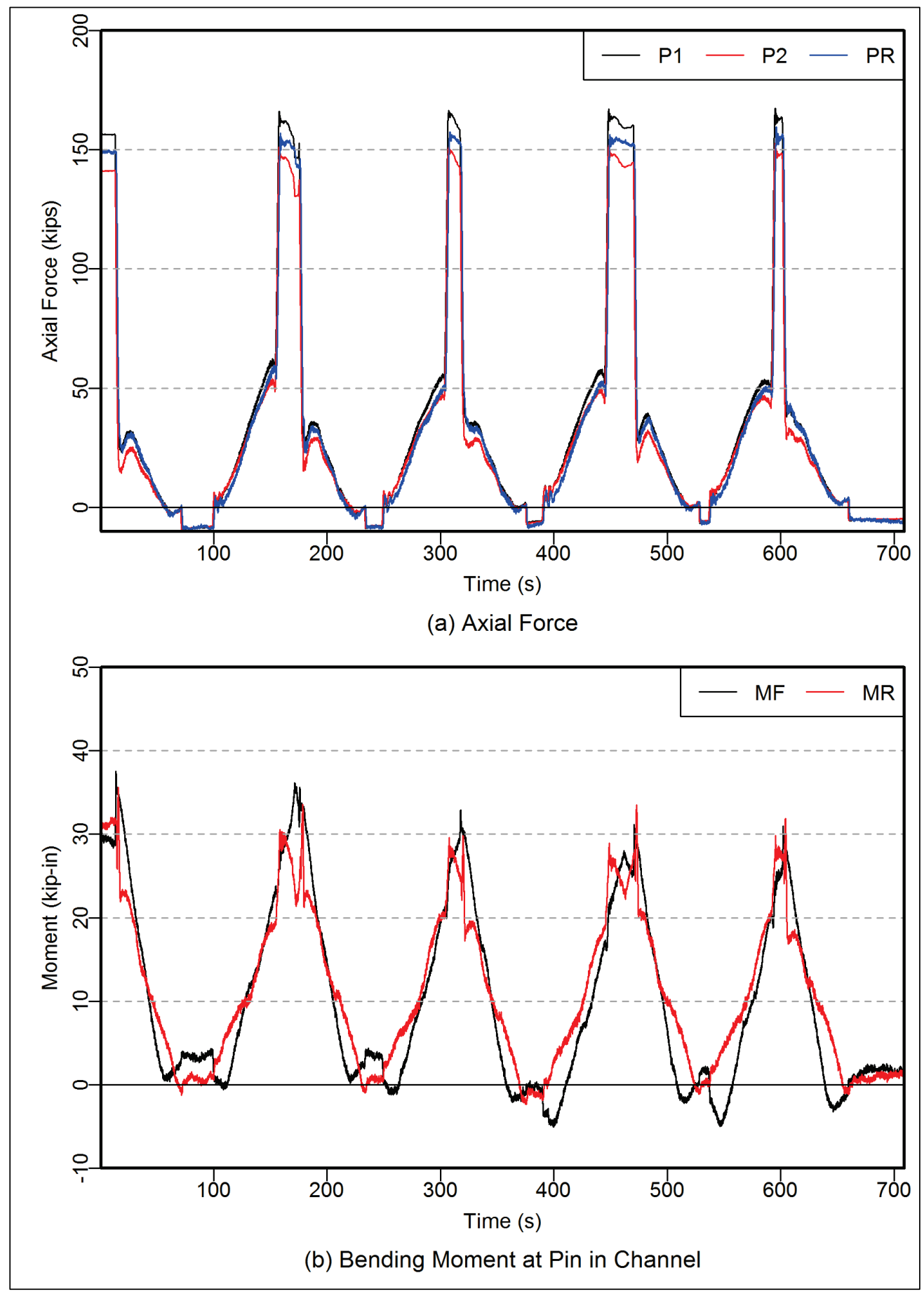


Figure 35. Computed forces in riverside miter channel pin - Set 2.

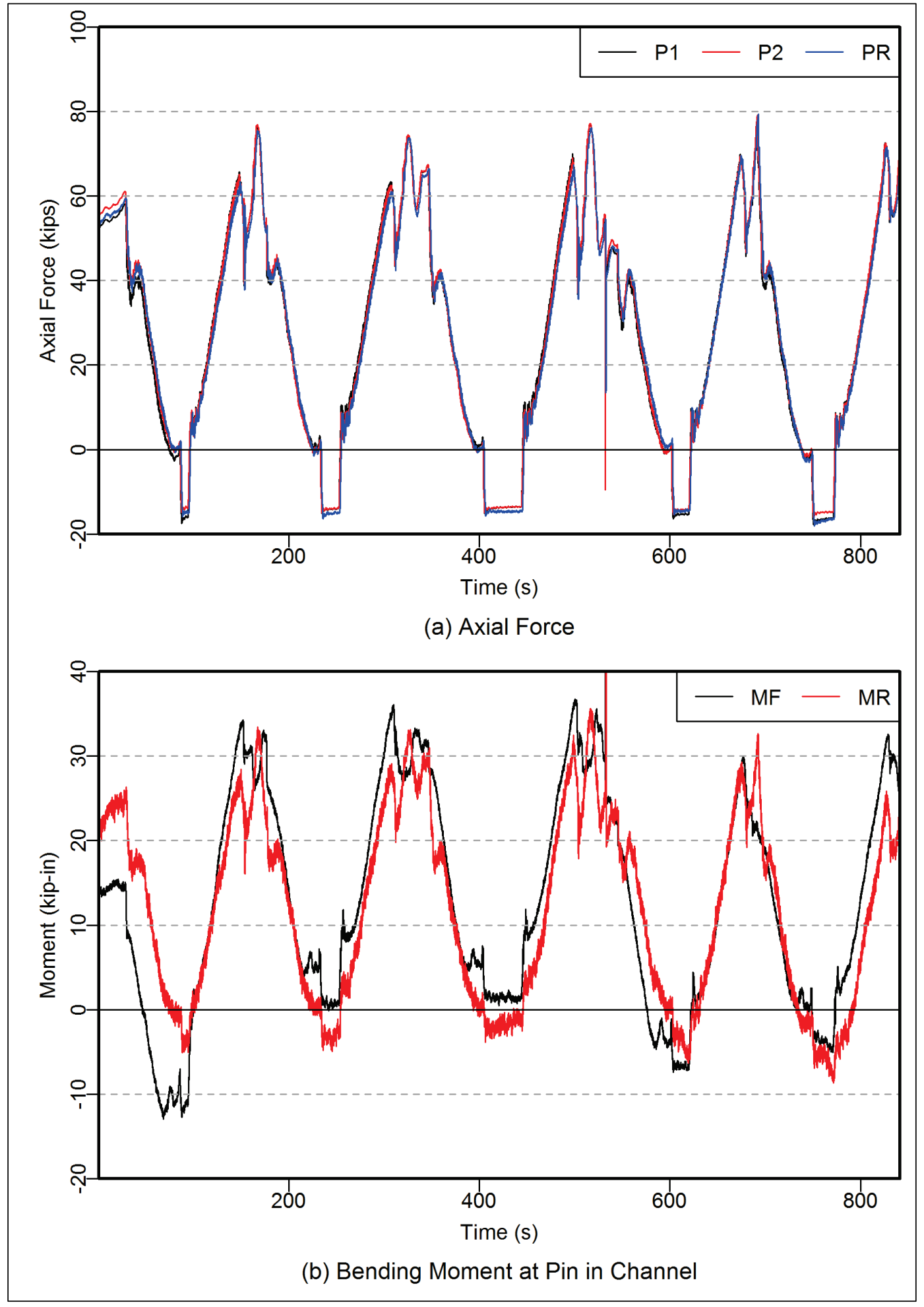


Figure 36. Computed forces in riverside miter channel pin - Set 3.

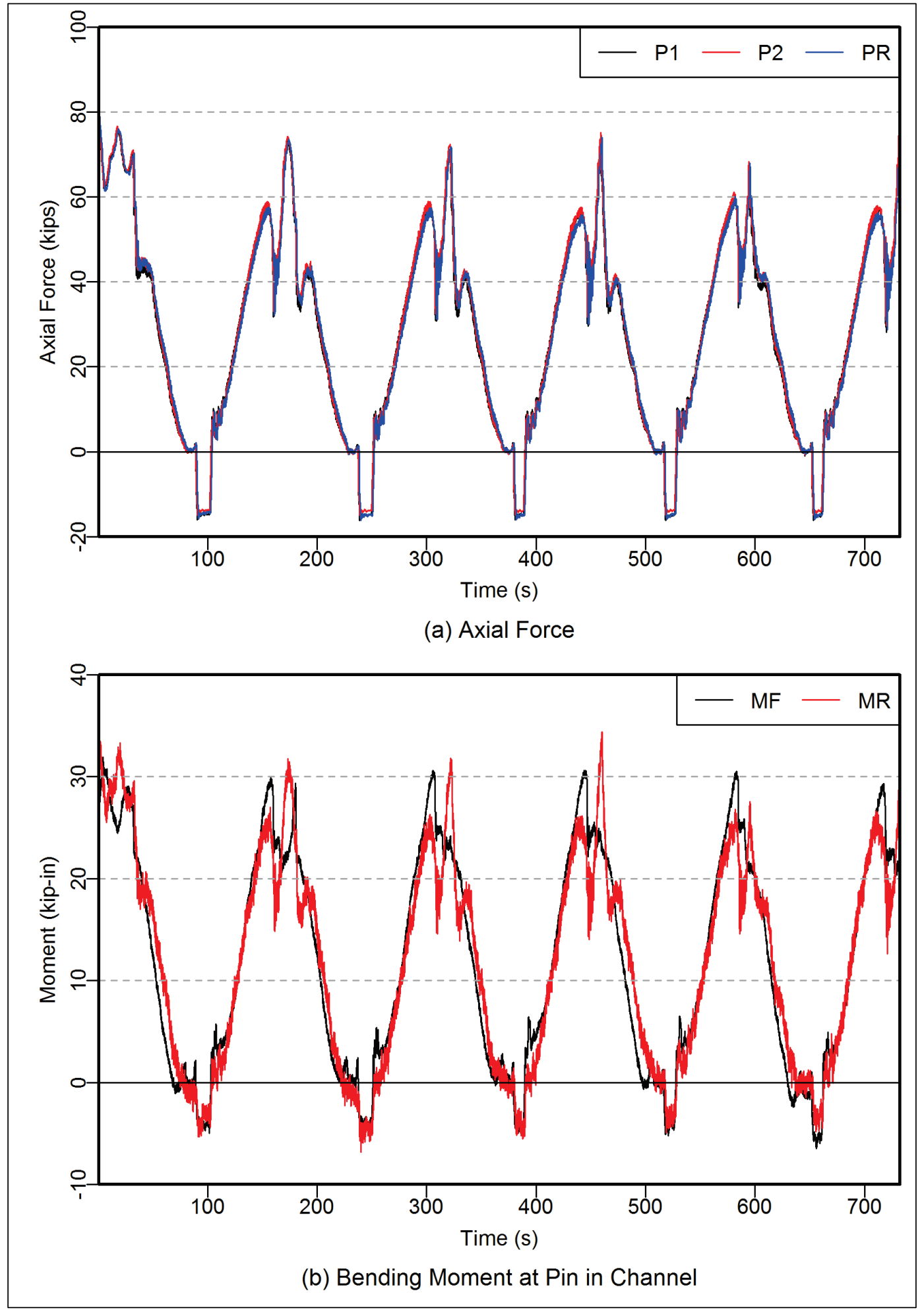


Figure 37. Computed forces in landside recess channel pin - Set 1.

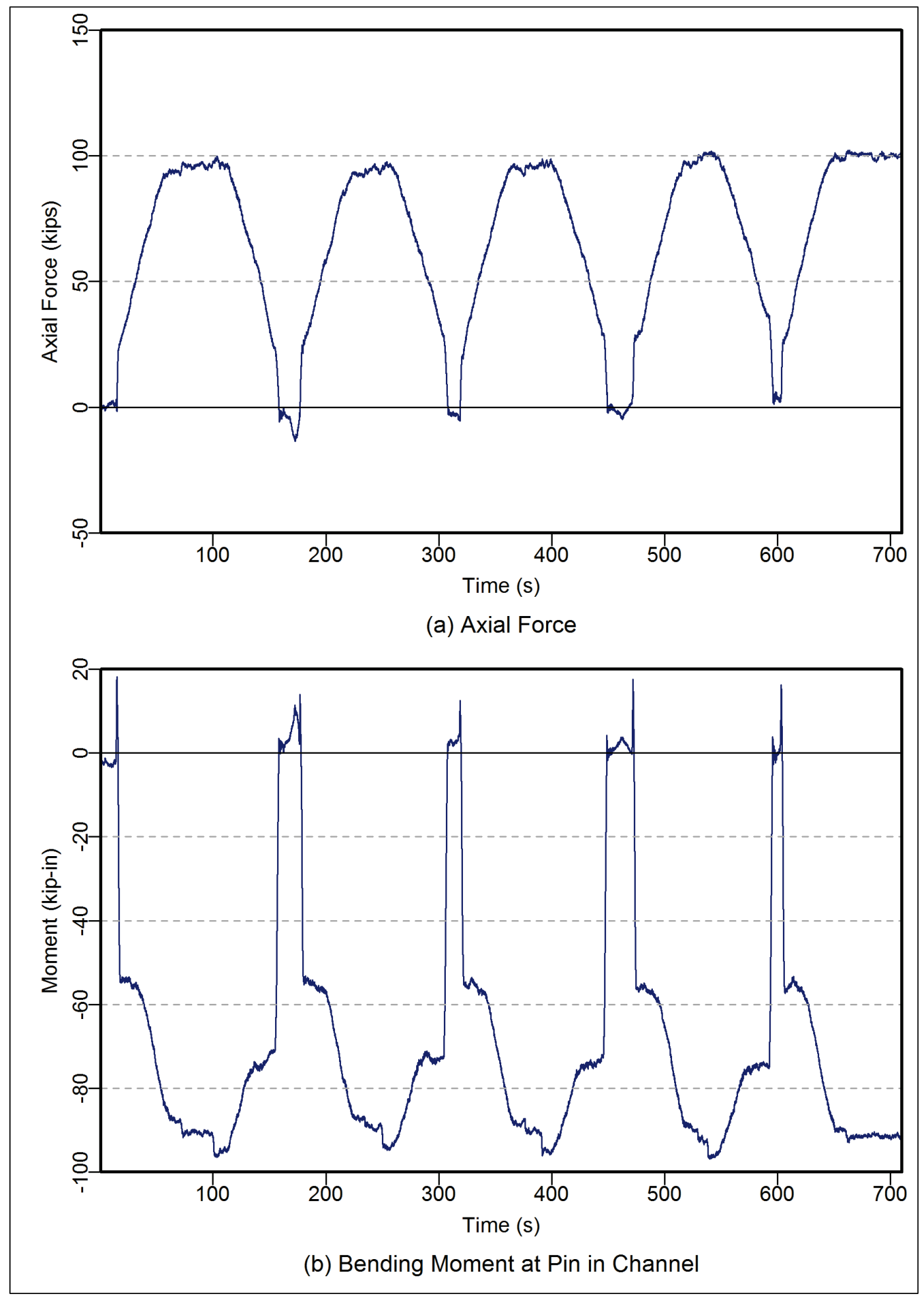


Figure 38. Computed forces in riverside recess channel pin - Set 3.

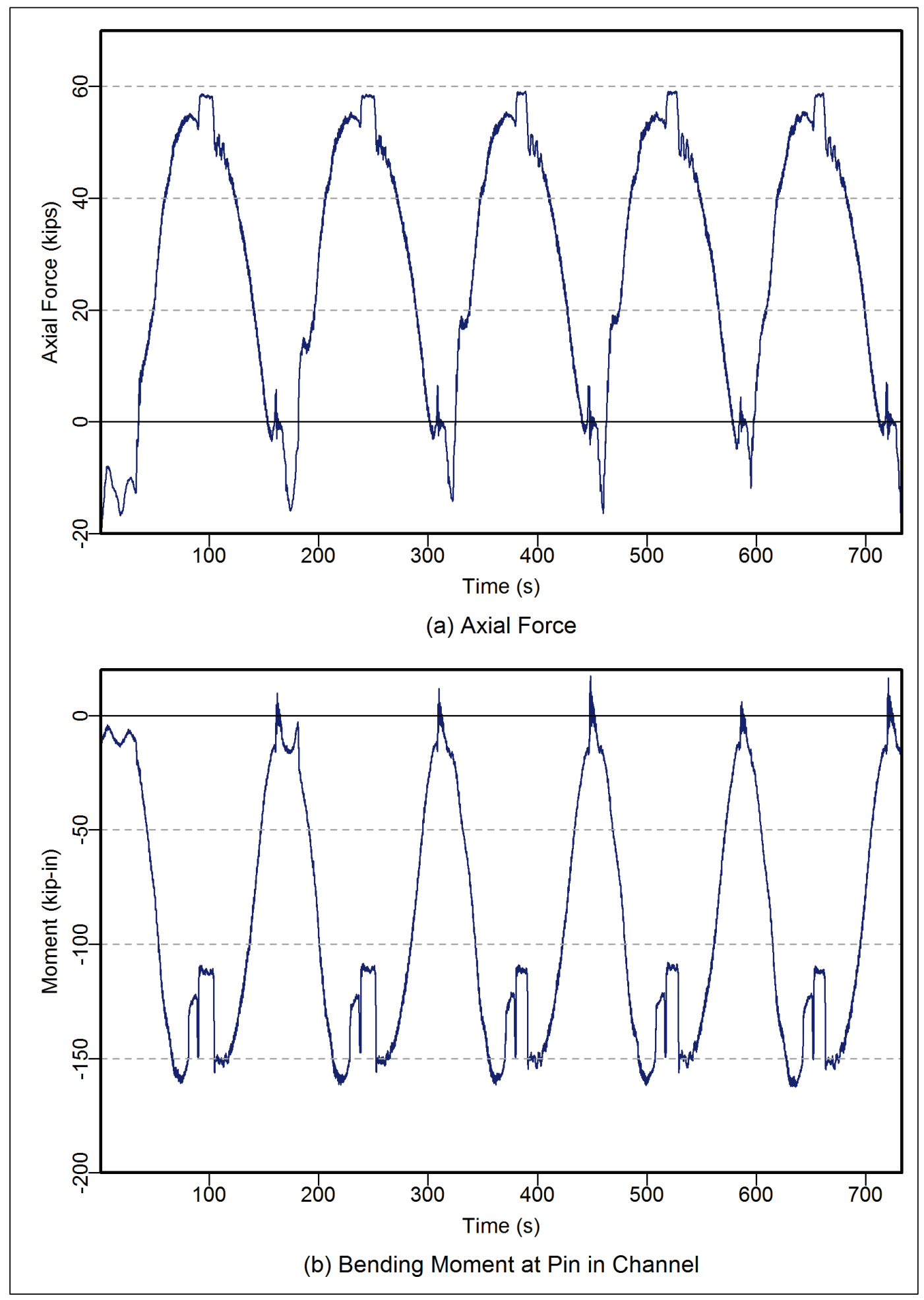


Figure 39. Finite element model of gudgeon linkage and channels.

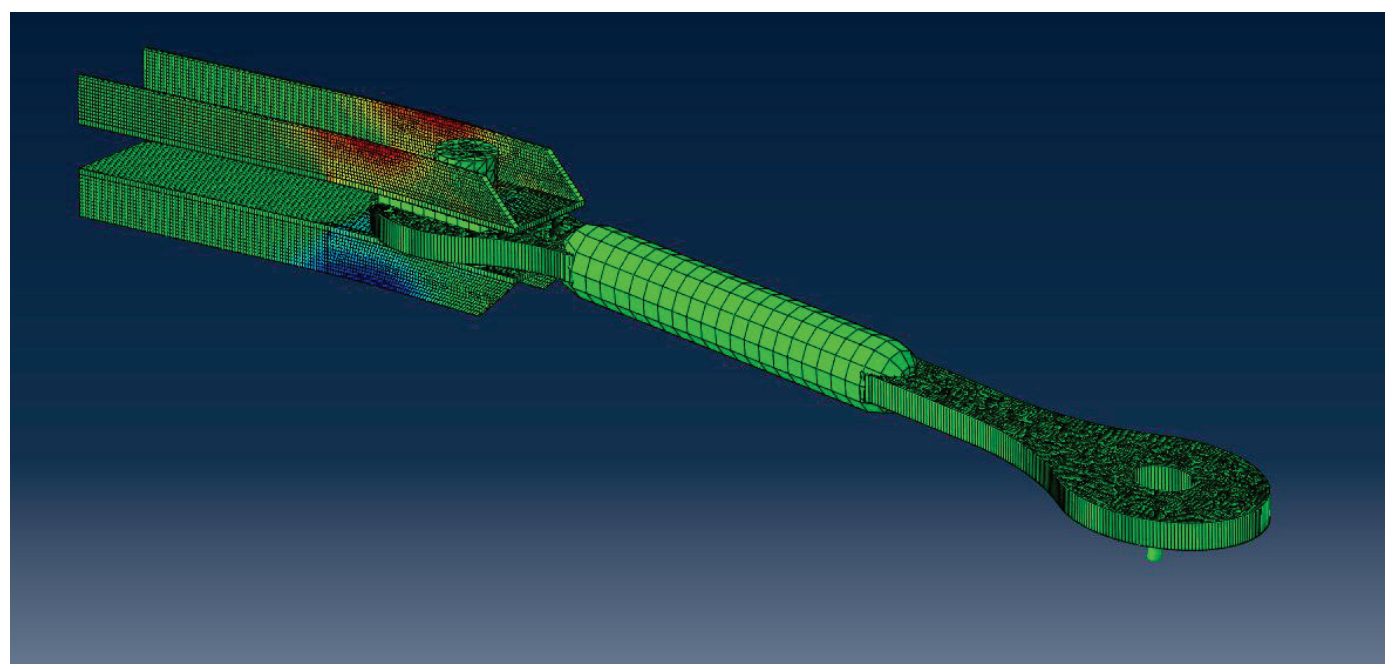

Figure 40. Finite element model - channel stresses (Von Mises).

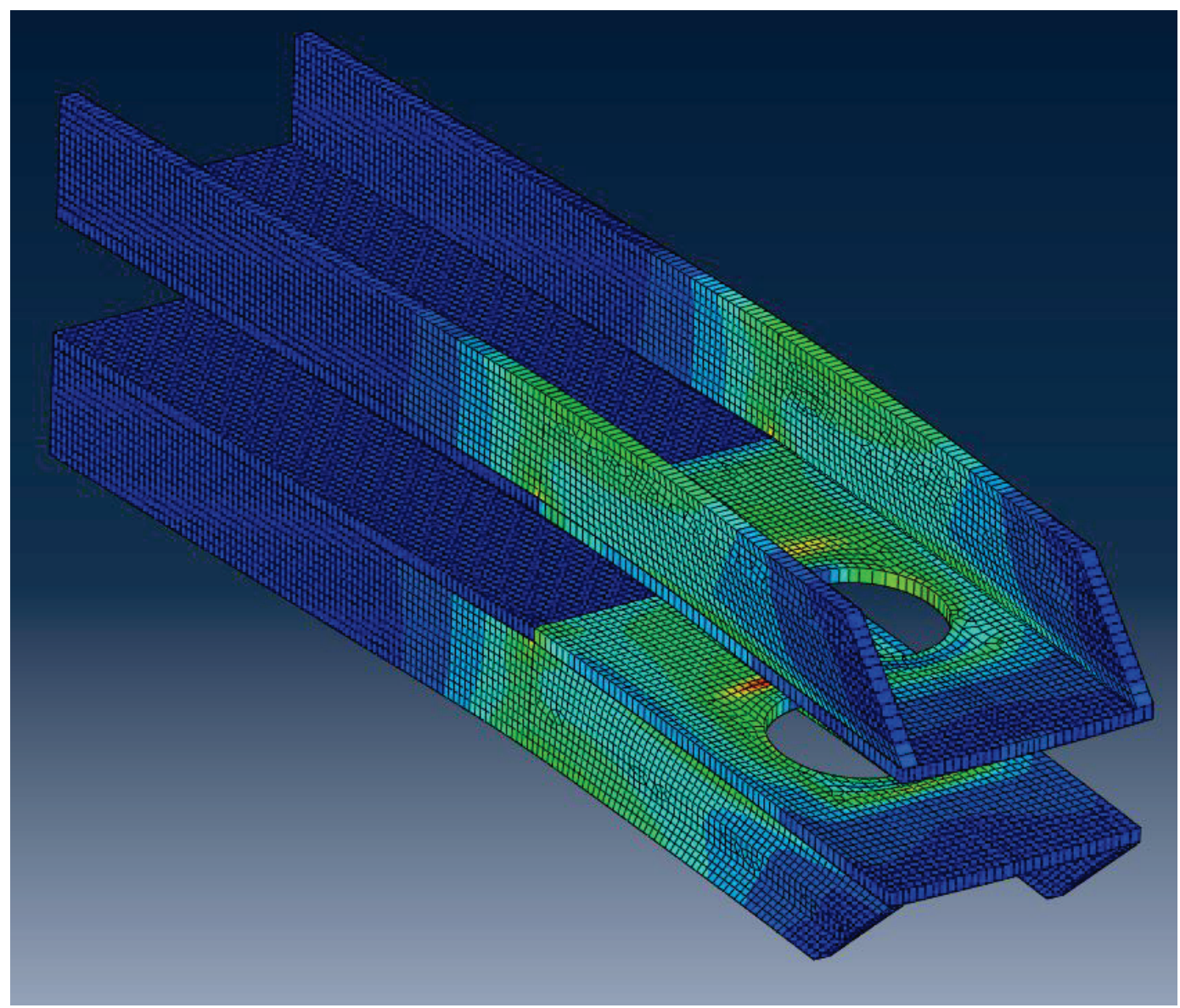


Table 3. Computed force range at anchorage channel pins.

\begin{tabular}{|l|c|c|c|c|}
\hline & Max. Tension (kip) & Min. Tension (kip) & $\begin{array}{c}\text { Max. Moment } \\
\text { (kip-in) }\end{array}$ & $\begin{array}{c}\text { Min. Moment } \\
\text { (kip-in) }\end{array}$ \\
\hline Land miter & 167 & -7.5 & 26.2 & 2.0 \\
\hline Land recess & 94.4 & -4.9 & -95.6 & 4.8 \\
\hline River miter & 77.0 & -16.4 & 33.3 & -4.4 \\
\hline River recess & 59.1 & -14.4 & -112 & -16.6 \\
\hline
\end{tabular}

Table 4. Finite element microstrain from measured forces (tension positive).

\begin{tabular}{|c|c|c|c|c|c|c|c|c|}
\hline $\begin{array}{c}\text { Channel } \\
\text { Gage } \\
\text { No. }\end{array}$ & \multicolumn{2}{|c|}{ Land Recess } & \multicolumn{2}{c|}{ Land Miter } & \multicolumn{2}{c|}{ River Recess } & \multicolumn{2}{c|}{ River Miter } \\
\cline { 2 - 9 } & Min. & Max. & Min. & Max. & Min. & Max. & Min. & Max. \\
\hline 1 & -6.9 & 134 & -10.7 & 233 & -9.4 & 59.1 & - & - \\
\hline 2 & -15.7 & 303 & -24.3 & 536 & -28.3 & 123 & -43 & 235 \\
\hline 3 & -16.0 & 310 & -24.8 & 547 & -29.2 & 128 & -44 & 240 \\
\hline 4 & -15.7 & 304 & -24.4 & 537 & -28.6 & 125 & -43 & 235 \\
\hline 5 & -7.1 & 137 & -10.2 & 221 & -9.7 & 59.5 & - & - \\
\hline 6 & -7.3 & 141 & -12.3 & 275 & -13.9 & 42.5 & - & - \\
\hline
\end{tabular}

Table 5. Finite element microstrain from vertical expansion (tension positive).

\begin{tabular}{|c|c|c|c|c|}
\hline & Land Recess & Land Miter & River Recess & River Miter \\
\hline 1 & 3,540 & 3,370 & 3,820 & - \\
\hline 2 & 3,050 & 3,090 & 3,130 & $3,090 *$ \\
\hline 3 & 3,160 & 3,190 & 3,280 & $3,190 *$ \\
\hline 4 & 3,050 & 3,100 & 3,170 & $3,100 *$ \\
\hline 5 & 3,370 & 3,540 & 3,720 & - \\
\hline 6 & $-3,170$ & $-3,030$ & $-3,730$ & - \\
\hline
\end{tabular}

* Gage locations in riverside miter channels model were identical to landside channels since actual gages were placed on modified structure at riverside miter.

Finite element models are only as accurate as the geometry, materials, and boundary conditions used in their definitions. The complexities of the actual channel geometries and loading from the warped geometry (out-ofplane moments and torsion) were not included, nor were rivets or doubler plates. The concrete confinement, in reality, is not perfectly fixed, nor is the linkage perfectly rigid. Given these differences, the model results are not expected to match the gage readings perfectly rigid. Table 6 shows the 
error (in percent) of the model results compared with the actual measured strains. Though there is some error, the order of magnitude of strain was similar, and these models are expected to be sufficient for their purposes in this study, especially considering the extreme uncertainties elsewhere in the evaluation model.

Table 6. Percent error of strain - finite element strains vs. measured.

\begin{tabular}{|c|c|c|c|}
\hline Channel Gage No. & Land Recess & Land Miter & River Recess \\
\hline 1 & 54.70 & -10.62 & -139.17 \\
\hline 2 & 75.05 & 0.63 & -7.05 \\
\hline 3 & 84.18 & 38.38 & -21.77 \\
\hline 4 & 82.87 & 45.84 & -38.65 \\
\hline 5 & - & 14.06 & -38.19 \\
\hline 6 & - & -58.90 & -160.84 \\
\hline
\end{tabular}

\subsection{Linear fatigue damage model}

Because the material properties of the embedded channel steel were unknown, the ERDC team assumed that the $8 \times 31 / 8 \mathrm{U} 22.7$ channels were hot-rolled mild steel with properties similar to ASTM A36 steel. A University of Illinois laboratory report (Higashida and Lawrence 1976) Strain Controlled Fatigue Behavior of Weld Metal and Heat-Affected Base Metal in A36 and A514 Steel Welds was used to determine a strainbased $\mathrm{S} / \mathrm{N}$ curve that includes both high-cycle (elastic) and low-cycle (inelastic) fatigue effects for crack initiation. In addition, notes from Professor Ali Fatemi at the University of Toledo (Fatemi 2016) on cyclic deformation and strain life were consulted to determine the effects of surface corrosion and mean stress on the $\mathrm{S} / \mathrm{N}$ curve.

Often fatigue crack initiation is described with an $\mathrm{S} / \mathrm{N}$ curve, which compares a cyclic stress range imposed on a material with the number of cycles of that stress range that will cause crack initiation (Schütz 1996). These S/N curves are often used with stresses well below the yield stress of the material and with a large (greater than $10^{6}$ ) number of cycles to failure $\left(2 N_{f}\right)$. The strain-life curves associated with these high cycles are often called high-cycle fatigue. Conversely, materials may be deformed (strained) such that they yield, and ductile materials may deform significantly without crack formation. Large cyclic strains beyond the proportional limit are typically associated with a much smaller fatigue life 
$\left(2 N_{f}<10^{5}\right)$. Strain life curves associated with these larger strains are often called low-cycle fatigue.

Accounting for both the high-cycle and low-cycle fatigue life phenomena, Morrow (1965) showed that a strain-based $\mathrm{S} / \mathrm{N}$ curve could be modeled as follows:

$$
\varepsilon_{a}=\frac{\sigma_{f}^{\prime}}{E}\left(2 N_{f}\right)^{b}+\varepsilon_{f}^{\prime}\left(2 N_{f}\right)^{c}
$$

where:

$$
\begin{aligned}
\mathcal{E}_{a}= & \text { cyclic strain amplitude (half of strain range) } \\
E= & \text { the modulus of elasticity, } \sigma_{f}^{\prime}, \text { is the fatigue strength coefficient } \\
b= & \text { the fatigue strength exponent } \\
\mathcal{E}_{f}^{\prime}= & \text { the fatigue ductility coefficient } \\
\mathrm{c}= & \text { the fatigue ductility exponent } \\
2 N_{f}= & \text { the total number of full strain cycles that will result in crack } \\
& \text { initiation. }
\end{aligned}
$$

An important note is that Equation 3.12 assumes the strain cycles imposed on the material are identical (i.e., the maximum and minimum strains are equal in magnitude but opposite in sign; therefore, the strains oscillate about zero strain).

The first term on the right-hand side of Equation 3.12 represents the elastic high-cycle fatigue behavior with a log-linear curve. The second term on the right-hand side represents the plastic low-cycle fatigue behavior, also with a log-linear curve. The underlying idea is that the strain experienced by the material can be described as a sum of elastic and plastic strains, and the total $\mathrm{S} / \mathrm{N}$ curve should include how each type of strain contributes to the fatigue damage, where $b$ ' is the unmodified exponent and $k s$ is a surface factor, taken as 0.72 for hot-rolled steel with a tensile strength of $58 \mathrm{ksi}$. The $b$ indicated by Higashida and Lawrence (1976) is -0.132, producing a modified value of -0.155 used in this study.

Figure 41 shows Equation (3.12) plotted for the A36 material described by Higashida and Lawrence (1976). The model values used are listed in Table 7. Both the elastic and inelastic curves are shown in addition to the total curve. 
The region in the anchorage channels where the channel transitions from embedded in concrete to exposed to air is prone to accelerated corrosion. Accelerated corrosion at a concrete/surface interface is caused by concentration cell corrosion mechanisms. Within the concrete, $\mathrm{pH}$ is high (approximately 13) due to the alkalinity of the concrete pore solution. In contrast, moisture at the steel surface outside the concrete will exhibit a near-neutral $\mathrm{pH}$ of 7 . The $\mathrm{pH}$ of aqueous solutions controls electrochemical potentials of steels in contact with those solutions. In the case of the alkaline $\mathrm{pH}$ within the concrete, electromechanical potentials will be more positive when compared with the neutral $\mathrm{pH}$ of moisture outside of the concrete. This difference in electrochemical potential at the interface of the steel at the concrete surface creates a driving force for electron transfer and resultant corrosion with steel outside and adjacent to the concrete surface becoming the anodic site for oxidation while steel embedded within the concrete acts as a cathodic site for reduction. The result is accelerated corrosion of steel adjacent to the concrete surface. This phenomena has been observed in other examples of steel anchorages in concrete including anchor bolts used in bridge bearings and for utility poles.

Referencing Fatemi (2016), surface corrosion defects will affect the high-cycle fatigue life but not the low-cycle. A modified $b$ exponent was recommended as follows:

$$
b=b^{\prime}+0.159 \log k_{s}
$$

where $b$ ' is the unmodified exponent and $k_{s}$ is a surface factor, taken as 0.72 for hot-rolled steel with a tensile strength of $58 \mathrm{ksi}$. The $b$ indicated by Higashida and Lawrence (1976) is -0.132, producing a modified value of -0.155 used in this study. 
Figure 41. S/N curve used for fatigue life evaluation.

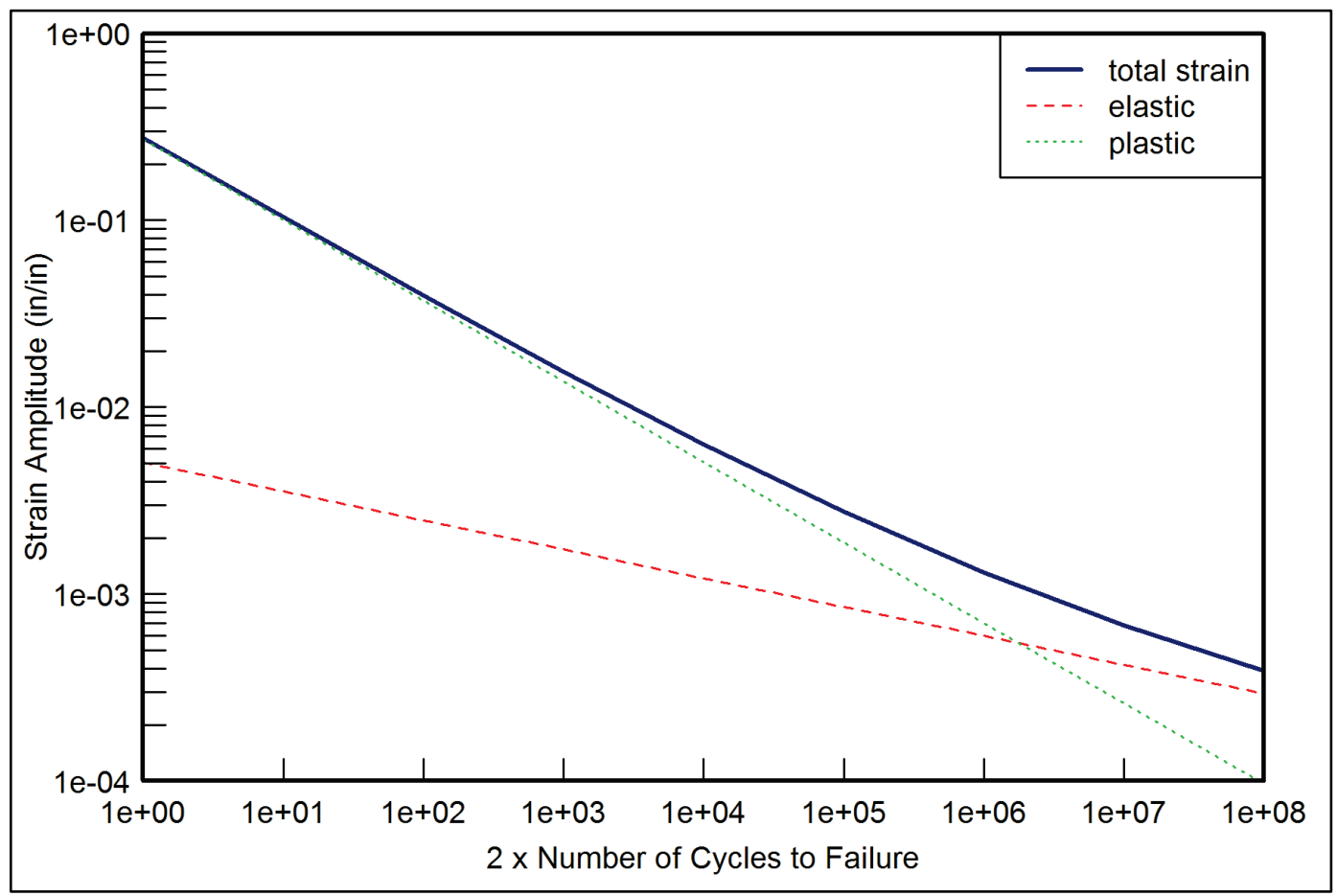

Table 7. Parameters for S/N curve.

\begin{tabular}{|l|l|}
\hline$\sigma_{f}^{\prime}$ & 147 \\
\hline$b$ & $-0.132+0.159 \log 0.72=-0.155$ \\
\hline$\varepsilon^{\prime}{ }_{f}$ & 0.271 \\
\hline$c$ & -0.431 \\
\hline
\end{tabular}

The actual strains experienced by the anchorage were not oscillating around a mean strain of zero. The concrete wall's vertical growth has pushed upwards on the channels. This upward displacement is resisted by the gudgeon linkage pulling back down because the steel miter gate is not also growing vertically. This downward pull has likely placed the channels in bending with a slowly developing strain state over the life of the lock. This slowly developing strain state is the point about which the operational strains oscillate. Therefore, including a significant non-zero mean strain/stress in the fatigue evaluation is necessary. The Smith, Watson, and Topper (1970) method, or the SWT method, was used to correct the estimation of $N_{f}$. The equation is as follows:

$$
\sigma_{\max } \varepsilon_{a} E=\left(\sigma_{f}^{\prime}\right)^{2}\left(2 N_{f}\right)^{2 b}+\sigma_{f}^{\prime} \varepsilon_{f}^{\prime} E\left(2 N_{f}\right)^{b+c}
$$




$$
\sigma_{\max }=\sigma_{m}+\sigma_{a}
$$

where:

$$
\begin{aligned}
\sigma_{m} & =\text { the mean stress } \\
\sigma_{a} & =\text { is the stress amplitude. }
\end{aligned}
$$

Note that the SWT equation predicts infinite fatigue life if $\sigma_{\max }$ is zero, meaning that tension is required for cracks to initiate. Equation (3.14) also assumes the cyclic strain has a constant amplitude and mean stress throughout loading.

To consider the slowly increasing strain state due to wall growth, the Miner's Rule (Miner 1945) of linear cumulative damage was used to determine, in essence, how much of the strain life was consumed by each strain cycle. Miner's Rule can be stated as follows:

$$
D=\sum_{i=1}^{k} \frac{n_{i}}{N_{f i}}
$$

where:

$D=$ a damage index

$K=$ is the total number of strain cycles

$n_{i}=$ is the number of cycles with a strain range

$i$, and $N_{f i}=$ is the number of cycles $N_{f}$ that would cause failure at just that strain range.

When the damage index $D$ is 1 or greater, cracking may be imminent.

The fatigue model used in this study did not consider residual stresses or out-of-plane loadings. The model also had large uncertainties associated with corrosion effects and magnitude, the applicability of the chosen $\mathrm{S} / \mathrm{N}$ curve to the actual channel material, and the accuracy of the cyclic history. To help correct for these model errors, a correction factor, $C$, was defined as $1 / D_{e m}$, where $D_{e m}$ was the damage index from the fatigue model calculated for the riverside miter channel since an actual crack had occurred in that channel. The model for the riverside miter required several assumptions. The concrete wall vertical growth of 1.08 in. was assumed to occur linearly over 75 years at a rate of 3,700 strain cycles per year. The strain cycles associated with opening/closing of the lock gates 
were assumed to match those indicated by the finite element model using the measured anchorage forces on the riverside miter linkage. The finite element model strains were used because the channel structure was changed significantly through doubler plates and welding during the crack repair. For each cycle, Equation 3.14 was solved to determine $N_{f i}$, and Equation 3.16 was used to determine the contribution to the damage index, $D_{e m}$, associated with strain cycle, $i$. The correction, $C$, was computed such that $C D_{e m}$ was unity, recognizing that cracking did occur in the channel web near year 75 of the service life.

The other three anchorage channel assemblies were assessed using the same model with only a few differences. The measured operational cyclic strain ranges were added to the linearly increasing strains from wall growth as indicated by the finite element model. Once Equation 3.16 was computed for each of the undamaged channels, the resulting $D$ values were multiplied by the correction factor, $C$, found for the riverside miter channel, which assumes the overall magnitude of model errors is similar for all channels. Each channel's corrected damage index was compared with unity as an indicator of potential cracking.

\subsection{Evaluation of gudgeon anchorage channels}

To calibrate the fatigue model for the web crack in the riverside miter anchor channel, operational cyclic strains were added to a linearly increasing strain state caused by vertical wall expansion. Both sets of strains were found from the finite element model, as the strain gages were placed on a post-repaired channel, which differed greatly in strain response due to the welding and doubler plates. Since the channel cracked in the web, only the web strains were used in the calculations. An elastic plastic model using $36 \mathrm{ksi}$ as yield stress and 29,000 ksi for $E$ was used to determine the stresses associated with the total strain cycles. A total of 277,500 strain cycles was used with Equations 3.1 and 3.16 to determine a $D_{e m}$ value of o.0131, indicating significant model errors. The corresponding $C$ value was 76.05 .

Though the $D_{e m}$ value indicated a poor model fit, the model was expected to have similar accuracy for all channels, and the correction factor $C$ would still provide a reasonable indicator of potential damage, given the very similar loadings, materials, and environment of all anchorages. Therefore, the corrected damage indices for the landside miter and recess anchorage, as well as the riverside recess anchorage, were computed with the model 
calibrated to the riverside miter anchorage. Table 8 lists the resulting damage indices.

Table 8. Corrected damage indices.

\begin{tabular}{|l|c|c|c|c|c|c|}
\hline \multirow{2}{*}{} & \multicolumn{7}{|c|}{ Channel Gage No. } \\
\cline { 2 - 8 } & $\mathbf{1}$ & $\mathbf{2}$ & $\mathbf{3}$ & $\mathbf{4}$ & $\mathbf{5}$ & $\mathbf{6}$ \\
\hline Land recess & 0.025 & 0.046 & 0.010 & 0.010 & - & - \\
\hline River recess & 0.278 & 0.253 & 0.358 & 0.395 & 0.403 & $\sim 0$ \\
\hline Land miter & 0.779 & 5.95 & 1.81 & 1.21 & 0.438 & $\sim 0$ \\
\hline
\end{tabular}

The results of the fatigue evaluation for the landside miter anchorage indicate that cracking is likely imminent in the top channel web. The maximum calculated corrected damage index for this channel is 5.95, which is much higher than unity. The damage indices for the other two gage locations' indices are also greater than unity. Given the similarity of this geometry, wall growth, loadings, and environment of the river and landsides of the lock, this is a reasonably accurate assessment. All indications are that the landside miter anchorage channels could crack at any time during operation moving forward.

The results of the fatigue evaluation for the river and landside recess anchorage channels did not indicate imminent cracking, with the highest corrected damage indices being 0.403 and 0.046 , respectively. However, this does not mean that these structures are not at risk of cracking. As mentioned, the model used here had tremendous uncertainty. These results simply say that, this model, as calibrated to the riverside miter channel cracking, does not indicate imminent damage. The actual situation, given the AAR-induced warped geometries and potential corrosion at the concrete-to-air interface, could cause these channels to be at a much higher risk than this model indicates.

\subsection{Evaluation of embedded A-frame}

The evaluation of the downstream embedded A-frame miter gate anchorage components by ANATECH (James 2006) was useful for providing insight into the reliability of the upstream anchorages. Given the similarity of construction of the embedded anchorages for the upstream and downstream miter gates, the general conclusions of the downstream evaluation are expected to also be applicable to the upstream embedded Aframe components. 


\section{Interpretation and Recommendations}

\subsection{Interpretation of evaluation}

The landside miter anchorage fatigue evaluation indicates that cracking is likely imminent in the top channel web. The maximum calculated corrected damage index for this channel is 5.95, much higher than unity, and the same indices for the other two gage locations also greater than unity. Given the similarity of this geometry, wall growth, loadings, and environment of the both sides of the lock, this is likely an accurate assessment. All indications are that the landside miter anchorage channels could crack at any time during operation moving forward.

The fatigue evaluations for the river and landside recess anchorage channels do not indicate imminent cracking because the highest corrected damage indices are 0.403 and 0.046 , respectively. However, these values should not be interpreted to mean that these structures are not at risk of cracking. As mentioned, the model used here had tremendous uncertainty, which could not be reduced significantly, even with more testing, due to the ambiguous lockage data. These results simply say that, using this model as calibrated to the riverside miter channel cracking, imminent damage is not indicated. Given the AAR-induced warpage to the geometries and potential corrosion at the concrete-to-air interface, these channels could be at a much higher risk than this model indicates.

Finite element models were not built for the upstream embedded miter gate A-frames. Based on the similarity of their construction to the downstream embedded A-frames, the conclusions (Chapter 2) from James (2006) are expected to be equally applicable for the upstream A-frames. These conclusions were that there was little risk of excessive concrete cracking in the monolith nor significantly reduced anchorage performance and no immediate repairs or replacements were recommended. More exact analyses could be performed but are not recommended due to their cost and the likelihood that they will mirror the results from the downstream study.

While cyclic fatigue of these channels is a worthy concern, the ERDC team has found during this study that the strain states from the warped geometry, caused by the vertical wall expansion, are more significant. All anchorage channels have likely experienced significant, unrecoverable 
plastic strains, placing the top channels into tension. No repair strategies exist that can remove these plastic strains. This state of plastic tension may create the situation where the channels are severely prone to cracking from either corrosion or fatigue.

\subsection{Recommendation for mitigation}

Based on the findings of this study, the ERDC team recommends that immediate steps are taken to increase awareness of cracking in the channels, especially those in the landside miter anchorage assembly. These steps may be continued weekly visual inspections or increased instrumentation for sensor-based crack detection methods, as deemed appropriate by the LRN and TVA. In addition to the increased awareness, plans should be made to replace the anchorage channels. Removing these channels from the A-frame, while preserving the other A-frame components, may be possible. This replacement would require the removal of concrete above the A-frames. Care should be taken to consider whether the removal of that concrete would jeopardize the integrity of the A-frame, which relies on its confinement in the monolith concrete, as indicated by ANATECH. 


\section{Summary and Conclusions}

\subsection{Summary}

The ERDC team has investigated the integrity of the embedded steel channels supporting the upper miter gate gudgeon linkages on each side of the lock chamber. Physical considerations included both pseudo-static deformations caused by the vertical expansion of the concrete walls relative to the lock gate and fatigue induced by operational cyclic stresses and. As part of the investigation, ERDC instrumented the miter and recess anchors to measure strains in the anchorage channels in response to the loading induced during lockage cycles. Additionally, ERDC collected and evaluated lock usage history, concrete expansion data, and structural response data to develop a fatigue model. Missing data and uncertainty regarding material properties led ERDC to use an alternative evaluation procedure that involved using the east miter channels to calibrate a damage index model and develop a model correction factor that was applied to the undamaged anchorage damage indices to investigate potential damage.

For the evaluation of the A-frames, the ERDC reviewed the 2006 ANATECH report (James 2006) and generally agrees with the findings that due to the vertical concrete expansion, the A-frames have likely yielded but likely have not ruptured. Also, James (2006) concluded that even if the A-frames have ruptured, the concrete is effectively supporting the A-frames and there is no significant risk to the monoliths or anchorage function. Therefore, the ERDC team does not have any recommendations concerning the integrity of the A-frames. The ERDC team does not recommend further specific evaluations of the upstream embedded A-frames as the findings from the report should hold for the upstream anchorage as well.

\subsection{Conclusions}

Major findings from this evaluation are the following:

- No immediate repair strategies or finite element analyses are needed for the upstream embedded A-frame structures. The embedded A-frame structures do not likely pose a risk to lock performance and 
safety. This finding does not hold for the anchorage channels extending from the monolith.

- Cracking in the top channel (especially the web) of the landside miter anchorage is expected due to the results of the fatigue analysis and general similarity of environmental and operational loads as those on the previously damaged riverside miter anchorage.

- All anchorage channels may be in a state of significant permanent inelastic deformation (yielding) due to the vertical wall expansion. This possible strain state, combined with corrosion at the concrete interface and cyclic operational loads, creates a situation prone to develop cracking (and eventual rupture) in the channels.

- There are no realistic repair strategies that will mitigate the possible existing plastic strains in the channels, including the repair already performed on the riverside miter channels.

- Due to the possible existence of plastic strains in the anchorage channels, all upstream miter gate anchorage channels are at significant risk of sudden crack formation and pose a risk to operational safety. Replacement may be the most viable option for safety.

- Options may be available to replace the anchorage channels without replacing the embedded A-frame components. However, the loss of concrete confinement occurring from the removal and replacement of the concrete embedding the channel-to-A-frame connection should be carefully considered to ensure that the channel replacement does not cause A-frame failure. 


\section{References}

Fatemi, A. 2016. Cyclic Deformation and Strain-Life Approach. Toledo, OH: University of Toledo. www.efatigue.com/training/Chapter_5.pdf.

HATCH. 2015a. Review and Evaluation of Instrumentation Data. H347652-0000-10124-0001. Report for Chickamauga Lock AAR Investigations, U.S. Army Corps of Engineers. Mississauga, Ontario: HATCH.

HATCH. 2015b. Alkali Aggregate Reaction Report. H347652-0000-10-124-0002. Report for Chickamauga Lock AAR Investigations, U.S. Army Corps of Engineers, Nashville, TN. Mississauga, Ontario: HATCH.

Higashida, Y., and F. V. Lawrence. 1976. Strain-Controlled Fatigue Behavior of Weld Metal and Heat-Affected Base Metal in A36 and A514 Steel Welds. Urbana, IL: University of Illinois.

James, R. J. 2006. Structural Evaluation of Embedded Miter Gate Anchorages Considering Alkali Aggregate Reaction. Report ANA-R-06-0697. San Diego, CA: ANATECH Corp.

Love, A. E. H. 1927. A Treatise on the Mathematical Theory of Elasticity. New York: Cambridge University Press, Dover Publications.

Miner, M. A. 1945. "Cumulative Damage in Fatigue." Transactions of American Society of Mechanical Engineers 67(A159).

Morrow, J. 1965. Cyclic Plastic Strain Energy and Fatigue of Metals. Internal Friction, Damping, and Cyclic Plasticity. ASTM STP 378, 45-87. West Conshohocken, PA: American Society for Testing and Materials.

Schütz, W. 1996. “A History of Fatigue.” Engineering Fracture Mechanics 54: 263-300.

Smith, K. N., P. Watson, and T. H. Hopper. 1970. "A Stress-Strain Function for the Fatigue of Metals.” Journal of Materials 5(4): 767-778. 


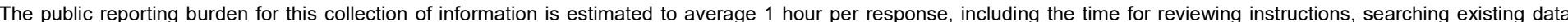

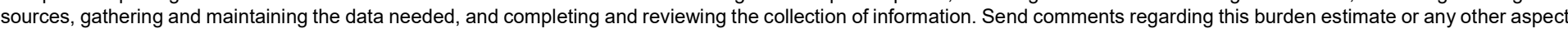

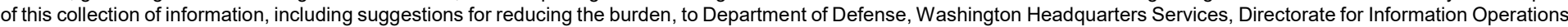

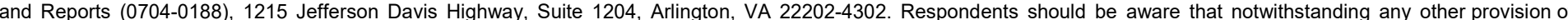
law, no person shall be subject to any penalty for failing to comply with a collection of information if it does not display a currently valid OMB control number.

PLEASE DO NOT RETURN YOUR FORM TO THE ABOVE ADDRESS.

\begin{tabular}{l|l|l}
$\begin{array}{l}\text { 1. REPORT DATE } \\
\text { September } 2017\end{array}$ & $\begin{array}{l}\text { 2. REPORT TYPE } \\
\text { Final Report }\end{array}$ & 3. DATES COVERED (FrOm - To) \\
\hline
\end{tabular}

\section{TITLE AND SUBTITLE}

5a. CONTRACT NUMBER

Concrete Growth and Fatigue Analysis of Chickamauga Lock Miter Gate Anchorages

5b. GRANT NUMBER

5c. PROGRAM ELEMENT NUMBER

\section{AUTHOR(S)}

Matthew D. Smith, Allen Hammack, Robert D. Moser, Quincy Alexander, Ben

Burnham, and Sarah L. Williams

5d. PROJECT NUMBER

111274

5e. TASK NUMBER

5f. WORK UNIT NUMBER

\section{PERFORMING ORGANIZATION NAME(S) AND ADDRESS(ES) (see reverse)}

\section{SPONSORING/MONITORING AGENCY NAME(S) AND ADDRESS(ES}

U.S. Army Corps of Engineers, Nashville District

110 9th Avenue South

Nashville, TN 37203-3863
8. PERFORMING ORGANIZATION

REPORT NUMBER

ERDC TR-17-10

10. SPONSOR/MONITOR'S ACRONYM(S)

LRN

11. SPONSOR/MONITOR'S REPORT NUMBER(S)

\section{DISTRIBUTION/AVAILABILITY STATEMENT}

Approved for public release; distribution is unlimited

\section{SUPPLEMENTARY NOTES}

\section{ABSTRACT}

Severe cracking has been observed on the miter gate anchorages at Chickamauga Lock, Nashville District, U.S. Army Corps of Engineers. A structural analysis of these anchorages was conducted to determine how much longer they could remain in service before failure is expected. This analysis included a review of existing structural analysis reports, estimates and prediction of observed concrete growth in the area near the anchorages, and fatigue life estimates. The fatigue life estimates included the concrete growth estimates and also included the stresses and strains taken from measurements recorded during miter gate movements during lockages. The results of this analysis are discussed as well as possible ways to extend the life of the existing anchorages and considerations for if and when the anchorages are replaced.

\section{SUBJECT TERMS}

Anchorage (Structural engineering), Chickamauga Lock and Dam (Tenn.), Concrete—Cracking, Concrete—Fatigue, Hydraulic gates, Locks (Hydraulic engineering), Service life (Engineering)

\section{SECURITY CLASSIFICATION OF:}

\begin{tabular}{|l|c|c|c|}
\hline a. REPORT & b. ABSTRACT & c. THIS PAGE & ABSTRACT \\
Unclassified & Unclassified & Unclassified & SAR \\
& & & \\
\end{tabular}

18. NUMBER OF PAGES

73 19a. NAME OF RESPONSIBLE PERSON

Allen Hammack

19b. TELEPHONE NUMBER (Include area code) 601-634-3628 


\section{PERFORMING ORGANIZATION NAME(S) AND ADDRESS(ES) (continued)}

Coastal and Hydraulics Laboratory

U.S. Army Engineer Research and Development Center 3909 Halls Ferry Road

Vicksburg, MS 39180-6199

Geotechnical and Structures Laboratory

U.S. Army Engineer Research and Development Center 3909 Halls Ferry Road

Vicksburg, MS 39180-6199

Information Technology Laboratory

U.S. Army Engineer Research and Development Center 3909 Halls Ferry Road

Vicksburg, MS 39180-6199 